\title{
EFEITO DE SABONETE LÍQUIDO E EM BARRA NA PELE DE RECÉM- NASCIDOS A TERMO SAUDÁVEIS: ENSAIO CLÍNICO RANDOMIZADO
}

\author{
Versão restrita da Tese apresentada ao Programa \\ de Pós-Graduação em Enfermagem da Escola de \\ Enfermagem da Universidade de São Paulo para \\ obtenção do título de Doutora em Ciências \\ Área de concentração: Cuidado em saúde \\ Orientadora: Prof. ${ }^{\text {a }}$ Dr. ${ }^{\text {a }}$ Maria De La Ó Ramallo \\ Veríssimo (EE-USP) \\ Co-orientadora: Prof. ${ }^{a}$ Dr. ${ }^{a}$ Maria Valéria Robles \\ Velasco (FCF-USP)
}

\section{VERSÃO RESTRITA}

A versão original encontra-se disponível na Biblioteca "Wanda de Aguiar Horta" da Escola de Enfermagem da Universidade de São Paulo e na Biblioteca Digital de Teses e Dissertações da Universidade de São Paulo.

\section{São Paulo}


AUTORIZO A REPRODUÇÃO E DIVULGAÇÃO TOTAL OU PARCIAL DESTE TRABALHO, POR QUALQUER MEIO CONVENCIONAL OU ELETRÔNICO, PARA FINS DE ESTUDO E PESQUISA, DESDE QUE CITADA A FONTE.

Assinatura:

Data:

Catalogação-na-publicação (CIP) Biblioteca Wanda de Aguiar Horta Escola de Enfermagem da Universidade de São Paulo

Ramos, Mily Constanza Moreno

Efeito de sabonete líquido e em barra na pele de recém-nascidos a termo saudáveis: ensaio clínico randomizado / Mily Constanza Moreno Ramos. São Paulo, 2020.

$182 \mathrm{p}$.

Tese (Doutorado) - Escola de Enfermagem da Universidade de São Paulo.

Orientador(a): Prof. ${ }^{a}$ Dr. ${ }^{a}$ Maria de La ó Ramallo Veríssimo Coorientador(a):Prof. ${ }^{a}$ Dr. ${ }^{a}$ Maria Valeria Robles Velasco Área de concentração: Cuidado em Saúde.

Ficha catalográfica automatizada.

Bibliotecária responsável: Fabiana Gulin Longhi (CRB-8: 7257) 
Nome: Mily Constanza Moreno Ramos

Título: Efeito de sabonete líquido e em barra na pele de recém-nascidos a termo saudáveis: ensaio clínico randomizado

Aprovado em: Data:

\section{Banca Examinadora}

Orientador: Prof. ${ }^{\text {a }}$ Dr. ${ }^{\text {a }}$ Maria De La Ó Ramallo Veríssimo

Instituição: Escola de Enfermagem da Universidade de São Paulo

Julgamento:

Assinatura:

Co-orientadora: Prof. ${ }^{a}$ Dr. ${ }^{a}$ Maria Valéria Robles Velasco (FCF-USP)

Instituição: Faculdade de Ciências Farmacêuticas da Universidade de São Paulo

Julgamento:

Assinatura:

Prof. Dr.

Instituição:

Julgamento:

Assinatura:

Prof. Dr.

Instituição:

Julgamento:

Assinatura:

Prof. Dr.

Instituição:

Julgamento:

Assinatura: 


\section{DEDICATÓRIA}

A minha mãe Milagros, tia Lília, tia Alicia e irmã Cindy pela compreensão nos momentos de ausência e pelo incentivo constante para continuar lutando pelos meus sonhos.

A minha esposa Erika Ramírez, pelas palavras de amor, compreensão e sabedoria ao longo desses anos.

A todas as famílias e bebês que participaram desta pesquisa! 


\section{AGRADECIMENTOS}

A Deus, sempre presente em todos os momentos da minha vida, me mostrando o caminho, me protegendo e me reconfortando. Obrigada pelo teu grandioso amor!

À professora Dra. Maria de La Ó Ramallo Veríssimo, pela confiança depositada em mim para a realização deste trabalho, pelo apoio constante nos momentos decisivos. Sua trajetória acadêmica é fonte de inspiração no meu caminho profissional.

À professora Dra. Maria Valéria Robles Velasco, pelo interesse e apoio demonstrado para a viabilização deste trabalho. Obrigada por ampliar a minha visão professional e pelos insights que fortaleceram o trabalho.

À professora Dra. Mariana Bueno, pelo acolhimento no início do processo, por sonhar junto comigo e fortalecer as minhas asas. Obrigada pelas orientações e ensinamentos que foram muito valiosos na minha formação como pesquisadora.

À Dra. Erika Gisseth León Ramírez, companheira em todos os tempos, obrigada pelo apoio acadêmico e emocional, nossas discussões trouxeram grandes aprendizados.

Às professoras Dra. Amélia Fumiko Kimura, Maria Alice Tsunechiro e Ilva Aragaki, pelas valiosas contribuições acadêmicas durante o desenvolvimento desta pesquisa.

Ao Hospital Universitário da Universidade de São Paulo e aos profissionais de saúde do Alojamento conjunto pela autorização e colaboração na realização desta pesquisa.

À empresa Tecnotest ltda., ao senhor Hamilton dos Santos e à senhora Daniela de Souza, pela disponibilização dos equipamentos e treinamentos que viabilizaram a realização desta pesquisa.

Ao laboratório de Cosmetologia da Faculdade de Ciências Farmacêuticas da USP e seus especialistas Claudinéia e Edgar, pelo apoio nas análises dos sabonetes e pelo suporte ao longo da coleta de dados.

À Gabriela Fernanda Peres e Yorladys Loaiza Agudelo pela colaboração e suporte durante a coleta de dados. 
Ao Programa de Pós-graduação em Enfermagem (PPGE) pelas oportunidades profissionais e acadêmicas que possibilitaram meu crescimento como pesquisadora.

À Coordenação de Aperfeiçoamento de Pessoal de Nível Superior (CAPES), pela concessão da bolsa de doutorado que possibilitou a condução desta pesquisa.

Aos membros do Grupo de pesquisa Cuidado em Saúde e Promoção do Desenvolvimento Infantil pelas contribuições acadêmicas que aprimoraram este trabalho. Aos funcionários da Escola de Enfermagem, do Departamento de Enfermagem Materno Infantil e Psiquiátrica, e da Secretária de Pós-graduação pela colaboração nas diversas atividades administrativas.

Ao grupo de escrita do PPGE, em especial às queridas colegas Giovanna, Aline, Denisse, e Belarmina. Sua companhia virtual ao longo da pandemia trouxe leveza ao processo de escrita da tese.

Às minhas colegas de doutorado Ligyana, Taine, Carol, e Katherine pela parceria acadêmica e amizade nesses quatro anos.

À Margarita, Carol, Carlos, Angela, Janaina, Mônica, Inês, Johanna, e Simone, amigos queridos, agradeço suas palavras, sua motivação e sua companhia. Os levo no coração!

Finalmente, agradeço meus peludinhos Arturo e Agatha pelo amor infinito, compreensão e conforto nos momentos alegres e tristes ao longo desses quatro anos. 
Há um tempo em que é preciso abandonar as roupas usadas, que já tem a forma do nosso corpo, e esquecer os nossos caminhos, que nos levam sempre aos mesmos lugares. $E$ tempo da travessia: $e$, se não ousarmos fazêla, teremos ficado, para sempre, à margem de nós mesmos.

Fernando Teixeira de Andrade (1946-2008) 
Ramos MCM. Efeito de sabonete líquido e em barra na pele de recém-nascidos a termo saudáveis: ensaio clínico randomizado [Tese]. São Paulo: Escola de Enfermagem, Universidade de São Paulo; 2020

\section{RESUMO}

Introdução. A pele do recém-nascido $(\mathrm{RN})$ é mais fina, tem maior perda de água transepidérmica (TEWL), e menor hidratação do estrato córneo $(\mathrm{SCH})$, comparada a dos adultos; seu pH varia entre 5,5 e 7,5. Tais características predispõem a ressecamento, infecções e doenças dermatológicas, como a dermatite atópica (DA). Sabonetes adequados previnem ou minimizam essas alterações e favorecem o amadurecimento da pele. Não há disponíveis estudos sobre o efeito dos sabonetes comumente usados no Brasil na pele de RN. Objetivos. 1 - Analisar as informações de rotulagem, características físicas e físico-químicas de sabonetes usados em RN; 2 - Comparar o efeito do sabonete líquido e em barra sobre o $\mathrm{pH}$, TEWL, SCH, teor de sebo e integridade da pele de RN a termo saudáveis; 3 - Verificar a relação entre variáveis demográficas e clínicas sobre os parâmetros biométricos da pele de RN a termo no período neonatal. Métodos. Tese desenvolvida em três etapas: 1- Estudo quantitativo e descritivo, com 17 sabonetes comercializados em São Paulo - Brasil. Foram analisados: tipos de tensoativos e testes de segurança do rótulo; e coloração, intensidade da fragrância e pH no laboratório. 2 - Ensaio clínico randomizado, paralelo, unicego, conduzido no Hospital Universitário da Universidade de São Paulo (HU/USP) com aprovação do Comitê de Ética em Pesquisa da Escola de Enfermagem da USP e do HU. 100 RN a termo saudáveis foram randomizados ao uso de sabonete líquido (grupo experimental) ou de sabonete em barra (grupo controle). $\mathrm{O} \mathrm{pH}$ da pele, a TEWL, a $\mathrm{SCH}$, o teor de sebo e a condição da pele foram avaliados antes e após o primeiro banho, às 48 horas, 14 e 28 dias após o nascimento, em cinco regiões corporais. Foi avaliada, também, a percepção das mães sobre o uso do sabonete. 3- Estudo longitudinal e prospectivo, quantitativo, secundário ao ensaio clínico randomizado, que analisou a associação entre variáveis demográficas e clínicas e parâmetros biométricos da pele. Resultados. Os resultados estão em três artigos. 1 - Verificou-se que os sabonetes comerciais tinham tensoativos com potencial de irritação baixo, ou moderado, e fragrância com intensidade variável. Quatro sabonetes líquidos e um em barra combinado apresentaram valores de $\mathrm{pH}$ próximos ao da pele do $\mathrm{RN}$. 2 - Observou-se valores de $\mathrm{pH}$ mais acidificados e maior hidratação na pele com o sabonete líquido. Não houve diferenças significativas na TEWL, teor de sebo, condição da pele e percepções das mães. 3 - Constataram-se associações: da TEWL com tipo de parto, raça/cor, idade gestacional, sexo e tempo; da SCH e histórico familiar de DA, raça/cor, idade gestacional e tempo; do teor de sebo com o histórico familiar de DA e o tempo. Conclusões. Há sabonetes disponíveis no mercado que não atendem critérios para a homeostase da pele do RN, apresentando potencial de irritação moderado, $\mathrm{pH}$ diferente do $\mathrm{pH}$ da pele e fragrância em intensidade variável. $\mathrm{O}$ sabonete líquido mostrou maiores benefícios que o sabonete em barra na pele do RN. Variáveis clínicas e demográficas influenciaram os parâmetros avaliados da pele, demandando estudos amplos sobre o tema.

Palavras chaves: recém-nascido, higiene da pele, sabonete, enfermagem neonatal, enfermagem em estomaterapia 
Ramos MCM. Effect of liquid and bar soap on the skin of healthy full-term newborns: a randomized clinical trial [Thesis]. São Paulo: School of Nursing, University of São Paulo; 2020

\begin{abstract}
Introduction. The skin of a newborn (NB) is thinner, has greater transepidermal water loss (TEWL), and less hydration of the stratum corneum (SCH) compared to adults' skin, and its $\mathrm{pH}$ varies between 5.5 and 7.5. These characteristics predispose the skin to dryness, infections and dermatological diseases such as atopic dermatitis (AD). Suitable soaps prevent or minimize these changes and favor the maturation of the skin. To our knowledge, there are no studies regarding the effect of soaps commonly used in Brazil on the skin of newborns. Aims. 1 - Analyze the labeling information, physical and physical-chemical characteristics of soaps used on newborns; 2 - Compare the effect of liquid and bar soap on the skin $\mathrm{pH}$, TEWL, SCH, sebum content and skin integrity of healthy newborns; 3 - Verify the relationship between the demographic and clinical variables on the biometric parameters of the skin of newborns in the neonatal period. Methods. This thesis was developed in three stages: 1- A quantitative and descriptive study analyzing 17 soaps sold in São Paulo - Brazil. The types of surfactants and label safety tests; and color, fragrance intensity, and $\mathrm{pH}$ were analyzed in the laboratory. 2 A randomized, parallel, single-blind clinical trial conducted at the University Hospital of the University of São Paulo (HU/USP) with approval from the Research Ethics Committee of the USP School of Nursing and the HU. 100 healthy full-term newborns were randomized to use liquid soap (experimental group) or bar soap (control group). Skin $\mathrm{pH}$, TEWL, SCH, sebum content and skin condition were evaluated before and after the first bath, 48 hours, 14 and 28 days after birth, in five regions of the body. The mothers' perceptions of the use of soap were also evaluated. 3- A longitudinal and prospective, quantitative study, secondary to the randomized clinical trial, which analyzed the association between demographic and clinical variables and biometric parameters of the skin. Results. The results are described in three articles. 1 - It was found that commercial soaps had surfactants with low or moderate irritation potential and fragrances with varying intensities. Four liquid soaps and one combined bar showed $\mathrm{pH}$ values close to that of the newborn's skin. 2 - More acidified $\mathrm{pH}$ values and greater skin hydration were observed with liquid soap. There were no significant differences in TEWL, sebum content, skin condition and the mothers' perceptions. 3 - Associations were found: from TEWL with type of delivery, race/color, gestational age, sex and time; SCH and family history of $\mathrm{AD}$, race/color, gestational age and time; tallow content with $\mathrm{AD}$ family history and time. Conclusions. There are soaps available on the market that do not meet the criteria for the homeostasis of newborn skin, presenting moderate irritation potential, $\mathrm{pH}$ different from skin $\mathrm{pH}$ and fragrance in varying intensity. Liquid soap showed greater benefits than bar soap on newborn skin. Clinical and demographic variables influenced the evaluated skin parameters, requiring extensive studies on the subject.
\end{abstract}

Keywords: newborn, skin hygiene, soap, neonatal nursing, enterostomal therapy nursing 


\section{LISTA DE TABELAS}

TABELA 1 - CARACTERÍSTICAS DOS SABONETES CONFORME DADOS DE ROTULAGEM, ANÁLISE NO LABORATÓRIO, SITES ESPECIALIZADOS E FONTES DE INFORMAÇÃO.

TABELA 2 - FREQUÊNCIAS ABSOLUTA E RELATIVA DO TIPO DE TENSOATIVOS SEGUNDO O TIPO DE SABONETE.

TABELA 3 - FREQUÊNCIAS ABSOLUTA E RELATIVA DO POSSÍVEL POTENCIAL DE IRRITAÇÃO CONFORME O TIPO DE SABONETE.

TABELA 4 - CARACTERÍSTICAS SOCIODEMOGRÁFICAS E CLÍNICAS INICIAIS DOS PARTICIPANTES CONFORME GRUPO DE ESTUDO. 87

TABELA 5 - AVALIAÇÃO DOS DESFECHOS PRIMÁRIOS NOS GRUPOS DO ESTUDO. 90

TABELA 6 - MODELO DE EFEITOS MISTOS COM INTERAÇÃO TRIPLA ENTRE REGIÃO, SABONETE E TEMPO.

TABELA 7 - AVALIAÇÃO CLÍNICA DA PELE DO RN. 92

TABELA 8 - CARACTERÍSTICAS DEMOGRÁFICAS E CLÍNICAS INICIAIS DOS RN INCLUÍDOS NO ESTUDO 106

TABELA 9 - MODELO DE EFEITOS Mistos COM INTERAÇÃO DUPLA ENTRE VARIÁVEIS DEMOGRÁFICAS E CLÍNICAS E DESFECHOS BIOMÉTRICOS DA PELE AO LONGO DE 28 DIAS APÓS O NASCIMENTO. 106 


\section{LISTA DE FIGURAS}

Figura 1 - FluXograma do ENSAIO CLÍNICO RANDOMIZADO. 46

FIGURA 2 - VARIAÇÃO DO POTENCIAL HIDROGENIÔNICO (PH) DOS SABONETES CONFORME TIPO DE SABONETE 65

FiguRA 3 - FLUXOGRAMA DE RECRUTAMENTO DO ESTUDO PILOTO 86

FIGURA 4 - VARIAÇÃO DE MÉDIAS DOS DESFECHOS PRIMÁRIOS CONFORME GRUPO DE ESTUDO E REGIÃO DO CORPO, AO LONGO DO TEMPO.

FIGURA 5 - REGIÕES ANATÔMICAS DE MENSURAÇÃO DOS DESFECHOS BIOMÉTRICOS 104

FiguRA 6 - FLUXOGRAMA DE RECRUTAMENTO DO ESTUDO 105

FigurA 7 - VARIAÇÃO DO PH DA PELE CONFORME O TIPO DE PARTO E A IDADE GESTACIONAL AO LONGO DO PRIMEIRO MÊS DE VIDA. 108

FigURA 8 - VARIAÇÃO DA TEWL CONFORME TIPO DE PARTO E IDADE GESTACIONAL AO LONGO DO PRIMEIRO MÊS DE VIDA 109

FIGURA 9 - VARIAÇÃO DA SCH CONFORME HISTÓRICO FAMILIAR DA E IDADE GESTACIONAL AO LONGO DO PRIMEIRO MÊS DE VIDA

Figura 10 - VARIAÇÃo DO TEOR DE SEBO CONFORME O HISTÓRICO FAMILIAR DA AO LONGO DO PRIMEIRO MÊS DE VIDA

\section{LISTA DE QUADROS}

QUADRO 1- CARACTERÍSTICAS DOS TENSOATIVOS MAIS FREQUENTES NOS SABONETES 


\section{LISTAS DE SIGLAS}

$\mathrm{AC}$

AIG

ANVISA

CAPES

CIR

CMC

CONSORT

DA

EC

ECPRN

ECR

GC

GE

GIG

HUUSP

ICQD

IG

INCI

$\mathrm{pH}$

PIG

REBEC

REDCap

RN

$\mathrm{SCH}$

TALE

TCLE
Alojamento Conjunto

Adequado para a Idade Gestacional

Agência Nacional de Vigilância Sanitária

Coordenação de Aperfeiçoamento de Pessoal de Nível Superior

Cosmetic Ingredient Review

Critical Micelle Concentration

Consolidated Standards of Reporting Trials

Dermatite Atópica

Estrato Córneo

Escala de Condição da Pele do Recém-Nascido

Ensaio Clínico Randomizado

Grupo Controle

Grupo Experimental

Grande para a Idade Gestacional

Hospital Universitário da Universidade de São Paulo

Instrumento Cartões de Qualidade da Dor

Idade Gestacional

International Nomenclature of Cosmetics Ingredients

Potencial Hidrogeniônico

Pequeno para Idade Gestacional

Registro Brasileiro de Ensaios Clínicos

Research Electronic Data Capture

Recém-nascido

Stratum Corneum Hydration

Termo de Assentimento Livre e Esclarecido

Termo de Consentimento Livre e Esclarecido

Transepidermal Water Loss 


\section{SUMÁRIO}

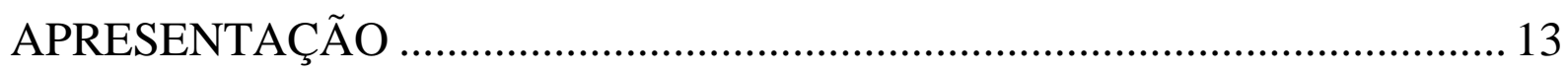

\section{CAPÍTULO I}

1. INTRODUÇÃO 17

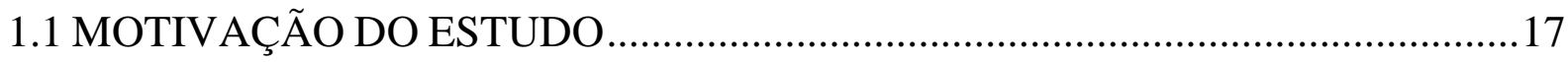

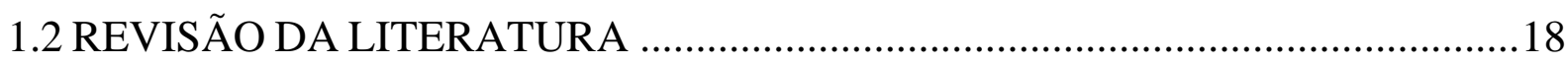

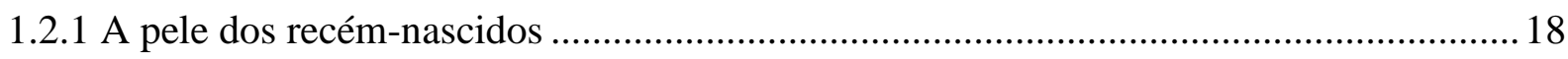

1.2.2 A higienização da pele dos recém-nascidos ..................................................................23

\section{CAPÍTULO II}

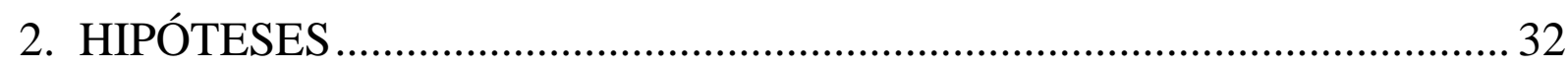

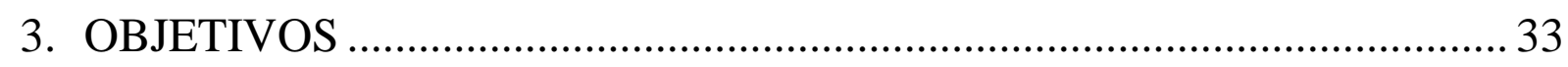

\section{CAPÍTULO III}

\section{MATERIAL E MÉTODOS} .35

4.1 ETAPA 1 - ANÁLISE DE INFORMAÇÕES DE RÓTULO, CARACTERÍSTICAS QUÍMICAS E FÍSICO-QUÍMICAS DE SABONETES LÍQUIDOS E EM BARRA

4.2 ETAPA 2 - COMPARAÇÃO DE EFEITO DO SABONETE LÍQUIDO E EM BARRA NA PELE

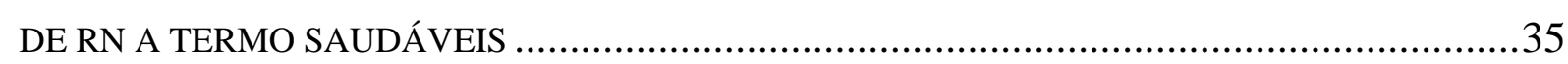

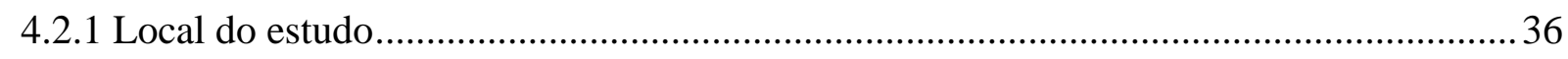

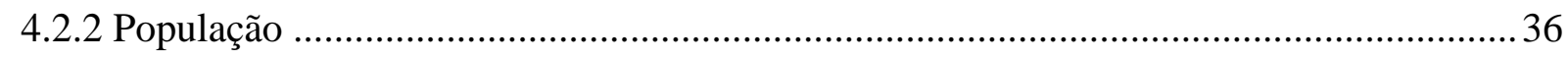

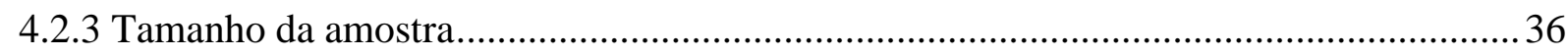

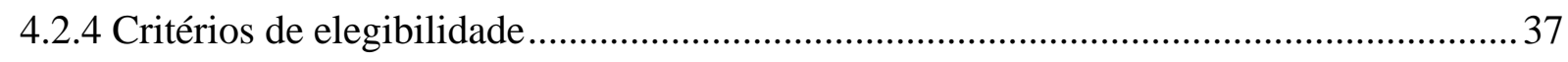

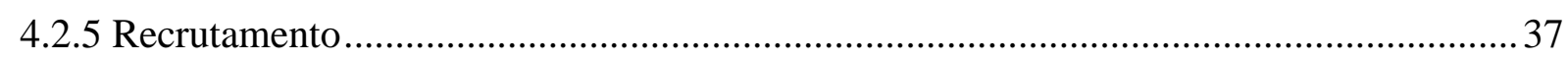

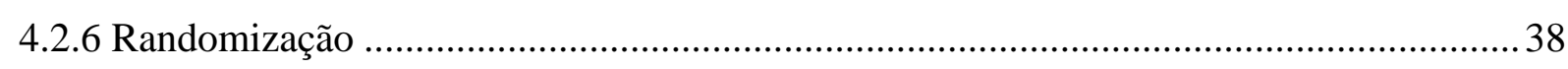

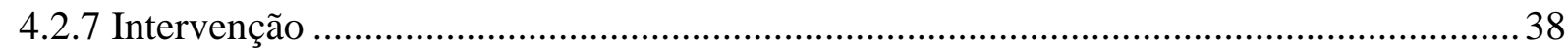

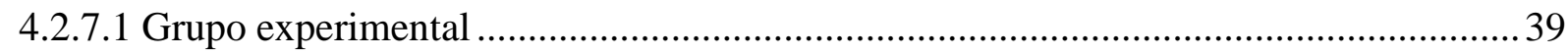

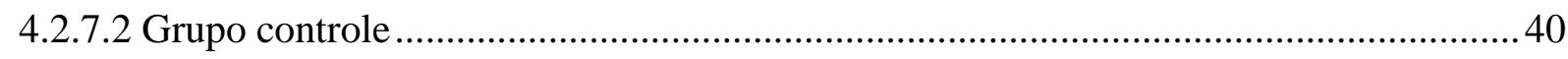

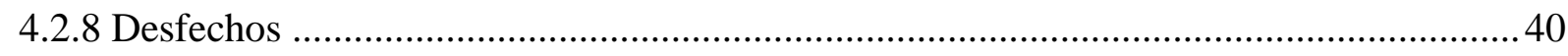

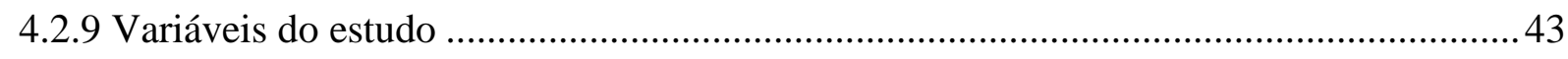




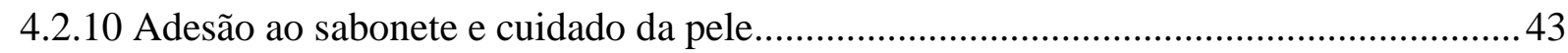

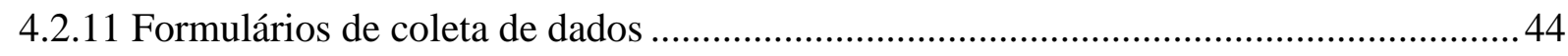

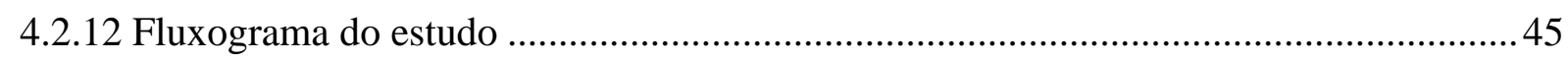

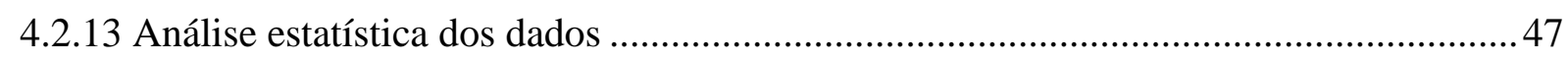

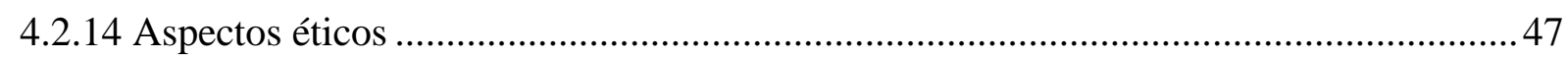

4.3 ETAPA 3 - INFLUÊNCIA DE VARIÁVEIS CLÍNICAS E DEMOGRÁFICAS SOBRE OS PARÂMETROS BIOMÉTRICOS DA PELE DO RN .....................................................48

\section{CAPÍTULO IV}

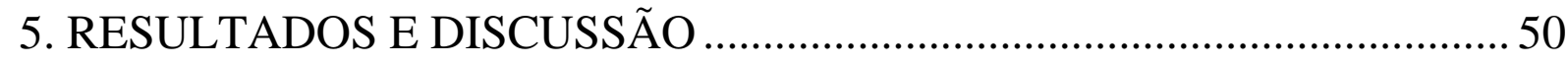

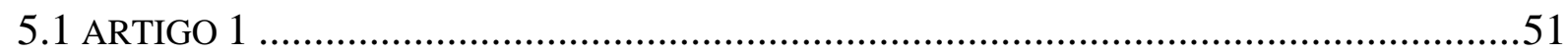

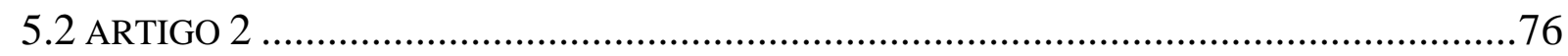

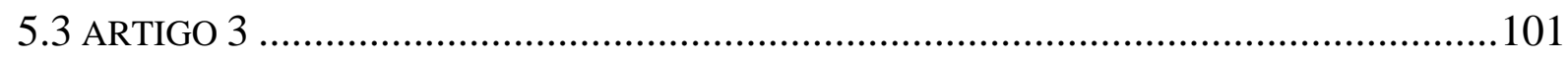

CAPÍTULO V

6. CONSIDERAÇÕES FINAIS ........................................................... 120

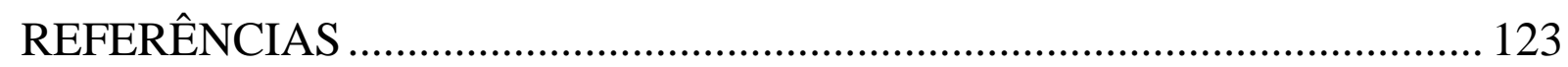

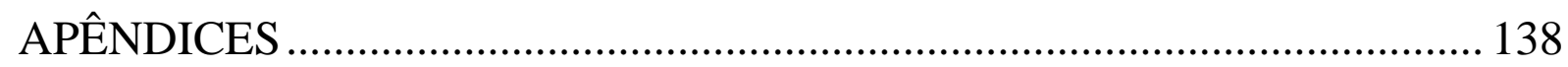

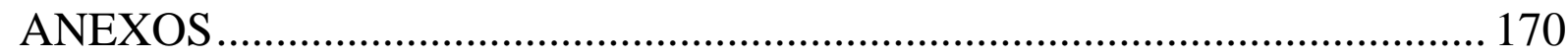




\section{APRESENTAÇÃO}

Esta tese foi estruturada em cinco capítulos, descritos a seguir:

- Capítulo I: inclui a motivação e introdução ao problema de pesquisa;

- Capítulo II: contém as hipóteses e objetivos do estudo;

- Capítulo III: aborda o percurso metodológico utilizado para o desenvolvimento do estudo de forma geral;

- Capítulo IV: resultados de três artigos. O artigo 1 analisa as informações de rotulagem, as características físicas (coloração e fragrância) e físico-químicas (valor de $\mathrm{pH}$ ) de sabonetes comerciais destinados a recém-nascidos e crianças. $\mathrm{O}$ artigo 2 apresenta dados sobre o efeito do sabonete líquido e em barra na pele de $\mathrm{RN}$ a termo saudáveis durante o primeiro mês de vida. E o artigo 3 explora a influência de variáveis demográficas e clínicas sobre os parâmetros biométricos da pele de $\mathrm{RN}$ a termo;

- Capítulo V: contém as considerações finais apresentando a síntese dos resultados principais, contribuições para prática, ensino e pesquisa e limitações da pesquisa. 


\section{}




\section{INTRODUÇÃO}

\subsection{MOTIVAÇÃO DO ESTUDO}

O cuidado de enfermagem orientado às crianças e neonatos tornou-se um tema de meu interesse desde a graduação em Enfermagem na Universidade Nacional da Colômbia. No ano 2010, realizei estágio como opção do Trabalho de Conclusão de Curso no programa "Cuidado à Criança e ao Adolescente com Feridas, Estomas e Incontinências”, na Fundación Hospital de la Misericordia, em Bogotá. Como trabalho final, elaborei uma série de casos avaliando a viabilidade da utilização do mel para o desbridamento, granulação e epitelização em queimaduras e lesões por pressão, em quatro crianças.

No ano seguinte, 2011, tive um profundo interesse em ampliar meus conhecimentos sobre metodologias de pesquisa e tratamento avançado de feridas, estomas e incontinências, pelo qual realizei um intercâmbio acadêmico na Escola de Enfermagem da Universidade de São Paulo, sob orientação da professora Vera Lúcia Conceição de Gouveia Santos. Durante esse estágio, tive a oportunidade de participar das aulas do curso de especialização em estomaterapia e de fazer estágios em serviços de estomaterapia de diferentes hospitais da cidade de São Paulo, além de cursar algumas disciplinas sobre metodologia de pesquisa.

Ao retornar para Colômbia, me formei e comecei a trabalhar como enfermeira em Unidades de Terapia Intensiva e Semi-Intensiva Pediátricas. Percebi que as crianças com queimaduras e feridas cirúrgicas complexas apresentavam dor de intensidade forte, e que eu não tinha conhecimentos adequados para avaliar e tratar essas dores. Aliado a isso, outros profissionais da equipe acreditavam que a criança não sentia dor e que sua queixa estava relacionada ao estresse do hospital, fato que não era investigado por meio de sinais específicos ou instrumentos de avaliação de dor apropriados para crianças.

Diante desses fatos da minha prática clínica, percebi que precisava aprimorar os meus conhecimentos sobre manejo de feridas complexas e decidi realizar a especialização em estomaterapia na Escola de Enfermagem da Universidade de São Paulo, no ano de 2013. Paralelamente, durante a realização da especialização, comecei a aprofundar sobre a avaliação da dor de crianças com feridas. Encontrei diversos trabalhos realizados pela professora Dra. Lisabelle Rossato, a respeito da avaliação da dor em crianças, utilizando um instrumento específico: o Instrumento Cartões de Qualidade da Dor (ICQD).

Quando entrei em contato com a professora Lisabelle, para conhecer com detalhe seu trabalho, consolidou-se o interesse de adaptar e validar o ICQD em crianças colombianas com feridas, visando disponibilizar um instrumento adequado para avaliação da dor em crianças 
pelos profissionais de saúde colombianos. Os motivos expostos possibilitaram a realização do meu mestrado acadêmico, no ano de 2014, sendo concluído no ano de 2016 e resultando na adaptação cultural e validação inicial do ICQD para o contexto colombiano.

Durante o percurso do segundo ano do mestrado acadêmico (2015) na Escola de Enfermagem da Universidade de São Paulo, fui convidada pela Dra. Beatriz Yamada para escrever um capítulo de livro sobre o banho de recém-nascidos (RN). Ao realizar a revisão de literatura sobre o tema, percebi a escassez de informações consistentes e decidi aprofundar meus conhecimentos em relação aos produtos de higiene para a pele de RN. Assim, surgiu o interesse de construir e realizar um ensaio clínico para estabelecer o efeito do sabonete líquido e do sabonete em barra sobre a pele de recém-nascidos comumente usados no contexto brasileiro tanto por cuidadores quanto por profissionais de saúde.

\subsection{REVISÃO DA LITERATURA}

\subsubsection{A pele dos recém-nascidos}

Os RN são classificados conforme sua idade gestacional em três categorias: RN prétermo, quando possuem menos de 37 semanas de gestação; RN a termo, quando tem entre 37 e 42 semanas de gestação; e em RN pós-termo, a partir de 42 semanas de gestação (Brasil, 2014). Ao longo do capítulo, serão discutidos conceitos relacionados à pele do $\mathrm{RN}$ a termo.

A pele é considerada o maior órgão do corpo humano. No RN, sua espessura corresponde a 70\% da espessura da pele do adulto (Kravchenko e Maibach, 2003). Em termos anatômicos e fisiológicos, a pele do RN, ao nascer, possui todos os elementos necessários para adaptar-se ao ambiente extrauterino e garantir a manutenção do equilíbrio hidroeletrolítico, regulação da temperatura, secreção de hormônios, proteção da radiação solar, prevenção de infecções e comunicação sensorial, embora estas funções encontrem-se diminuídas e em processo de maturação até o primeiro ano de vida (Fluhr et al., 2010; Telofski et al., 2012; Visscher e Narendran 2014a). Inclusive existem autores que defendem que a maturidade da pele acontece até os 36 meses de vida (Stamatas et al., 2010).

Em um RN a termo, a epiderme encontra-se completamente desenvolvida, sendo responsável em uma grande proporção pela função barreira da pele (Fluhr et al. ,2010). No entanto, existem diferenças na estrutura, função e composição entre a pele de um RN e de um adulto, que se traduzem em diferenças funcionais evidentes (Telofski et al., 2012).

O estrato córneo (EC) é 30\% mais fino do que no adulto (10 a 20 camadas), variando

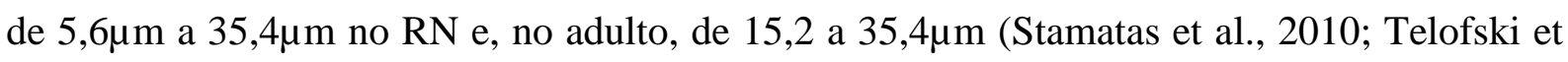


al., 2012). O tamanho dos corneócitos e os queratinócitos é menor, resultando em uma produção de fatores de hidratação natural diminuída (NMF - sigla em inglês para Natural Moisturizing Factor), com níveis de hidratação inferiores da pele (Fluhr et al. 2010). Estas duas características incrementam o risco não apenas para o ressecamento da pele, mas também para a penetração de substâncias com efeitos mais intensos (Nikolovski et al., 2008) devido à maior relação entre a superfície corpórea e o peso que possuem os RN comparados aos adultos (Cooke et al., 2018). A hidratação do estrato córneo ( $\mathrm{SCH}$ - sigla em inglês para Stratum Corneum Hydration) da pele aumenta gradativamente ao longo das quatro primeiras semanas de vida (Stamatas et al., 2011).

Após o nascimento, a pele começa um processo imediato de evaporação da água que está presente na superfície, razão que contribui para a menor hidratação do estrato córneo, também, sendo inferior à pele de crianças maiores e adultos e estabilizando-se entre a segunda semana e o primeiro mês após o nascimento (Fluhr et al., 2010). Estudo realizado demonstrou que o estrato córneo em zonas como a fronte, o tórax posterior, o abdômen e o antebraço apresentaram maior hidratação no primeiro dia de vida em comparação com a de um adulto (Hoeger e Enzmann 2002). Outro estudo avaliou que os níveis de umidade e de hidratação foram menores na região perianal do que em outras regiões do corpo, sobretudo no primeiro mês de vida, provavelmente devido ao uso da fralda (Visscher et al., 2000; Fluhr et al., 2010).

A Perda de Água Transepidérmica (TEWL - sigla em inglês para Transepidermal Water Loss) no RN apresenta valores inferiores a $10 \mathrm{~g} / \mathrm{m}^{2} / \mathrm{h}$ (Fluhr et al. 2010). No entanto, valores de TEWL são variáveis e influenciados pela idade gestacional, região anatômica e fatores ambientais, como temperatura ambiente e umidade relativa (Fluhr et al., 2010; Stamatas et al., 2011).

Quanto à influência da idade gestacional, estudos demonstraram que não há diferenças significativas na TEWL entre a pele do RN e do adulto (Fluhr et al., 2010; Visscher e Narendran 2014a). Outros autores encontraram que os RN pré-termo apresentaram valores elevados de TEWL comparados aos dos RN a termo. Isso significa que quanto menor a idade gestacional, menor a maturidade do estrato córneo e, em consequência, haverá maior valor de TEWL (Visscher e Narendran 2014a). Entretanto, estudo encontrou que crianças entre os 3 e 12 meses apresentaram valores significativamente mais altos quando comparados aos adultos (Nikolovski et al., 2008). Valores elevados de TEWL podem levar o RN à hipotermia, desidratação e hiperosmolaridade (Gurgel et al., 2011).

Em relação à influência dos fatores ambientais, temperaturas elevadas do ar geram valores elevados de TEWL, assim como um ambiente úmido em proporções adequadas 
resultam em valores inferiores de TEWL (Fluhr et al., 2010). E, no que diz respeito à região anatômica, algumas regiões, como solas dos pés, palmas das mãos e a região anterior do antebraço, apresentaram maiores valores de TEWL, fato que pode ser explicado pelo aumento da transpiração gerado pela influência das emoções e pela flexão das extremidades no período neonatal inicial (Fluhr et al., 2010).

Por outro lado, a pele dos RN nasce coberta por uma camada hidrofóbica de moléculas lipídicas denominada de vernix caseoso, que se estende da cabeça aos pés e de trás para frente, e está composta por água (80\%), lipídeos (10\%) e proteínas (10\%) (Visscher e Narendran 2014b). Estudo realizado em $430 \mathrm{RN}$ determinou a porcentagem de vernix caseoso sobre a superfície corpórea, encontrando que a área coberta nos RN pré-termo foi de $72 \%$, nos $\mathrm{RN}$ a termo foi $38 \%$ e nos $\mathrm{RN}$ pós-termo foi $12 \%$, tendo uma relação inversamente proporcional com a idade gestacional, ou seja, à menor idade gestacional maior porcentagem de vernix caseoso (Visscher et al., 2005).

Em geral, o vernix é reabsorvido nas primeiras 24 horas de vida, atuando principalmente como barreira biológica contra as infecções e facilitando o passo pelo canal de parto (Visscher et al., 2014). Além disso, contém agentes bioativos nas frações lipídicas e proteicas, tais como a calgranulina A, B e C, cistatina A e UGRP-1 com efeito sobre patógenos bacterianos e fúngicos como Candia Albicans sp, Streptococcus do grupo B, Listeria monocytogenes e Klebsiella pneumoniae sp (Visscher et al., 2014). Outras funções relatadas envolvem: desenvolvimento e hidratação do estrato córneo, prevenção da perda de água, formação do manto ácido, termoregulação corpórea, e promoção da cicatrização (Visscher et al. 2005; Fluhr et al. 2010; Visscher e Narendran 2014b). Estudo demonstrou que regiões do corpo de $\mathrm{RN}$ com vernix caseoso tiveram maior hidratação, $\mathrm{pH}$ mais ácido e menor eritema do que regiões de RN sem vernix (Visscher et al., 2005). Assim sendo, a Organização Mundial da Saúde recomenda que o vernix caseoso permaneça na pele no mínimo 6 horas após o nascimento (World Health Organization, 2009; Taieb, 2018).

Outro aspecto destacado é o $\mathrm{pH}$ da pele do $\mathrm{RN}$ após o nascimento, que pode variar entre 6,0 e 7,5; ou seja, de levemente acidificado, neutro, e ligeiramente alcalino (Oranges et al., 2015). Porém, enfrenta um processo de acidificação entre o terceiro e o quarto dia de vida, adquirindo estabilidade gradativamente ao longo do primeiro mês, com valores em torno de 5,0. Além disso, após elevações do $\mathrm{pH}$, a pele do $\mathrm{RN}$ pode demandar maior tempo para restaurar os valores fisiológicos em comparação à pele do adulto (Fluhr et al., 2010; Fernandes et al., 2011). 
O manto ácido da pele ( $\mathrm{pH}$ 4,5 a 5,5) é fundamental na resistência contra bactérias, como na redução da expressão de duas proteínas estafilocócicas de superfície (fator de aglutinação $\mathrm{B}$ e a proteína de ligação à fibronectina), assim como na inibição da proliferação de S. aureus (Antunes et al., 2017). Também, propicia a manutenção da microbiota residente normal, que é constituída por bactérias Gram-positivas (Staphylococcus sp, S. epidermidis, Micrococcus luteus, Corynebacterium, Streptococcus sp) (Antunes et al., 2017).

$\mathrm{O}$ pH ácido contribui na maturação da barreira epidérmica e nos processos de reparação tecidual e esfoliação celular (Ali e Yosipovitch 2013; Kuo et al., 2020). A formação dos componentes lipifílicos do estrato córneo envolve enzimas dependentes de $\mathrm{pH}$ ácido, como a $\beta$-glucocerebrosidase e a esfingomielinase ácida, cujo pH é 5,6 e 4,5, respectivamente. Elas participam ativamente da síntese de ceramida, importante lipídeo na barreira de permeabilidade do estrato córneo (Ali e Yosipovitch 2013; Visscher et al., 2015). Também existem proteases ligadas à descamação do estrato córneo, como a serina, a kalicreína 5 e a kalicreína 7, que possuem pH neutro. À medida que o pH da pele aumenta, estas proteases são ativadas, enquanto as enzimas responsáveis pela geração de ceramidas, que possuem $\mathrm{pH}$ ácido, são inativadas e comprometem a estrutura e a função do estrato córneo, muitas vezes evidenciado por um ressecamento intenso da pele (Fluhr et al., 2010; Ali e Yosipovitch 2013; Visscher et al., 2015).

Além disso, o valor do $\mathrm{pH}$ é influenciado por fatores intrínsecos, como: idade, raça, região anatômica, predisposição genética, suor, sebo, hidratação da pele; e extrínsecos: temperatura ambiente, umidade relativa do ar, estação do ano (Ali e Yosipovitch 2013; Kuo et al., 2020). Por exemplo, estudos têm demonstrado que, no primeiro mês de vida, o pH encontra-se elevado na região perineal em comparação com outras regiões do corpo, provavelmente pela oclusão da fralda e o contato da pele com substâncias alcalinas como a urina e fezes (Visscher et al., 2000; Lavender et al., 2012).

Outrossim, o teor de sebo constitui um dos maiores compostos do filme hidrolipídico cutâneo, composto por triglicerídeos, ésteres de cera e esqualeno, que atuam como um mecanismo inespecífico de proteção da barreira cutânea. Durante a primeira semana após o nascimento, aumenta a atividade das glândulas sebáceas, devido ao efeito dos hormônios transplacentários. Fluhr et al., (2010) apontaram que enquanto existe menor produção de sebo em RN do sexo feminino ao nascimento, seguida por aumento no terceiro e quarto dias de vida, nos RN do sexo masculino ocorre diminuição progressiva ao longo das semanas. Após este período, os níveis de sebo diminuem e aumentam novamente na puberdade. 
Em relação às glândulas sudoríparas do RN a termo, a produção de suor começa após o nascimento, em resposta aos fatores ambientais, pelo aumento da temperatura, e aos fatores emocionais, como: estresse, dor e medo e, inclusive, estímulos táteis (Fluhr et al., 2010). A sudorese provocada pelos fatores emocionais ocorre, principalmente, nas palmas e solas. No entanto, a sudorese derivada de estímulos ambientais acontece na fronte, região anterior do tórax e superior do braço (Fluhr et al., 2010). O RN caracteriza-se, ainda, pela incapacidade de regular a temperatura de frio ou calor nos extremos, devido à influência direta do fluxo de sangue que alcança o tecido subcutâneo (Kravchenko e Maibach 2003; Fluhr et al., 2010).

No que diz respeito à produção de melanina pelos melanócitos, nos $\mathrm{RN}$ encontra-se diminuída, devido à formação de grânulos em maturação, gerando maior sensibilidade e menor proteção contra os raios solares (Oliveira, 2012).

Na junção dermoepidérmica, ocorre diminuição da coesão entre a epiderme e a derme, e sob estímulo mecânico intenso pode colaborar no desenvolvimento de lesões de pele (Visscher et al., 2013). Também ocorre a produção de colágeno inferior, mas em constante desenvolvimento entre três e seis meses após o nascimento. A derme pode conter elevada concentração de proteoglicanos que ocasiona maior quantidade de água na região (Fernandes et al., 2011; Oliveira, 2012; Yamada, 2015).

O tecido subcutâneo nos RN a termo é de espessura menor ou, em alguns RN prétermo, pode estar ausente (Oliveira, 2012). Além disso, a microvasculatura da pele apresenta um plexo denso horizontal com rede capilar desorganizada, existindo diminuição no enovelamento dos capilares em algumas regiões do corpo e no controle vasomotor. Os laços capilares são detectáveis somente na região das unhas, palmas e solas, sendo totalmente observáveis até na segunda semana de vida (Fluhr et al., 2010; Longo et al., 2013).

Por último, a pele do RN é chave no fortalecimento da imunidade inata por meio de um conjunto de citocinas pró e anti-inflamatórias, proteínas estruturais, lipídios, células apresentadoras de antígenos específicos e a barreira física do estrato córneo (Visscher e Narendran 2014a). No estrato córneo encontra-se duas proteínas antimicrobianas, lisozima e lactoferrina, em níveis cinco vezes maiores que nos adultos, sendo que os queratinócitos secretam citocinas e quimiocinas para ativar a imunidade, ademais de duas classes de peptídeos antimicrobianos, como as defensinas beta humanas e as catelcidinas, que aumentam diante de dano tecidual na epiderme ou infecção (Niyonsaba et al., 2009; Visscher e Narendran 2014a). Também as glândulas sebáceas secretam lipídios, que contêm ácidos graxos específicos, e as glândulas sudoríparas écrinas secretam dermicina, substâncias que 
possuem atividade antimicrobiana e, no caso da dermicina, esta estimula os queratinócitos para secretar citocinas (Niyonsaba et al., 2009).

Em função das importantes peculiaridades anatômicas e fisiológicas relacionadas à pele dos RN, cuidados específicos são indispensáveis para favorecer a integridade da barreira cutânea, adequado amadurecimento da pele e prevenir o aparecimento de doenças ou lesões dermatológicas que repercutam no desenvolvimento dos RN.

\subsubsection{A higienização da pele dos recém-nascidos}

Os RN hospitalizados são vulneráveis à ocorrência de lesões e problemas de pele, não apenas pela sua imaturidade cutânea, conforme detalhado no item "A pele do recém-nascido", mas especialmente pela manipulação da pele em razão de diversos procedimentos clínicos e cuidado diário da pele. Entre os problemas de pele mais comuns, encontram-se: xerose, dermatite associadas à incontinência (comumente denominada dermatite de fralda), infecções de pele e dermatite atópica (DA) (Lavender et al., 2011; Kutlubay et al., 2017; Cooke, 2018).

A DA é uma doença dermatológica crônica, cuja manifestação clínica comum é o eczema (eritema, edema, inflamação, descamação, prurido) (DaVeiga, 2012; Antunes et al., 2017). Outras mudanças observadas na pele envolvem: incremento na TEWL, alteração do pH da pele, aumento da permeabilidade do EC, alterações na expressão de peptídeos antimicrobianos e perda da integridade cutânea (Telofski et al., 2012). Estudos demonstraram que o aumento da TEWL na pele dos RN aos dois dias de vida foi identificado como preditor no desenvolvimento de DA, e aos dois anos de idade, de alergia, e além disso, esteve relacionado à diminuição da colonização da pele por Staphylococcus aureus sp (Kelleher et al., 2015; Horimukai et al., 2016).

A prevalência da DA tem aumentando nos últimos anos, variando entre $1 \%$ e $20 \%$ (DaVeiga, 2012). Ao redor de $45 \%$ dos casos são diagnosticados nos primeiros seis meses de vida, $60 \%$ no primeiro ano e $85 \%$ até os cinco anos de idade (Bieber, 2008); e cerca de um terço dos casos diagnosticados na infância permanecerão na vida adulta (Silverberg, 2016). A predisposição genética (mutação no gene que codifica a filagrina) e os fatores ambientais contribuem para o desenvolvimento da doença (DaVeiga, 2012). Dentre os fatores ambientais, encontram-se: exposição materna durante a gestação ao estresse, exposição passiva de fumo de tabaco, clima, poluentes, fumaça de tabaco, água dura (alta concentração de sais cálcio e magnésio), dieta e contato com substâncias irritantes, como os sabonetes (Antunes et al., 2017). Dependendo da composição química, os sabonetes podem gerar alterações na barreira cutânea, facilitando a penetração de substâncias químicas e microrganismos que contribuem no desenvolvimento da doença (Antunes et al., 2017). 
Ao nascimento, os RN são expostos a diversas ações de cuidado provenientes de profissionais de saúde, pais e/ou cuidadores. O banho configura-se como a intervenção mais frequente e comum de cuidado diário à pele e tem por objetivo remover a sujidade, saliva, fezes e gordura aderida à camada externa da pele (Telofski et al., 2012). Em geral, durante a realização do banho são usados sabonetes líquidos ou em barra, géis de banho ou somente água dependendo da cultura e do país (Telofski et al., 2012).

Os sabonetes em barra são os produtos de limpeza mais antigos e, em muitos países ainda, são usados para a higiene do RN. Entre as variações de sabonetes, destacam-se: tradicional, transparente (glicerina), combar (combinados, ou seja, sabonete tradicional em barra mais syndet), syndet e antibacterianos. Ampliaremos a descrição do sabonete tradicional, transparente (glicerina) e combar por serem os mais usados no banho do RN.

Os sabonetes em barra tradicionais, geralmente, são derivados do processo de saponificação, ou seja, da reação entre um álcali sobre glicerídeos de origem animal ou vegetal, formando um tensoativo aniônico, que geram espuma intensa e removem gordura e lipídeos do EC (Draelos, 2018). Seu pH é comumente alcalino (entre 9 e 11) (Draelos, 2018) e, ao interagir com a água e a superfície da pele, passam por uma reação de hidrólise liberando o álcali sobre a pele, que eleva seu $\mathrm{pH}$ em torno de 8,0 até que ocorra seu reequilíbrio (Friedman, 2016; Blaak e Staib, 2018). Os sabonetes em barra transparentes, ou semitransparentes, são menos alcalinos, com valores de pH entre 8 e 10, em função da neutralização com aminas alcalinas mais leves (trietanolamina) (Draelos, 2018). Também podem conter glicerina (concentração variada), que visa impedir a cristalização e opacificação do produto (Friedman, 2016). E, no último lugar da categoria, os sabonetes em barra combar são combinações de sabonete em barra tradicional (tensoativos aniônicos suaves) mais o syndet (tensoativos sintéticos). Seu valor de pH está entre 5,0 e 7,5 e proporcionam menor irritação da pele e menor remoção dos lipídeos do EC (Draelos, 2018).

$\mathrm{O}$ uso de sabonetes com $\mathrm{pH}$ alcalino $(>7,1)$ impacta sobre a coesão e a integridade do EC devido à ativação de proteases que degradam os componentes proteicos e à inativação das enzimas responsáveis pela produção de ceramidas (Ali e Yosipovitch, 2013; Blaak and Staib 2018). Além disso, prejudicam os processos de recuperação e esfoliação celular, podendo ser visíveis clinicamente: ressecamento, descamação, prurido e eritema na pele (Ali e Yosipovitch, 2013; Antunes et al., 2017; Blaak e Staib, 2018). O poder tampão da pele permite equilibrar os valores de $\mathrm{pH}$ após o aumento (Mendes et al., 2016). Porém, ainda não tem sido determinado o tempo que a pele do RN leva para se estabilizar. Assim, uma disrupção constante do $\mathrm{pH}$ da pele pode interferir na alteração da microbiota residente e 
aumento da colonização por bactérias e fungos patógenos (Cunha e Procianoy, 2006; Ali e Yosipovitch, 2013; Antunes et al., 2017).

Por outro lado, os sabonetes líquidos são produtos de limpeza que vêm sendo amplamente usados nos últimos anos. Este tipo de sabonete contém tensoativos sintéticos em uma dispersão aquosa. Os tensoativos têm como função diminuir a tensão superficial de um sistema e possuem na sua estrutura molecular grupos com afinidade pela água (hidrofílicos) e pelos lipídeos (lipofílicos), que conforme sua carga podem ser classificados em: aniônicos, anfóteros e não-iônicos.

Os tensoativos aniônicos possuem carga negativa na sua parte hidrófila, e, em geral, promovem limpeza adequada e boa formação de espuma. Classificam-se em quatro categorias segundo seu grupo polar: sulfonados, sulfatados, carboxilados, e fosfatados (Hibbs, 2006). Dependendo de sua estrutura química, quantidade e interação com outras substâncias, podem ser suaves ou agressivos com a pele. Um exemplo de um tensoativo suave é o Sodium Cocoyl Isethionate, e de um tensoativo agressivo está o Sodium Lauryl Sulfate, conhecido por desnaturar as proteínas do EC e atingir camadas mais profundas da pele (Hibbs, 2006; Daltin, 2011).

Os tensoativos anfóteros, dependendo do $\mathrm{pH}$ do meio onde se encontram, exibem carga positiva ou negativa na porção hidrofílica da molécula (Otterson, 2006). Por isto, podem ser combinados com tensoativos aniônicos ou não-iônicos para melhorar: suavidade, estabilidade da espuma, limpeza e viscosidade (Otterson, 2006). Conforme sua composição química, classificam-se em: derivados de sulfobetaínas, aminoácidos, betaínas e imidazolina. Como exemplos das últimas duas categorias estão o Cocamidopropyl Betaína e o Disodium cocoamphodiacetate, tensoativos considerados suaves para a pele e os olhos em comparação com alguns tipos de aniônicos (Otterson, 2006).

Os tensoativos não-iônicos não apresentam carga positiva ou negativa na parte hidrófila. Existem diversos tipos de tensoativos não-iônicos, entre eles: os alquilfenóis, ésteres de açúcar, alcanolamidas, óxidos de aminas, ácidos graxos, aminas graxas, polióis, derivados de óxido de etileno e/ou óxido de propileno (Hepworth, 2006). Caracterizam-se por proporcionar estabilidade às micelas (agrupações de tensoativos), aumentando a suavidade do sabonete com a pele. Destacam-se no grupo o Polyethylene glycol (PEG) - 80 sorbitan Laurate e Coco-Glucoside, considerados suave com a pele (Telofski et al., 2012).

Outrossim, os sabonetes, além dos tensoativos, podem conter outros ingredientes que impactam na função barreira da pele e podem contribuir no desenvolvimento de alterações na pele, como: fragrâncias, espessantes, antioxidantes, conservantes e corantes. Embora o rótulo 
proporcione informações sobre testes dermatológicos, $\mathrm{pH}$ balanceado ou ingredientes naturais ou orgânicos, isto não garante a ausência de reações decorrentes de seu uso (Visscher e Narendran, 2014a; Blume-Peytavi et al., 2016; Kuller, 2016).

Em geral, os países possuem legislações que regulamentam a fabricação e comercialização de produtos de higiene para a população pediátrica. No Brasil, a Agência Nacional de Vigilância Sanitária (Anvisa) é a responsável pela regulamentação desses produtos. Na RDC n 211, de 14 de julho de 2005 (Brasil, 2005) (p. 3), atualizada como RDC $\mathrm{n}^{\circ}$ 07, de 10 de fevereiro de 2015 (Brasil, 2015a), encontra-se a definição de cosméticos, produtos de higiene e perfumes como:

"preparações constituídas por substâncias naturais ou sintéticas de uso externo
nas diversas partes do corpo humano, pele, sistema capilar, unhas, lábio, órgãos
genitais externos, dentes e membranas mucosas da cavidade oral, com o
objetivo exclusivo ou principal de limpá-los, perfumá-los, alterar sua aparência
e/ou corrigir odores corporais e/ou protegê-los ou mantê-los em bom estado".

Além disso, a RDC nº 211 classificava os sabonetes infantis como grau de risco 2, ou seja, exigiam comprovação de segurança e/ou eficácia e informações de cuidados, modo e restrições de uso (Yamada, 2015b). No ano de 2018, a RDC n 237, de 16 de julho, determinou que esses produtos continuariam como grau de risco 2 , sendo que a empresa deve conservar em seu poder os testes de segurança e eficácia, e deve realizar a notificação e envio da documentação relacionada aos requisitos técnicos anteriores via on-line (Brasil, 2015a, 2018).

Também, na RDC $\mathrm{n}^{\circ} 15$, de 24 de abril de 2015, a Anvisa estabelece que os produtos de higiene devem estar constituídos por ingredientes próprios e seguros, e determina os requisitos técnicos para a concessão do registro do produto. Especificamente para sabonetes em barra, orienta que deverão ter alcalinidade livre e máxima de 0,5\% (Brasil, 2015b). No entanto, não oferece orientações sobre o valor de $\mathrm{pH}$ exigido para cada tipo de sabonete, nem exige disponibilizar nos rótulos informações sobre o valor de $\mathrm{pH}$, proporção dos ingredientes e sua respectiva função, e apenas solicita que sejam citados os componentes na nomenclatura internacional INCI (International Nomenclature of Cosmetics Ingredients). Outras legislações regulamentam substâncias específicas dos produtos, entre elas: corantes, conservantes e fragrâncias permitidas (Brasil, 2012b, 2012c, 2012a)

Adicionalmente, os fabricantes dos produtos tem a opção de realizar estudos de aceitabilidade em voluntários, sob condições reais de uso com o fim de constatar desconforto ou irritações e, dependendo do especialista que acompanhou o estudo, podem ser atribuídos os claims no rótulo (Brasil, 2012): 
- Dermatologicamente testado, avaliado em seres humanos sob controle de dermatologista;

- Oftalmologicamente testado, avaliado em seres humanos sob controle de oftalmologista, acompanhado ou não de dermatologista;

- Clinicamente testado, avaliado em humanos sob controle de dermatologista, ou outro especialista de acordo com a finalidade do produto;

- Avaliado por pediatras, avaliado em humanos (crianças), sob controle de pediatra, acompanhado ou não de dermatologista, desde que o produto tenha sido aprovado previamente em todos os testes de segurança realizados em adultos;

- Hipoalergênico, avaliado sob controle de dermatologista ou alergologista comprovando a baixa capacidade de induzir sensibilização.

Entretanto, tais estudos, em geral, são realizados na população adulta saudável e, uma vez obtida comprovação de segurança, poderão ser testados na pele de crianças em condições habituais de uso (teste de aceitabilidade cosmética), sob supervisão do pediatra e preservandose os preceitos éticos e os interesses da empresa.

Pesquisas analisaram o valor de $\mathrm{pH}$ e o rótulo de sabonetes usados na higiene de adultos e crianças. Mendes et al., (2016) avaliaram o pH de 47 sabonetes infantis em barra e 20 na forma líquida disponíveis no mercado. Os resultados demonstraram que no grupo de sabonetes em barra, 45 (95,8\%) tiveram $\mathrm{pH}>8,0$; e no grupo dos sabonetes líquidos, 7 (35\%) com pH entre 7,0 e 7,9, e $13(65 \%)$ com pH entre 4,4 e 6,9. Quanto ao rótulo, apenas dois sabonetes traziam informação relacionada ao $\mathrm{pH}$ do produto. Volochtchuk et al., (2000) analisaram o pH de 68 sabonetes disponíveis no mercado brasileiro, sendo 26 para uso infantil nas apresentações em barra e líquido, encontrando que dos sabonetes em barra $(n=23)$, somente um apresentou $\mathrm{pH}<6,9$, e o restante tiveram $\mathrm{pH}>8,0$. Quanto aos sabonetes líquidos $(\mathrm{n}=3)$, um dos produtos avaliados apresentou $\mathrm{pH}$ 7,0 e 7,9; e dois, entre 6,0 e 6,9. Embora o $\mathrm{pH}$ dos sabonetes avaliados no segundo caso tenha sido considerado ácido na escala de $\mathrm{pH}$, encontraram-se além do parâmetro fisiológico (entre 4,4 e 5,6) de $\mathrm{pH}$ da pele. Outra pesquisa (Tarun et al., 2014) verificou que 17\% (n=11) de 64 sabonetes analisados tiveram discrepâncias entre os valores de $\mathrm{pH}$ observados e as descrições presentes nos rótulos como "pH neutro" e "pH balanceado".

Agências nacionais de saúde, associações governamentais e de profissionais de saúde construíram guias e consensos que oferecem informações para orientar a pais, cuidadores e 
profissionais de saúde a respeito do cuidado da pele de RN, mas nem sempre as informações são congruentes. Na Inglaterra, o guia nacional "Cuidado Pós-Natal até 8 Semanas Após o Nascimento" (United Kingdom, 2015) orienta que não devem ser adicionados produtos de limpeza à água do banho e, também, não devem ser usados loções ou lenços umedecidos. Quando necessário, usar um produto de limpeza, que deve ser neutro e sem perfume. Nos Estados Unidos da América, o guia "Cuidado da Pele Neonatal" (AWHONN, 2013) recomenda usar no banho produtos com pH neutro ou levemente acidificado (5,5 a 7,0), com mínimo impacto sobre o $\mathrm{pH}$ da pele, seguros para os olhos e que contenham conservantes. E o consenso europeu sobre as melhores práticas no cuidado da pele de RN saudáveis (BlumePeytavi et al., 2016) recomenda fortemente que a limpeza da pele seja realizada apenas com água ou adicionando à água da banheira um sabonete líquido adequadamente formulado, ou seja, com pH neutro a levemente acidificado usando syndets na sua composição.

No Brasil, o Guia de Atenção à Saúde do Recém-nascido orienta que a limpeza da pele do neonato deve ser realizada de maneira suave com material neutro não tóxico e não abrasivo (Brasil, 2014). Além disso, o consenso de cuidado com a pele do RN recomenda o uso de sabonete líquido que não altere o $\mathrm{pH}$ normal da pele e que utilize conservantes para evitar a contaminação por bactérias e fungos (Carvalho et al., 2015). Contudo, sabonetes em barra e líquidos que não atendem às recomendações citadas anteriormente são comercializados e usados no Brasil por pais, cuidadores e profissionais de saúde.

Estudos primários e secundários têm sido conduzidos em $\mathrm{RN}$ a termo saudáveis, com o objetivo de determinar o efeito do uso rotineiro de alguns produtos de higiene sobre a pele deles. Revisão sistemática (Walker et al., 2005) sobre o tema determinou que não havia estudos prospectivos bem desenhados, em $\mathrm{RN}$ a termo, que avaliassem o efeito dos sabonetes e detergentes sobre a integridade da pele. No entanto, a partir do ano de 2010, foram publicados estudos primários sobre o tema.

Estudo realizado por Bartels et al., (2010) comparou três regimes de banho: gel de banho de $\mathrm{pH}=5.5(\mathrm{~GB})$, grupo em uso de água limpa e creme após o banho $(\mathrm{A}+\mathrm{C})$, grupo em uso de gel de banho de $\mathrm{pH}=5,5$ e creme após o banho $(\mathrm{GB}+\mathrm{C})$, frente ao uso de água (A), em 64 RN a termo saudáveis. Após oito semanas, o $\mathrm{GB}+\mathrm{C}$ apresentou diminuição significativa de TEWL na região frontal da face, abdômen e perna $(\mathrm{p}<0,000)$, assim como aumento na hidratação do estrato córneo $(\mathrm{p}<0,000)$ quando comparado com o grupo A. O grupo GB apresentou diminuição significativa no $\mathrm{pH}$ nas regiões do corpo avaliadas, em comparação com o grupo que utilizou somente água $(\mathrm{p}<0,000)$. Como limitação do estudo, constatou-se 
que não houve clareza no cálculo amostral e os procedimentos para a randomização dos RN nos grupos.

Estudo de Dizon et al., (2010), que objetivou avaliar a tolerabilidade de um novo sabonete líquido Johnson's top-to-toe ${ }^{\circledR}$ (grupo I) em comparação com o Sebamed ${ }^{\circledR}$ (grupo II) e água normal (grupo III) sobre a pele de 180 crianças menores de um ano (60 em cada grupo), verificou que não houve mudanças significativas em relação ao eritema, edema, secura ou descamação induzida por algum dos três produtos testados. As crianças dos grupos I e III apresentaram diminuição significativa do pH após uma semana de utilização, mas o pH retornou ao valor inicial na segunda semana. Não foram encontradas redução de TEWL significativas nos grupos I e III em duas semanas, o produto padrão usado no grupo II, provocou apenas aumento relativo desta variável e não foi significativo. Não foram produzidas irritações cutâneas em nenhum dos grupos, após duas semanas de uso dos produtos. Nesse estudo, não houve detalhamento sobre o cálculo amostral e os procedimentos de randomização, e houve conflito de interesses, pois quatro dos autores trabalhavam na empresa que elaborou os produtos testados e que financiou a pesquisa.

Ensaio clínico randomizado (Lavender et al., 2013), que objetivou examinar se um produto de limpeza de pele formulado não era inferior ao uso da água em $307 \mathrm{RN}$ a termo saudáveis, randomizados em dois grupos, $159 \mathrm{RN}$ e $148 \mathrm{RN}$, respectivamente, encontrou que aos 14 dias de utilização, o uso do sabonete não foi inferior ao uso da água em termos de TEWL $(-0,17$ [1,42 - 1.09] $p=0,79)$. Não houve diferenças estatisticamente significativas no valor de $\mathrm{pH}$, nem na avaliação de ressecamento e eritema da pele aos 14 e 28 dias de utilização. No entanto, a hidratação do estrato córneo no grupo que usou o sabonete foi maior aos 14 dias de uso $(2,9[0,43-5,47] p=0,022)$ e aos 28 dias de uso $(2,4$ [-0,40 - 5,20] $p=0,093$.

Revisão sistemática (Cooke et al., 2018) identificou quais práticas de cuidados (banho, cuidado da região perianal, cuidado do cabelo/couro cabeludo, tratamento da pele seca e massagem) protegem a pele do RN de zero a seis meses. No relacionado ao banho, os autores concluíram que não existe diferença significativa entre o uso de sabonete líquido ou da água sobre a função barreira da pele desses bebês, sugerindo que profissionais de saúde podem indicar para os pais e cuidadores ambas as práticas.

Estudo conduzido por Lund, Kuller e Durand (2020) mensurou o pH, TEWL e SCH da pele antes e depois do primeiro banho em $100 \mathrm{RN}$ a termo que usaram sabonete líquido ou água, verificando que o $\mathrm{pH}$ da superfície da pele, TEWL e SCH diminuem significativamente 
após o primeiro banho sem afetar o desenvolvimento da barreira da pele, independentemente do banho ter sido realizado com água ou sabonete líquido.

Os estudos anteriores expostos (Bartels et al., 2010; Dizon et al., 2010; Lavender et al., 2013) demonstram que o uso de sabonete líquido adequadamente formulado ou da água para a higiene do RN não prejudicou a estrutura e função da pele. No entanto, ainda não têm sido conduzidos estudos primários comparando o efeito de sabonete em barra e líquido sobre a pele do RN a termo.

Diante disso, as perguntas de pesquisas para o presente trabalho foram:

- Quais as características físicas e químicas dos sabonetes em barra e líquidos comumente usados nos RN?

- Qual o efeito do sabonete líquido e do sabonete em barra no $\mathrm{pH}$ da pele, perda de água transepidérmica (TEWL), hidratação do estrato córneo (SCH), teor de sebo e integridade da pele de RN a termo saudáveis?

- Existe influência de variáveis clínicas e demográficas do RN sobre os parâmetros biométricos da pele durante o período neonatal? 


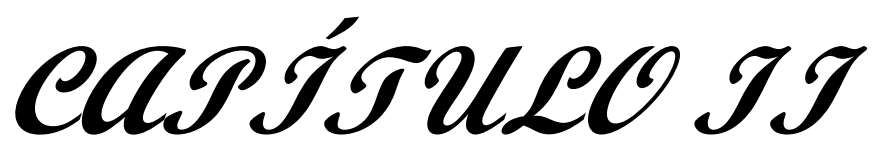




\section{HIPÓTESES}

As hipóteses formuladas para o presente trabalho foram:

- O uso de sabonete líquido é diferente do uso de sabonete em barra, no valor de pH, perda de água transepidérmica, hidratação do EC, teor de sebo e manutenção da integridade da pele de RN a termo saudáveis (Artigo 2).

- As variáveis clínicas e demográficas do RN (histórico paterno ou materno de dermatite atópica, tipo de parto, raça, sexo, idade gestacional, peso e altura ao nascimento) têm influência sobre os parâmetros biométricos da pele durante o período neonatal (Artigo 3). 


\section{OBJETIVOS}

- Analisar as informações de rotulagem, as características físicas (coloração e fragrância) e físico-químicas (valor de $\mathrm{pH}$ ) de sabonetes usados em recém-nascidos (Artigo 1).

- Comparar o efeito do sabonete líquido e em barra sobre o $\mathrm{pH}, \mathrm{TEWL}, \mathrm{SCH}$, teor de sebo e integridade da pele de $\mathrm{RN}$ a termo saudáveis (Artigo 2).

- Verificar a relação entre variáveis demográficas e clínicas sobre o pH, TEWL, SCH e teor de sebo da pele de $\mathrm{RN}$ a termo no período neonatal (Artigo 3). 


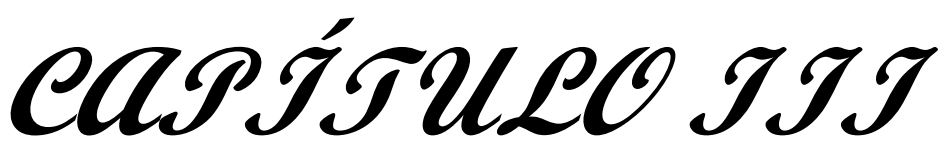




\section{MATERIAL E MÉTODOS}

O presente estudo foi desenvolvido em três etapas, são elas:

\subsection{ETAPA 1 - Análise de informações de rótulo, características químicas e físico- químicas de sabonetes líquidos e em barra}

Trata-se de um estudo quantitativo e descritivo, que analisou 17 sabonetes usados em $\mathrm{RN}$, sendo 8 na forma moldada em barra e 9 na forma líquida comercializados em São Paulo Brasil. Os sabonetes foram selecionados de acordo com a preferência de uso de mães, cuidadores e profissionais de saúde responsáveis pelo cuidado de $\mathrm{RN}$ internados no Alojamento Conjunto do Hospital Universitário da Universidade de São Paulo. Os produtos analisados foram de marcas diferentes, como Johnson's baby ${ }^{\circledR}$, Huggies ${ }^{\circledR}$, Granado ${ }^{\circledR}$, Pom Pom $^{\circledR}$, Luddy $^{\circledR}$ e Dove ${ }^{\circledR}$, por serem as mais usadas pelos cuidadores e profissionais de saúde da região. Os dados analisados foram: informações de rotulagem (tipos de tensoativos, testes de segurança e descrição do valor de $\mathrm{pH}$ ); características físicas (coloração e intensidade da fragrância) e físico-químicas (valor de $\mathrm{pH}$ ), estas duas últimas realizadas em laboratório de Cosmetologia da Faculdade de Ciências Farmacêuticas da Universidade de São Paulo.

\subsection{ETAPA 2 - Comparação de efeito do sabonete líquido e em barra na pele de RN a termo saudáveis}

Trata-se de um Ensaio Clínico Randomizado (ECR) prospectivo, paralelo, unicego e com dois braços. O ECR é considerado como o padrão ouro na pesquisa clínica para determinar o efeito de uma variável sobre outra, mantendo todas as variáveis constantes. Este tipo de estudo caracteriza-se por randomizar os participantes da pesquisa, alocando aleatoriamente cada participante em um grupo específico para assim obter grupos adequadamente comparáveis na avaliação dos desfechos (Curtis et al., 2015).

Para a construção e desenvolvimento deste ECR foram seguidas as recomendações do Consort (Consolidated Standards of Reporting Trials) por se tratar de um Guia Internacional para melhorar a transparência e a qualidade de apresentação dos Ensaios Clínicos Randomizados (ECR) (Schulz et al., 2010). O Guia contém um check-list composto por itens distribuídos nas seguintes categorias: título, introdução, métodos, resultados, discussão, e outras informações. 


\subsubsection{Local do estudo}

O estudo foi conduzido no Alojamento Conjunto (AC) do Hospital Universitário da Universidade de São Paulo (HU/USP), localizado na Zona Oeste da cidade de São Paulo, no campus da Cidade Universitária. Trata-se de um hospital público e de ensino de nível secundário vinculado ao Sistema Único de Saúde.

O HU/USP conta com a área materno-infantil, composta pelas unidades de Centro Obstétrico, Alojamento Conjunto, Unidade Neonatal, Pediatria, Unidade de Terapia Intensiva Pediátrica e Neonatal. O AC tem como prioridade o atendimento integral à mulher e ao RN desde o nascimento até a alta hospitalar, com exceção daqueles que apresentem complicações clínicas que precisem de cuidados específicos e complexos (Soares et al., 2010).

O referido serviço possui 32 leitos para acomodação de mães e RN em enfermarias e apartamentos. Para o mês de janeiro de 2018, a taxa de ocupação foi de $71 \%$, resultando no atendimento de 199 puérperas e recém-nascidos. Como parte do cuidado à puérpera e ao $\mathrm{RN}$, o AC conta com um protocolo estabelecido para realizar o banho de recém-nascidos, executado diariamente no período da manhã, sendo ensinado para as mães pelos profissionais de saúde que trabalham no AC, por meio de sessões educativas sobre cuidados no pós-parto, amamentação e cuidados com o RN, incluindo uma videoaula sobre o passo a passo do banho de imersão. Em relação à utilização de sabonete, as mães e/ou cuidadores escolhem o produto da sua preferência, seja em barra ou líquido.

\subsubsection{População}

A população foi conformada por recém-nascidos a termo saudáveis, internados no Alojamento Conjunto do Hospital Universitário da Universidade de São Paulo (HU/USP).

\subsubsection{Tamanho da amostra}

O tamanho da amostra foi calculado com base no estudo de Lavender et al. (2013), usando os valores iniciais (antes do banho) e finais de pH (após 28 dias) da pele de $\mathrm{RN}$ a termo, por meio do modelo de ANOVA para medidas repetidas com erro de $5 \%$ e poder de $95 \%$ e um tamanho de efeito de 0,19, obtendo uma amostra de 58 pacientes. Acrescentando uma perda de $60 \%$ no seguimento, foi totalizada uma amostra de $100 \mathrm{RN}$ para permitir 50 por grupo. 


\subsubsection{Critérios de elegibilidade}

\section{Critérios de inclusão}

- Idade gestacional ao nascimento entre 37 semanas e 42 semanas e seis dias;

- RN nascidos no Centro Obstétrico da instituição;

- $\quad$ RN com respiração espontânea;

- Ausência de anomalias congênitas, como: anencefalia, mielomeningocele, gastroquise, espinha bífida; e doenças dermatológicas, como: epidermólise Bulhosa, impetigo neonatal, ictiose, onfalite neonatal.

\section{Critérios de exclusão}

- RN com neuropatias ou cardiopatias, diagnosticadas após a inclusão;

- $\mathrm{RN}$ que receberam fototerapia;

- $\mathrm{RN}$ transferidos do alojamento conjunto para unidade neonatal ou unidade de terapia intensiva após a inclusão.

As manifestações cutâneas, como cútis marmorata, eritema tóxico, acne neonatal e miliária, não foram consideradas como afecções ou doenças dermatológicas.

\subsubsection{Recrutamento}

O protocolo de pesquisa foi apresentado aos enfermeiros e técnicos do serviço antes de iniciar o recrutamento. A equipe de pesquisa solicitou não realizar o banho dos $\mathrm{RN}$ até verificação dos critérios de elegibilidade e o convite de participação. A inclusão dos RN ocorreu entre segundas e quartas-feiras, quando a pesquisadora ou sua auxiliar realizavam o rastreio inicial nos prontuários das mães e dos RN para verificar os critérios de elegibilidade do RN. Após a autorização verbal das enfermeiras para conversar com a mãe ou o responsável, nos casos da mãe ter idade inferior a 18 anos, a pesquisadora ou auxiliar a(s) convidava para participar da pesquisa, explicando os objetivos, os procedimentos de coleta de dados e a necessidade de retornar ao hospital para os seguimentos. Caso aceitassem participar, era solicitada a assinatura do Termo de Consentimento Livre e Esclarecido (TCLE) (Apêndice A) ou Termo de Assentimento Livre e Esclarecido (TALE) (Apêndice B). Posteriormente, informações sociodemográficas e clínicas eram coletadas e realizada a randomização. 


\subsubsection{Randomização}

A randomização foi simples, para verificar se o RN, independentemente da predisposição familiar de DA, apresentaria reações ou alterações dermatológicas pelo uso desses produtos, principalmente do sabonete em barra. A lista de randomização foi gerada no site www.randomization.com, por uma pessoa externa à pesquisa, que preparou os envelopes opacos e lacrados. Os envelopes foram mantidos em armário fechado, com o intuito de garantir o sigilo no processo de alocação. O envelope era aberto diante da mãe e os participantes da pesquisa foram alocados em dois grupos: experimental (sabonete líquido) ou controle (sabonete em barra), com uma distribuição de $50 \mathrm{RN}$ em cada grupo.

\subsubsection{Intervenção}

A intervenção consistia na utilização diária de sabonete líquido ou de sabonete em barra no banho diário de $\mathrm{RN}$ a termo, durante os primeiros 28 dias de vida.

Para a realização do primeiro banho do $\mathrm{RN}$, duas auxiliares de pesquisa participaram do estudo, sendo uma delas estudante do último ano de graduação em Enfermagem, e a outra, técnica de enfermagem. Ambas foram treinadas pela pesquisadora principal sobre os aspectos gerais da pesquisa, como: rastreio, recrutamento e abordagem da mãe, randomização, uso do aplicativo móvel para registro dos dados e equipamento de desfechos biométricos, orientações à mãe na alta hospitalar, agendamentos e contato com a mãe para os seguimentos; e sobre questões específicas do procedimento do banho do RN, conforme o protocolo da instituição. A fidelidade da intervenção foi avaliada pela pesquisadora principal por meio de observação direta aleatória de alguns procedimentos de banho nos RN incluídos, sendo verificada a adesão das auxiliares ao protocolo de pesquisa.

$\mathrm{O}$ primeiro banho de imersão do RN foi realizado pela auxiliar de pesquisa, após verificação da temperatura corporal do RN e após no mínimo seis horas de vida; ocorria em sala específica, com duração de 5 minutos, emprego de água da torneira (abastecimento) com temperatura entre 37 e $38^{\circ} \mathrm{C}$, sem retirar o vernix da pele e com disponibilidade de berço aquecido para reequilibrar a temperatura do RN após o banho.

O banho de imersão foi realizado seguindo-se as recomendações da literatura (Loring et al., 2012; Freitas, 2015; Blume-Peytavi et al., 2016) e conforme o protocolo da instituição. Previamente à imersão do RN na banheira, o rosto foi higienizado com um algodão umedecido, seguida de secagem por toques com toalha de algodão. Depois a cabeça foi umedecida com água mais aplicação de sabonete, com posterior enxágue e secagem. Quando havia a presença de fezes na fralda antes de imergir o RN na banheira, foi higienizada a área 
perianal com um algodão umedecido. Para a higiene do corpo, o RN foi imergido na banheira com água da torneira até uma altura de $13 \mathrm{~cm}$ para garantir a imersão do corpo até o pescoço. Os glúteos ficaram apoiados no fundo da banheira, ensaboando-se com a mão: pescoço, tronco, membros, dorso, genitália e região glútea; e na sequência foi removido o sabonete com a água da banheira. Por fim, o RN foi retirado da banheira e seco com a toalha de algodão (Freitas, 2015).

Os banhos posteriores no hospital foram realizados pelas mães, com apoio do técnico de enfermagem. Para garantir a realização do procedimento de maneira adequada, todas as mães participaram de uma sessão educativa com as enfermeiras do AC, após 24 horas de internação. Nessa sessão foi explicado o procedimento do banho com apoio de um vídeo que mostrou o passo a passo do procedimento. Durante a internação, a pesquisadora principal ou a auxiliar de pesquisa orientavam a mãe e familiares sobre o procedimento do banho em casa, como: quantidade de sabonete diário a ser usado e a conservação do produto, restrição de uso de outros produtos tópicos (ex.: óleos, lenços umedecidos, hidratante), troca de fralda e limpeza da região perianal, possíveis manifestações cutâneas do RN e condutas a serem tomadas. Na alta hospitalar, foi entregue um envelope contendo uma via do Termo de Consentimento Livre e Esclarecido (TCLE) (Apêndice A) e/ou Termo de Assentimento Livre e Esclarecido (TALE) (Apêndice B), orientações de cuidado de pele (Apêndice C), folheto do banho ilustrado (Apêndice D) e o agendamento dos retornos ao hospital na carteirinha do hospital. Foi informado às mães que seriam lembradas dois dias antes da data de retorno para avaliação no hospital, por meio de ligação ou mensagem de texto (utilizando-se o aplicativo WhatsApp ${ }^{\circledR}$ ). Além disso, foi entregue sabonete em quantidade suficiente para o banho dos RN por 28 dias.

\subsubsection{Grupo experimental}

O grupo experimental (GE) foi constituído por RN que usaram o sabonete líquido, da marca Johnson's ${ }^{\circledR}$ Baby sabonete líquido recém-nascido ( ${ }^{\odot}$ Johnson \& Johnson do Brasil Indústria e Comércio de Produtos para Saúde Ltda.), comercialmente disponível. A quantidade de sabonete usada diariamente era de três pumps (cabeça, parte anterior e posterior do corpo). Para a conservação do produto, foi orientado guardar em um lugar seco, sem luz direta solar, e sem retirar a válvula do produto. Conforme análise prévia (dados não publicados), o produto continha uma combinação de um tensoativo anfótero com um tensoativo não-iônico, ambos com potencial de irritação baixo, proporcionando limpeza suave para a pele. Além disso, não contém corantes, sua fragrância é suave e o valor de pH ao redor 
de 5,4. É hipoalergênico e dermatologicamente testado. Os ingredientes descritos no rótulo, conforme a classificação internacional INCI (International Nomenclature of Cosmetic Ingredients), são: Aqua, Coco-Glucoside, Cocamidopropyl Betaine, Coco-Glucoside/Glyceryl Oleate, Phenoxyethanol, Acrylates/ C10-30 Alkyl Acrylate Crosspolymer, Sodium Benzoate, Sodium Hydroxide, p-Anisic Acid, Parfum.

\subsubsection{Grupo controle}

O grupo controle (GC) foi constituído por RN que usaram o sabonete em barra, da marca Huggies ${ }^{\circledR}$ sabonete extra suave (Kimberly-Clark ${ }^{\mathrm{TM}}$ ), comercialmente disponível e usado como cuidado padrão na instituição hospitalar. Quanto à quantidade a ser usada, foi orientado ensaboar a mão e, na sequência passá-la suavemente na pele. Isto deveria ser realizado três vezes (cabeça, parte anterior e posterior do corpo). Para a conservação do produto, foi entregue uma saboneteira que devia ser mantida limpa e seca. Conforme análise prévia (dados não publicados), o sabonete contém uma combinação de tensoativos aniônicos com um não-iônico, que podem ter um potencial de irritação baixo a moderado. O produto apresenta cor branca, com intensidade de fragrância forte e valor de $\mathrm{pH}$ ao redor de 10,0. É dermatologicamente testado. Seus ingredientes, conforme a classificação INCI, são: Sodium tallowate, Sodium palm kernealate, Aqua, Glycerin, Sodium chloride, Sodium hydroxide, Tetrasodium EDTA, Etidronic acid, Disodium distyrylbiphenyl disulfonate, Zea mays starch, Parfum, Decyl glucoside, Citric acid, Glyceryl stearate, Acetamide MEA, Titanium dioxide, Etidronic acid, Tetrasodium EDTA, BHT, Benzyl salicylate, Citronellol, Coumarin, Hexyl cinnamal, Limonene, Linalool, Alpha-isomethyl ionone. Tanto os sabonetes líquidos quanto os em barra comprados para o estudo pertenciam ao mesmo lote de fabricação.

\subsubsection{Desfechos}

\subsubsection{Avaliação dos desfechos}

A avaliação basal dos desfechos foi realizada antes do banho (T0) e as de seguimento foram realizadas uma hora após o primeiro banho (T1), às 48 horas de vida (T2), aos $14 \pm 3$ dias de vida (T3) e aos $28 \pm 3$ dias de vida (T4).

Todas as avaliações (T0 a T4) foram realizadas pelo pesquisador principal ou auxiliar de pesquisa em um quarto no $\mathrm{AC}$, com temperatura ambiente entre 20 e $24^{\circ} \mathrm{C}$ e umidade relativa (UR) entre 40 e $60 \%$. Nos retornos, as avaliações foram realizadas pelo menos duas horas após o banho no RN, realizado no domicílio. Antes de tomar as medidas, foram 
retiradas as roupas do $\mathrm{RN}$ para condicionamento da pele por 10 minutos e verificando se a temperatura corporal estava entre $36,5^{\circ} \mathrm{C}$ e $37,5^{\circ} \mathrm{C}$. Caso estivesse chorando, o $\mathrm{RN}$ era tranquilizado pela mãe. Cada avaliação tinha duração de 20 a 25 minutos.

\subsubsection{Desfechos primários}

Para a mensuração dos desfechos que envolvem medidas biométricas da pele, foi utilizada uma unidade central chamada Multi Probe Adapter MPA-5 ${ }^{\circledR}$ (Courage \& Khazaka, Colônia, Alemanha), que reúne vários instrumentos de medida por meio do acoplamento de sondas, cujos dados foram obtidos por meio de um software específico (Anexo 1). As sondas têm sido usadas em pesquisas com RN a termo (Garcia Bartels et al., 2010; Lavender et al., 2011, 2013; Fluhr et al., 2012; Cooke et al., 2016).

- Valor de pH da pele: foi mensurado com a sonda Skin-pH-Meter ${ }^{\circledR} 905$ (Courage \& Khazaka, Colônia, Alemanha) durante dois segundos (Anexo 2). O valor de $\mathrm{pH}$ indica a concentração hidrogeniônica de uma solução ou superfície. A escala de pH pode variar de zero até 14. O uso de sabonete líquido ou em barra pode elevar ou diminuir os valores de pH da pele, sendo que aqueles esperados para a pele do RN após alcançar estabilização seriam entre 4,5 e 5,5, ou seja, levemente acidificados. O valor de 7,0 é considerado o ponto neutro e pode estar presente nos primeiros dias de vida do RN, e acima de 7,1 indica pH alcalino e são prejudiciais para a manutenção da barreira da pele e da microbiota residente. $\mathrm{O} \mathrm{pH}$ foi mensurado duas vezes, em quatro regiões do corpo: antebraço direito (ponto médio entre o pulso e o cotovelo), abdômen (ponto médio entre apêndice xifoide e a cicatriz umbilical), glúteo direito (quadrante inferior externo) e coxa direita (ponto médio entre o joelho e a fossa ilíaca) nos tempos: antes do banho (T0), uma hora depois do primeiro banho (T1), às 48 horas de vida (T2), aos $14 \pm 3$ dias de vida (T3) e aos $28 \pm$ 3 dias de vida (T4).

- Perda de Água Transepidérmica (TEWL): foi mensurada usando a sonda Tewameter ${ }^{\circledR}$ TM 300 (Courage \& Khazaka, Colônia, Alemanha) durante 30 segundos, tomando o valor de média final (Anexo 3). As medições foram realizadas seguindo as diretrizes publicadas para medições de TEWL (Rogiers, 2001). O aparelho mede a quantidade de água que evapora da pele, sendo considerado como um indicador da função barreira da pele (Darlenski et al., 2009). Valores inferiores a $10 \mathrm{~g} / \mathrm{m}^{2} / \mathrm{h}$ indicam função barreira adequada da pele (Fluhr et al., 2012). A TEWL foi mensurada nas mesmas regiões e momentos que o $\mathrm{pH}$. 
- Hidratação do estrato córneo (SCH): empregou-se a sonda Corneometer ${ }^{\circledR} 825$ (Courage \& Khazaka, Colônia, Alemanha) por dois segundos (Anexo 4). Os valores foram obtidos em unidades arbitrárias, variando entre zero e 130, mostrando o nível de água presente no estrato córneo. A SCH foi mensurada nas mesmas regiões e momentos que o pH.

- Teor de sebo: foi mensurado com o cassette Sebumeter ${ }^{\circledR}$ SM81O (Courage \& Khazaka, Colônia, Alemanha) (Anexo 5). A fita do cassete foi colocada em contato com a pele durante 30 segundos; depois foi inserida na abertura do equipamento para leitura do valor em unidades arbitrárias da secreção sebácea da pele que podem variar de zero até 350 . O teor de sebo foi mensurado nas mesmas regiões e momentos que o $\mathrm{pH}$.

\subsubsection{Desfechos secundários}

- Avaliação da integridade da pele: a pele do $\mathrm{RN}$ foi avaliada por meio da Escala de Condição da Pele do Recém-Nascido (ECPRN), construída e validada nos Estados Unidos da América no ano de 2004 (Lund e Osborne, 2004). Anos mais tarde, foi adaptada e validada para o idioma português do Brasil por Schardosim et al., (2014) (Anexo 6). Esta escala avalia três aspectos da pele: secura, eritema, ruptura/lesão. Cada item possui três opções de resposta com escores de 1, 2 e 3 (1 pele sem alterações e 3 a pior condição da pele). O escore final é dado pela soma das respostas de cada categoria, obtendo pontuações entre 3 e 9 , sendo 3 a melhor condição e 9 a pior condição da pele. Além disso, destaca-se que para a avaliação do eritema, a escala oferece duas opções de resposta relacionada à superfície corporal: eritema visível $<50 \%$ da superfície corporal (=2), e eritema visível $>$ ou $=$ a $50 \%$ da superfície corporal (=3). Para garantir a avaliação objetiva da superfície corporal afetada no RN, foi utilizada a classificação de porcentagem de queimadura (regra dos 9\%) para menores de um ano proposta pela Sociedade Brasileira de Cirurgia Plástica (2008) (Ver item 4.12, Apêndice L). A Escala da Condição da Pele do Recém-Nascido foi aplicada avaliando o corpo inteiro nos mesmos momentos que o $\mathrm{pH}$. Ressalta-se que manifestações cutâneas comuns nos RN, como cútis marmorata, eritema tóxico, acne neonatal e miliária, não foram consideradas como alterações na pele, porém registradas no formulário de coleta de dados.

- Percepção da mãe sobre o uso de sabonete para o banho do RN: A percepção dos pais sobre o sabonete foi obtida usando um questionário elaborado pelas autoras para o presente estudo, contendo informações relacionadas com o uso, enxague, cheiro, limpeza, 
aparência da pele e continuidade de uso do sabonete (Ver item 4.12, Apêndice M). O questionário foi aplicado somente na última avaliação (T4) da pesquisa.

\subsubsection{Variáveis do estudo}

\subsubsection{Variáveis independentes}

O uso do sabonete líquido ou do sabonete em barra foram as variáveis independentes do estudo.

\subsubsection{Variáveis dependentes}

$\mathrm{O}$ pH, a perda de água transepidérmica (TEWL), a hidratação do estrato córneo (SCH), teor de sebo e a integridade da pele (secura, eritema e lesão de pele) foram as variáveis dependentes do estudo.

\subsubsection{Variáveis de caracterização da demográfica e clínica}

- Data e horário do início do estudo;

- Idade da mãe;

- Escolaridade da mãe;

- Estado civil da mãe;

- História familiar (materna/paterna) de dermatite atópica;

- Raça do RN;

- Data e hora de nascimento;

- Tipo de parto (vaginal, cesárea ou fórceps);

- Idade do RN - e idade gestacional;

- Sexo;

- Peso ao nascimento;

- Altura ao nascimento;

- Relação entre peso e idade gestacional (Pequeno para idade gestacional - PIG, Adequado para a idade gestacional - AIG, Grande para a idade gestacional - GIG).

\subsubsection{Adesão ao sabonete e cuidado da pele}

A adesão foi mensurada por meio da aplicação de um questionário à mãe ou cuidador sobre a realização do procedimento do banho conforme o folheto entregue na alta hospitalar, uso diário do sabonete, uso de outros produtos tópicos, aparência da pele, diagnóstico de 
doenças, entre elas a DA (ver item 4.12, Apêndice J). Esse questionário foi aplicado nos seguimentos T3 e T4.

\subsubsection{Formulários de coleta de dados}

Foram construídos 11 formulários posteriormente inseridos na plataforma eletrônica Research Electronic Data Capture (REDCap). A seguir, estão listados os formulários junto com uma breve descrição sobre o conteúdo e os momentos em que foram aplicados ao longo da pesquisa:

- Critérios de elegibilidade: formulário com perguntas sobre os critérios de inclusão necessários para participar do estudo. Este formulário foi aplicado na avaliação inicial (T0) (Apêndice E).

- Caracterização sociodemográfica e clínica: formulário com informações da mãe/responsável, tais como data e horário do início do estudo, idade, escolaridade, estado civil, história familiar (materna/paterna) de dermatite atópica, telefone, e-mail, número do prontuário; e informações do RN, como: raça do $\mathrm{RN}$, data e hora de nascimento, tipo de parto (vaginal, cesárea ou fórceps), idade do $\mathrm{RN}$ - e idade gestacional, sexo, peso ao nascimento, altura ao nascimento, relação entre peso e idade gestacional, número do prontuário. $\mathrm{O}$ formulário foi aplicado na avaliação inicial (T0) (Apêndice F).

- Randomização: formulário sobre o tipo de sabonete atribuído ao RN conforme a randomização computadorizada previamente realizada e foi aplicado na avaliação inicial (T0) (Apêndice G).

- Desfechos biométricos da pele antes do primeiro banho: formulário com as informações: temperatura corporal antes do banho; horas de vida; data e hora do primeiro banho; condições ambientais da sala; e dados específicos sobre os desfechos, como $\mathrm{pH}$, TEWL, SCH, teor de sebo; e pontuações da escala da Condição da Pele do Recém-Nascido. O formulário foi aplicado na avaliação inicial (T0) (Apêndice H).

- Critérios de exclusão no hospital: formulário com perguntas relacionadas aos critérios de exclusão, como: fototerapia, diagnóstico de anomalias congênitas ou transferência a outra unidade da instituição. O formulário foi aplicado às 48 horas de vida do RN (T2) (Apêndice I).

- Dados clínicos follow-up: formulário com perguntas sobre a realização diária do procedimento de banho, conforme explicado no hospital e com o sabonete atribuído; utilização de outros produtos tópicos na pele e as razões; condições da pele segundo 
percepção do cuidador; doenças agudas no RN; e uso de medicações. O formulário foi aplicado aos 14 dias de vida (T3) e aos 28 dias de vida (T4) (Apêndice J).

- Critérios de exclusão follow-up: formulário com perguntas sobre o diagnóstico de anomalias congênitas, especialmente cardíacas e neurológicas. O formulário foi aplicado aos 14 dias de vida (T3) e aos 28 dias de vida (T4) (Apêndice K).

- Desfechos biométricos da pele follow-up: formulário com informações sobre a temperatura corporal; condições ambientais da sala; e dados específicos sobre os desfechos, como $\mathrm{pH}$, TEWL, SCH, teor de sebo; e pontuações da escala da Condição da Pele do Recém-Nascido. O formulário foi aplicado após o primeiro banho (T1), às 48 horas (T2), aos 14 dias (T3) e aos 28 dias de vida do RN (T4) (Apêndice L).

- Percepção da mãe, pai ou cuidador sobre o uso de sabonete para o banho do recémnascido: formulário com perguntas relacionadas ao uso, enxague, cheiro e limpeza do sabonete. Além disso, os pais foram questionados sobre aparência da pele do RN e continuidade de uso do sabonete atribuído. O formulário foi aplicado no momento final da pesquisa, ou seja, aos 28 dias de vida do RN (T4) (Apêndice M).

- Encerramento do estudo: formulário com informações sobre: data da última avaliação, tempo de seguimento total, finalização do estudo, motivos de não ter finalizado o estudo, perda de seguimento e motivos, data do último contato telefônico, internações/consultas e os motivos, e óbito e causas do óbito. O formulário foi aplicado no momento final da pesquisa, ou seja, aos 28 dias de vida do RN (T4) (Apêndice N).

\subsubsection{Fluxograma do estudo}

O presente estudo teve uma duração de 15 meses, de outubro de 2018 até dezembro de 2019. A Figura 1 apresenta o fluxograma com as etapas desenvolvidas no estudo: 


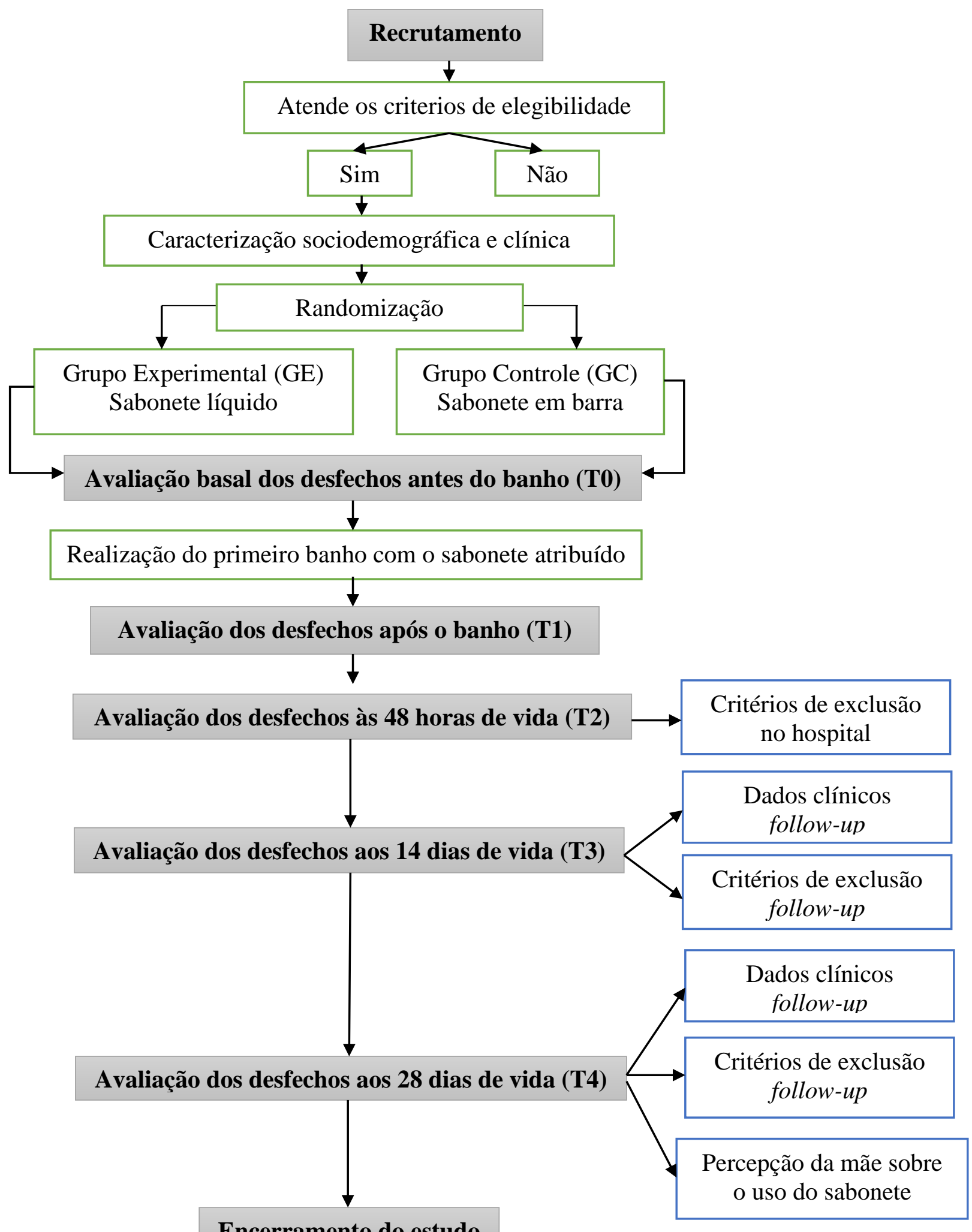

Figura 1 - Fluxograma do Ensaio Clínico Randomizado. 


\subsubsection{Análise estatística dos dados}

Os dados foram coletados no aplicativo Research Electronic Data Capture (REDCap) instalado em tablets. Os dados dos RN e mães, assim como as datas de ligações e de avaliações foram gerenciados eletronicamente na plataforma REDCap e hospedados no Hospital das Clínicas da Faculdade de Medicina da Universidade de São Paulo (Harris et al., 2009, 2019). Os dados foram exportados para uma planilha do programa Microsoft Excel ${ }^{\circledR}$ 365 e analisados no pacote estatístico R versão 4.0.0. Os grupos foram denominados Sabonete A e Sabonete B para garantir o cegamento da análise de dados (Polit, 2011; Lang e Stroup, 2020).

A análise descritiva dos dados foi realizada por meio de valores de frequências absoluta e relativa para variáveis categóricas; e para variáveis numéricas, foram utilizadas medidas de tendência central, como média e desvio padrão. A comparação das características sociodemográficas dos grupos foi avaliada utilizando os testes Wilcoxon-Mann-Whitney, teste-t, Qui-quadrado e Exato de fisher. Todas as análises de efeito foram conduzidas por intenção de tratar, ou seja, analisando os dados disponíveis dos 100 RN incluídos independentemente de ter concluído o estudo ou ter usado o sabonete atribuído. As comparações entre as variáveis contínuas foram realizadas usando um modelo de efeitos mistos longitudinais com interação tripla (sabonete $\times$ região $\times$ tempo). As pontuações da ECPRN foram analisadas usando o mesmo modelo com interação dupla (sabonete $\times$ tempo). A comparação da percepção dos pais e cuidadores sobre a uso do sabonete entre os grupos foi avaliada utilizando o teste Qui-quadrado e Exato de Fisher. O nível de significância estabelecido para todos os testes foi $\mathrm{p}<0,05$.

\subsubsection{Aspectos éticos}

Conforme as diretrizes da Resolução 466/2012 do Ministério da Saúde do Brasil, o projeto foi submetido e aprovado pelo Comitê de Ética em Pesquisa da Escola de Enfermagem da Universidade de São Paulo, parecer n ${ }^{\circ}$ 2.542.895 (Anexo 7), e pelo Comitê de Ética em Pesquisa do HU/USP, parecer $n^{\circ} 2.714 .918$ (Anexo 8).

Todas as mães ou responsáveis que aceitaram participar do estudo assinaram o Termo de Consentimento Livre e Esclarecido (TCLE) (Apêndice A). No caso de mães com menos de 18 anos, foi solicitada a assinatura do Termo de Assentimento Livre e Esclarecido (TALE) (Apêndice B) pela mãe do RN e do TCLE pelo responsável legal. 
O protocolo do estudo foi registrado no REBEC - Registro Brasileiro de Ensaios Clínicos -, sob número RBR-93996y, e Número Universal do Ensaio (Universal Trial Number - UTN) U1111-1216-6390 e RBR-93996y.

\subsection{ETAPA 3 - Influência de variáveis clínicas e demográficas sobre os parâmetros biométricos da pele do $\mathbf{R N}$}

Trata-se de um estudo longitudinal e prospectivo com abordagem quantitativa, secundário a ensaio clínico randomizado, conduzido em um hospital universitário público em São Paulo, Brasil, com prévia autorização do CEP do HU/USP. Amostra de conveniência composta por $100 \mathrm{RN}$ a termo saudáveis. Foi analisada a associação entre as variáveis demográficas e clínicas e os parâmetros biométricos. Os dados demográficos e clínicos neonatais incluíram histórico paterno ou materno de dermatite atópica (DA), tipo de parto, raça, sexo, idade gestacional (IG), peso e altura ao nascimento. E os parâmetros biométricos incluíram perda de água transepidérmica (Tewameter ${ }^{\circledR}$ TM 300, Courage \& Khazaka, Colônia, Alemanha), hidratação do estrato córneo (Corneometer ${ }^{\circledR} 825$, Courage \& Khazaka, Colônia, Alemanha), pH da pele (Skin-pH-Meter ${ }^{\circledR}$ 905, Courage \& Khazaka, Colônia, Alemanha) e teor de sebo (Sebumeter ${ }^{\circledR}$ SM81O, Courage \& Khazaka, Colônia, Alemanha). Estes últimos foram considerados como desfechos primários no ensaio clínico e foram mensurados duas vezes, em cinco regiões corporais no RN antes do primeiro banho, aos 14 dias e aos 28 dias após o nascimento. 


\section{eAPร́รUนO IV}




\section{RESULTADOS E DISCUSSÃO}

Este capítulo apresenta como resultado três artigos, são eles:

- ARTIGO 1 - Sabonetes usados em recém-nascidos: análise de informações de rotulagem e características físicas e físico-químicas;

- ARTIGO 2 - Efeito de sabonete líquido e em barra na pele de recém-nascidos a termo saudáveis: ensaio clínico randomizado;

- ARTIGO 3 - Influência de variáveis demográficas e clínicas nos parâmetros biométricos da pele de RN: estudo longitudinal prospectivo. 


\section{CAPצ́รURO V}




\section{CONSIDERAÇÕES FINAIS}

Os resultados da presente pesquisa foram obtidos por meio da análise de sabonetes líquido e em barra comercialmente disponíveis para a higiene de RN; condução de um Ensaio Clínico Randomizado comparando o uso de sabonete líquido e em barra na pele de RN a termo saudáveis, e análise da influência de variáveis demográficas e clínicas sobre a fisiologia cutânea do RN.

O Artigo 1 apresentou a análise de informações de rotulagem, características físicas e físico-químicas de sabonetes comerciais comumente usados no Brasil na higiene do RN, encontrando que todas as formulações empregaram tensoativos que tinham potencial de irritação baixo ou moderado; quanto ao $\mathrm{pH}$, a maioria dos sabonetes líquidos e alguns em barra combinados apresentaram valores próximos ao da pele; e a fragrância esteve presente em todas as formulações com intensidade variável.

O Artigo 2 comparou o uso de sabonete líquido e em barra sobre os valores de $\mathrm{pH}$, TEWL, SCH, teor de sebo, condição da pele e percepção da mãe sobre o uso do produto em 100 $\mathrm{RN}$ a termo saudáveis. Os resultados indicaram que o sabonete líquido manteve os valores de $\mathrm{pH}$ mais acidificados e maior hidratação na pele do que o sabonete em barra. Porém, não houve diferenças significativas na TEWL, teor de sebo, condição da pele e percepções das mães.

Por fim, o Artigo 3 analisou a influência das variáveis demográficas e clínicas sobre os parâmetros biométricos da pele de RN a termo, demonstrando: aumento nos valores de $\mathrm{pH}$ da pele após duas semanas de vida nos RN que nasceram via cesárea, de raça preta e com menor IG; maiores níveis de TEWL na segunda e quarta semana de vida nos RN que nasceram via cesárea, de raças preta e amarela, de sexo feminino e com maior IG; menores níveis de SCH após o nascimento e aos 28 dias de vida nos RN de raças parda, preta e branca, com maior IG e com histórico familiar de DA; e menores níveis de teor de sebo, após o nascimento nos RN com histórico familiar de DA.

No âmbito da prática, os resultados mencionados no Artigo 1 podem oferecer ferramentas aos profissionais de saúde, pais e cuidadores de RN para a seleção de sabonetes que preservem a fisiologia cutânea e promovam a maturação da pele do RN. Os achados do Artigo 2 podem contribuir na melhora das orientações dos protocolos e dos guias nacionais sobre os produtos ou sabonetes que apresentam maiores benefícios sobre a pele do RN a termo. E os achados do 
Artigo 3 podem orientar os profissionais de saúde sobre quais as características demográficas e clínicas têm o potencial de impactar na fisiologia cutânea do RN e planejar estratégias de cuidado da pele, baseadas em evidências científicas que previnam alterações cutâneas como a xerose, dermatite atópica, dermatite associada à incontinência, infecções de pele, dentre outras.

No âmbito do ensino, os resultados podem fortalecer o corpo de conhecimentos das disciplinas de enfermagem neonatal e pediátrica dos cursos de graduação em Enfermagem do Brasil, com impacto direto na formação de futuros profissionais de saúde capazes de estabelecer intervenções e orientações de cuidado da pele de RN baseadas na evidência científica, assim como educar os profissionais de saúde, pais e cuidadores sobre as melhores práticas de higiene ao RN.

No âmbito da pesquisa, este estudo configura uma aproximação inicial a um campo pouco explorado no Brasil, apontando a necessidade de conduzir estudos futuros que explorem as práticas de higiene e as razões de seleção de sabonetes por profissionais, pais e cuidadores de RN; estudos clínicos de desenvolvimento e avaliação de produtos de higiene em parceria com a indústria farmacêutica, que preservem a função barreira da pele e possuam comprovação de segurança específica para RN. Além disso, é necessário conduzir outros ensaios clínicos com maiores amostras que avaliem o efeito de sabonetes líquidos e em barra, hidratantes, cremes barreira e óleos sobre a estrutura e função da pele de RN a longo prazo.

Algumas limitações foram encontradas ao longo do desenvolvimento do estudo, como: impossibilidade de comparação dos resultados obtidos devido à evidência científica limitada sobre as características físicas e físico-químicas de sabonetes destinados a RN e crianças; efeito de sabonete em barra na pele de RN; e a influência de variáveis demográficas e clínicas sobre a fisiologia cutânea do RN. Outrossim, este estudo não contou com financiamento específico para sua realização, limitando os recursos humanos e materiais. Ademais, este estudo foi desenvolvido em uma única instituição e com uma amostra específica de $100 \mathrm{RN}$, o que pode limitar a generalização dos resultados para uma população mais ampla de $\mathrm{RN}$ de outras regiões geográficas do Brasil. Por último, apesar de solicitar às mães e cuidadores dos RN a utilização exclusiva dos sabonetes pesquisados, foram introduzidos outros produtos tópicos que, também, tiveram influência sobre os resultados obtidos nos desfechos pesquisados. 


\section{REFERENNegas}




\section{REFERÊNCIAS}

Ali SM, Yosipovitch G. Skin pH: From basic science to basic skin care. Acta Derm Venereol. 2013;93(3):261-7.

Antunes AA, Solé D, Carvalho VO, Bau AEK, Kuschnir FC, Mallozi MC, et al. Guia prático de atualização em dermatite atópica - Parte I: etiopatogenia, clínica e diagnóstico. Posicionamento conjunto da Associação Brasileira de Alergia e Imunologia e da Sociedade Brasileira de Pediatria. Arq Asma, Alerg e Imunol. 2017a;1(2):131-56.

Antunes AA, Solé D, Carvalho VO, Bau AEK, Kuschnir FC, Mallozi MC, et al. Guia prático de atualização em dermatite atópica - Parte II: abordagem terapêutica. Posicionamento conjunto da Associação Brasileira de Alergia e Imunologia e da Sociedade Brasileira de Pediatria. Arq Asma, Alerg e Imunol. 2017b;1(2):157-82.

Associação Brasileira da Indústria de Higiene Pessoal Perfumaria e Cosméticos. III Caderno de tendências 2014-2015 [Internet]. São Paulo: ABIHPEC; 2015. [citado em 2020 Jan 17] Disponível em: http://www.abihpec.org.br/ABIHPEC_Caderno_de_Tendencias_2014_2015.pdf

Association of Women's Health, Obstetric and Neonatal Nurses. Neonatal skin care evidencebased clinical practice guideline, 3rd ed. Washington, DC: AWHONN, 2013.

Bergfeld WF, Belsito D V, Hill RA, Klaassen CD, Liebler D, Marks JG, et al. Amended Safety Assessment of Fatty Acyl Sarcosines and Sarcosinate Salts as Used in Cosmetics [texto da Internet]; 2016a. [citado 2020 Jan 17]. Disponível em: https://cirsafety.org/sites/default/files/Sarcosine.pdf

Bergfeld WF, Belsito D V, Hill RA, Klaassen CD, Liebler D, Marks JG, et al. Safety Assessment of Inorganic Hydroxides as Used in Cosmetics [texto da Internet]; 2016b. [citado 2020 Jan 17]. Disponível em: https://cir-safety.org/sites/default/files/inorganic hydroxides_0.pdf

Bergfeld WF, Belsito D V, Hill RA, Klaassen CD, Liebler D, Marks JG, et al. Safety Assessment of Fatty Acids \& Fatty Acid Salts as Used in Cosmetics [texto da Internet]; 2019. [citado 2020 Jan 17]. Disponível em: https://cir-safety.org/supplementaldoc/safety-assessment-fatty-acidsfatty-acid-salts-used-cosmetic 
Bergfeld WF, Donald V, Hill RA, Klaassen CD, Liebler DC, Marks JG, et al. Safety Assessment of Alkyl Sultaines as Used in Cosmetics [texto da Internet]; 2018. [citado 2020 Jan 17]. Disponível em: https://cir-safety.org/sites/default/files/sultaines_0.pdf

Bieber T. Atopic dermatitis. N Engl J Med. 2008;358:1483-94.

Blaak J, Staib P. The Relation of pH and Skin Cleansing. Curr Probl Dermatology. 2018;54:13242.

Blume-Peytavi U, Lavender T, Jenerowicz D, Ryumina I, Stalder J, Torrelo A, et al. Recommendations from a European Roundtable Meeting on Best Practice Healthy Infant Skin Care. Pediatr Dermatol. 2016;33(3):311-21.

Boncheva M, Damien F, Normand V. Molecular organization of the lipid matrix in intact Stratum corneum using ATR-FTIR spectroscopy. Biochim Biophys Acta - Biomembr. 2008;1778(5):1344-55.

Brasil. Ministério da saúde. Agência Nacional de Vigilância Sanitária. Resolução - RDC nº 211, de 14 de Julho de 2005. Estabelece a Definição e a Classificação de Produtos de Higiene Pessoal, Cosméticos e Perfumes, conforme Anexo I e II desta Resolução e dá outras definições [texto da Internet]. Brasília (DF): Ministério da Saúde; 2005. [citado 2020 Jan 17]. Disponível em: http://bvsms.saude.gov.br/bvs/saudelegis/anvisa/2005/rdc0211_14_07_2005.html

Brasil. Ministério da saúde. Agência Nacional de Vigilância Sanitária. Resolução - RDC n²9, de $1^{\circ}$ de junho de 2012. Aprova o Regulamento Técnico Mercosul sobre Lista de Substâncias de Ação Conservante permitidas para Produtos de Higiene Pessoal, Cosméticos e Perfumes e dá outras providências. [texto da Internet]. Brasília (DF): Ministério da Saúde; 2012a. [citado 2020 Jan 17]. Disponível em: http://bvsms.saude.gov.br/bvs/saudelegis/anvisa/2012/rdc0029_01_06_2012.html

Brasil. Ministério da saúde. Agência Nacional de Vigilância Sanitária. Resolução - RDC n44, de 9 de agosto de 2012. Aprova o Regulamento Técnico Mercosul sobre Lista de substâncias corantes permitidas para produtos de higiene pessoal, cosméticos e perfumes e dá outras providências [texto da Internet]. Brasília (DF): Ministério da Saúde; 2012b. [citado 2020 Jan 17]. 
Disponível en: http://bvsms.saude.gov.br/bvs/saudelegis/anvisa/2012/rdc0044_09_08_2012.html

Brasil. Ministério da saúde. Agência Nacional de Vigilância Sanitária. Resolução - RDC nº3, de 20 de Janeiro de 2012. Aprova o Regulamento Técnico listas de substâncias que os produtos de higiene pessoal, cosméticos e perfumes não devem conter exceto nas condições e com as restrições estabelecidas e dá outras providências [texto da Internet]. Brasília (DF): Ministério da Saúde; 2012c. [citado 2020 Jan 17]. Disponível em: http://bvsms.saude.gov.br/bvs/saudelegis/anvisa/2012/rdc0003_18_01_2012.pdf

Brasil. Ministério da saúde. Agência Nacional de Vigilância Sanitária. Resolução - RDC n ${ }^{\circ}$, de 30 de Janeiro de 2014. Dispõe sobre os requisitos técnicos para a regularização de produtos de higiene pessoal, cosméticos e perfumes e dá outras providências. [texto da Internet]. Brasília (DF): Ministério da Saúde; 2014. [citado 2020 Jan 17]. Disponível em: http://bvsms.saude.gov.br/bvs/saudelegis/anvisa/2014/rdc0004_30_01_2014.html

Brasil. Ministério da saúde. Agência Nacional de Vigilância Sanitária. Resolução - RDC n 7, de 11 de fevereiro de 2015. Dispõe sobre os requisitos técnicos para a regularização de produtos de higiene pessoal, cosméticos e perfumes e dá outras providências. [texto da Internet]. Brasília (DF): Ministério da Saúde; 2015a. [citado 2020 Jan 17]. Disponível em: http://bvsms.saude.gov.br/bvs/saudelegis/anvisa/2015/rdc0007_10_02_2015.pdf

Brasil. Ministério da saúde. Agência Nacional de Vigilância Sanitária. Resolução - RDC n ${ }^{0} 15$, de 24 de abril de 2015. Dispõe sobre os requisitos técnicos para a concessão de registro de produtos de higiene pessoal, cosméticos e perfumes infantis e dá outras providências. [texto da Internet]. Brasília (DF): Ministério da Saúde; 2015b. [citado 2020 Jan 17]. Disponínel em: http://bvsms.saude.gov.br/bvs/saudelegis/anvisa/2015/rdc0015_24_04_2015.pdf

Brasil. Ministério da saúde. Agência Nacional de Vigilância Sanitária. Resolução - RDC nº237 de 2018. Altera a Resolução da Diretoria Colegiada - RDC n 7, de 10 de fevereiro de 2015, e a Resolução da Diretoria Colegiada - RDC n ${ }^{\circ}$ 15, de 24 de abril de 2015. [texto da Internet]. Brasília (DF): Ministério da Saúde; 2018. [citado 2020 Jan 17]. Disponível em: http://bvsms.saude.gov.br/bvs/saudelegis/anvisa/2015/rdc0007_10_02_2015.pdf 
Brasil. Ministério da saúde. Manual AIDPI Neonatal. [texto da Internet]. Brasília (DF): Ministério da Saúde; 2014. [citado 2020 Jan 17]. Disponível em: http://bvsms.saude.gov.br/bvs/publicacoes/maual_aidpi_neonatal_quadro_procedimentos.pdf

Brasil. Ministerio de saúde. Atenção à Saúde do Recém-Nascido: guía para os profissionais de saúde. Problemas repsiratórios, cardiocirculatórios, metabólicos, neurológicos, ortopédicos e dermatológicos Volume 3. [texto da internet]. Brasília (DF): Ministério da Saúde; 2014. [citado 2020 Jan 17]. Disponível em: http://bvsms.saude.gov.br/bvs/publicacoes/atencao_saude_recem_nascido_v3.pdf

Brasil. Agência Nacional de Vigilânia Sanitária. Guia para Avaliação de Segurança de Produtos Cosméticos. [texto da internet]. Brasília (DF): Agência Nacional de Vigilânia Sanitária; 2012. [citado 2020 Jan 17]. Disponível em: https://www.gov.br/anvisa/ptbr/centraisdeconteudo/publicacoes/cosmeticos/publicacoes/guia-para-avaliacao-de-seguranca-deprodutos-cosmeticos.pdf/view

Burnett C, Belsito D V, Hill RA, Klaassen CD, Liebler D, Marks JG, et al. Amended Safety Assessment of Isethionate Salts as used in Cosmetics. Int J Toxicol. 2017a;36(Supplement 1):5S$16 \mathrm{~S}$.

Burnett C, Belsito D V, Hill RA, Klaassen CD, Liebler D, Marks JG, et al. Safety Assessment of Plant-DeriVed Fatty Acid Oils. Int J Toxicol. 2017b;36(Supplement 3):51S-129S.

Burnett C, Bergfeld WF, Belsito D V, Hill RA, Klaassen CD, Liebler D, et al. Final Report of the Cosmetic Ingredient Review Expert Panel on the Safety Assessment of Cocamidopropyl betaine (CAPB). Int ournal Toxicol. 2012;31(Supplement 1):77S-111S.

Burnett C, Bergfeld WF, Belsito D V, Hill RA, Klaassen CD, Liebler D, et al. Safety Assessment of Amino Acid Alkyl Amides as Used in Cosmetics. Int J Toxicol. 2017c;36(Supplement 1):17S$56 \mathrm{~S}$.

Carvalho VO, Markus JR, Abagge KT, Giraldi S, Campos TB. Consenso de cuidado com a pele do recém-nascido. [Internet]. Ed. Sociedade Brasileira de Pediatria; 2015 [citado em 2020 Out 20]. Disponível em: https://www.sbp.com.br/fileadmin/user_upload/flipping-book/consenso- 
cuidados-pele/cuidados-com-a-pele/assets/downloads/publication.pdf

Chittock J, Cooke A, Lavender T, Brown K, Wigley A, Victor S, et al. Development of stratum corneum chymotrypsin-like protease activity and natural moisturizing factors from birth to 4 weeks of age compared with adults. Br J Dermatol. 2016;175(4):713-20.

Cooke A. Infant dry skin: Clinical practice and the evidence to support it. Br J Midwifery. 2018;26(3):150-6.

Cooke A, Bedwell C, Campbell M, McGowan L, Ersser SJ, Lavender T. Skin care for healthy babies at term: A systematic review of the evidence. Midwifery. 2018;56:29-43.

Cooke A, Cork MJ, Victor S, Campbell M, Danby S, Chittock J, et al. Olive oil, sunflower oil or no oil for baby dry skin or massage: A pilot, assessor-blinded, randomized controlled trial (the oil in baby skincare [observe] study). Acta Derm Venereol. 2016;96(3):323-31.

Corazza M, Lauriola MM, Bianchi A, Zappaterra M, Virgili A. Irritant and sensitizing potential of eight surfactants commonly used in skin cleansers: An evaluation of 105 patients. Dermatitis. 2010a;21(5):262-8.

Corazza M, Lauriola MM, Zappaterra M, Bianchi A, Virgili A. Surfactants, skin cleansing protagonists. J Eur Acad Dermatology Venereol. 2010b;24(1):1-6.

Cosmetic Ingredient Review (CIR) Expert Panel. Annual Review of Cosmetic Ingredient Safety Assessments: 2005/2006. Int J Toxicol. 2008;27(Suppl.1):77-142.

Cosmetic Ingredient Review. [Internet]. Washington DC: CIR; c2016 [citado em 2020 Jan 17]. Disponível em: https://www.cir-safety.org/ingredients

Cunha M, Procianoy R. Banho e colonização da pele do pré-termo. Rev Gaúcha Enferm. 2006;27(2):203-8.

Curtis BM, Barrett BJ, Parfrey PS. Randomized Controlled Trials 1: Design. In: Parfrey PS, Barret B, editors. Clinical epidemiology. New York: Human Press; 2015. p. 159-175. 
Daltin D. Tipos de tensoativos. In: Daltin D, editor. Tensoativos química, propriedades e Aplicações. São Paulo: Edgard Blücher Ltda; 2011. p. 45-84.

Darlenski R, Fluhr JW. Influence of skin type, race, sex, and anatomic location on epidermal barrier function. Clin Dermatol. 2012;30(3):269-73.

Darlenski R, Sassning S, Tsankov N, Fluhr JW. Non-invasive in vivo methods for investigation of the skin barrier physical properties. Eur J Pharm Biopharm. 2009;72(2):295-303.

DaVeiga SP. Epidemiology of atopic dermatitis: A review. Allergy Asthma Proc. 2012;33(3):227-34.

Dizon V, Galzote C, Estanislao R, Mathew N, Sarkar R. Tolerance of Baby Cleansers in Infants: A Randomized Clinical Trial. Indian Pediatr. 2010;47(11):959-63.

Draelos ZD. The science behind skin care: Cleansers. J Cosmet Dermatol. 2018;17(1):8-14.

European Union. Commission Decision of 9 February 2006. Amending Decision 96/335/EC establishing an inventory and a common nomenclature of ingredients employed in cosmetic products. [texto da Internet]. Bruselas: European Union; 2006 [citado 2020 Jan 22]. Disponível em: https://eur-lex.europa.eu/legalcontent/EN/TXT/HTML/?uri=CELEX:32006D0257\&from=EN

Fernandes J, Machado M, Oliveira Z. Prevenção e cuidados com a pele da criança e do recémnascido. An Bras Dermatol. 2011;86(1):102-10.

Fiume MM, Heldreth B, Bergfeld WF, Belsito D V., Hill RA, Klaassen CD, et al. Safety Assessment of Diethanolamides as Used in Cosmetics. Int. J. Toxicol. 2013a. p. 36S-58S.

Fiume MM, Heldreth B, Bergfeld WF, Belsito D V., Hill RA, Klaassen CD, et al. Safety assessmento of decyl glucoside and other alkyl glucosides as used in cosmetics. Int $\mathrm{J} \mathrm{T}$. 2013b;32(Supplement 3):22S-48S.

Fiume MM, Heldreth BA, Bergfeld WF, Belsito D V., Hill RA, Klaassen CD, et al. Safety Assessment of Ethanolamides as Used in Cosmetics. Int. J. Toxicol. 2015. p. 18S-34S. 
Fluhr JW, Darlenski R, Lachmann N, Baudouin C, Msika P, De Belilovsky C, et al. Infant epidermal skin physiology: Adaptation after birth. Br J Dermatol. 2012;166(3):483-90.

Fluhr JW, Darlenski R, Taieb A, Hachem J, Baudouin C, Msika P, et al. Functional skin adaptation in infancy - almost complete but not fully competent. Exp Dermatol. 2010;19:483-92.

Freitas P. Respostas fisiológicas e comportamentais de recém-nascidos pré-termos submetidos a duas técnicas de banho de imersão: ensaio clínico cruzado [tese]. São Paulo: Universidade de São Paulo; 2015.

Friedman M. Chemistry, Formulation, and Performance of Syndet and Combo Bars. In: Spitz L, editor. Soap Manuf Technol. 2 ed. London: Elsevier Inc; 2016. p. 73-106.

Garcia Bartels N, Mleczko A, Schink T, Proquitté H, Wauer RR, Blume-Peytavi U. Influence of bathing or washing on skin barrier function in newborns during the first four weeks of life. Skin Pharmacol Physiol. 2009;22(5):248-57.

Garcia Bartels N, Scheufele R, Prosch F, Schink T, Proquitte H, Blume-peytavi U. Effect of Standardized Skin Care Regimens on Neonatal Skin Barrier Function in Different Body Areas. Pediatr Dermatol. 2010;27(1):1-9.

Gfatter R, Hackl P, Braun F. Effects of soap and detergents on skin surface pH, stratum corneum hydration and fat content in infants. Dermatology. 1997. p. 258-62.

Goossens A. Contact-Allergic Reactions to Cosmetics. J Allergy. 2011;2011:1-6.

Gray M, Beeckman D, Bliss DZ, Fader M, Logan S, Junkin J, et al. Incontinence-associated dermatitis: A comprehensive review and update. J Wound, Ostomy Cont Nurs. 2012;39(1):6174.

Gurgel P, Caetano J, Lopes M, Rolim M, Almeida P, Magalhães F, et al. Eficácia do uso de membrana semipermeável em neonatos pré-termo na redução de perdas transepidérmicas. Rev Esc Enferm USP. 2011;45(4):818-24.

Hanson JL, Warshaw EM. Contact Allergy to Surfactants in a Hypoallergenic Liquid Cleanser. Dermatitis. 2015;26(6):284-6. 
Harris PA, Taylor R, Minor BL, Elliott V, Fernandez M, O'Neal L, et al. The REDCap consortium: Building an international community of software platform partners. J Biomed Inform. 2019;95(103208):1-10.

Harris PA, Taylor R, Thielke R, Payne J, Gonzalez N, Conde JG. Research electronic data capture (REDCap)-A metadata-driven methodology and workflow process for providing translational research informatics support. J Biomed Inform. 2009;42:377-81.

Hepworth PH. Non-ionic Surfactants. In: Farn RJ, editor. Chem Technol Surfactants. Oxford: Blackwell Publishing Ltda; 2006. p. 133-50.

Herrwerth S, Leidreiter H, Wenk HH, Farwick M, Ulrich-Brehm I, Grüning B. Highly concentrated cocamidopropyl betaine - the latest developments for improved sustainability and enhanced skin care. Tenside Surf. Det. 2008;45(6):304-8.

Hibbs J. Anionic surfactants. In: Farm R, editor. Chem Technol Surfactants. Oxford: Blackwell Publishing Ltda; 2006. p. 91-132.

Hoeger PH, Enzmann CC. Skin physiology of the neonate and young infant: A prospective study of functional skin parameters during early infancy. Pediatr Dermatol. 2002;19(3):256-62.

Hoppel M, Baurecht D, Holper E, Mahrhauser D, Valenta C. Validation of the combined ATRFTIR/tape stripping technique for monitoring the distribution of surfactants in the stratum corneum. Int J Pharm. 2014;472(1-2):88-93.

Horimukai K, Morita K, Narita M, Kondo M, Kabashima S, Inoue E, et al. Transepidermal water loss measurement during infancy can predict the subsequent development of atopic dermatitis regardless of filaggrin mutations. Allergol Int. 2016;65(1):103-8.

Jackson C, Paye M, Maibach H. Mechanism of skin irritation by surfactants and Anti-Irritants for surfactant based product. In: Barel A, Paye M, Maibach H, editors. Handb Cosmet Sci Technol. 4a. ed. Boca Raton: CRC PressTaylor \& Francis Group; 2014. p. 353-66.

Jacob SE, Atnini S. Cocamidopropyl betaine. Dermatitis. 2008;19(3):157-60.

Karsa D. What are surfactants? In: Farn RJ, editor. Chem Technol Surfactants. Oxford: Blackwell 
Publishing Ltd; 2006. p. 1-7.

Kelleher M, Dunn-Galvin A, Hourihane JOB, Murray D, Campbell LE, McLean WHI, et al. Skin barrier dysfunction measured by transepidermal water loss at 2 days and 2 months predates and predicts atopic dermatitis at 1 year. J Allergy Clin Immunol. 2015;135(4):930-5.

Kelleher MM, O'Carroll M, Gallagher A, Murray DM, Dunn Galvin A, Irvine AD, et al. Newborn transepidermal water loss values: A reference dataset. Pediatr Dermatol. 2013;30(6):712-6.

Knor T, Meholjić-Fetahović A, Mehmedagić A. Stratum corneum hydration and skin surface pH in patients with atopic dermatitis. Acta Dermatovenerol Croat. 2011;19(4):242-7.

Kravchenko I, Maibach H. Percutaneous penetration. Steven H, Howard M. Neonatal Skin: Structure \& Function. $2^{\text {nd }}$ edition. New Work: Marcel Dekker; 2003. p. 285-98.

Kuller JM. Update on Newborn Bathing. Newborn Infant Nurs Rev. 2014;14(4):166-70.

Kuller JM. Infant skin care. What are the issues? Adv Neonatal care. 2016;16(5):3-12.

Kuo SH, Shen CJ, Shen CF, Cheng CM. Role of $\mathrm{pH}$ value in clinically relevant diagnosis. Diagnostics. 2020;10(2):1-17.

Kutlubay Z, Tanakol A, Engýn B, Onel C, Sýmsek E, Serdaroglu S, et al. Newborn Skin: Common Skin Problems. Maedica (Bucur). 2017;12(1):42-7.

Lang, TA.; Stroup, DF. Who knew? The misleading specificity of "double-blind" and what to do about it. Trials. 2020;21(1):1-7.

Lavender T, Bedwell C, Brien EO, Cork MJ, Turner M, Hart A. Infant skin-cleansing product versus water: A pilot randomized, assessor-blinded controlled trial. BMC Pediatr. 2011;11(1):35.

Lavender T, Bedwell C, Roberts SA, Hart A, Turner MA, Carter L, et al. Randomized, Controlled Trial Evaluating a Baby Wash Product on skin barrier function in healthy, term neonates. JOGNN. 2013;42:203-14. 
Lavender T, Bedwell C, Tsekiri-O'Brien, Hart A, Turner M, Cork M. A qualitative study exploring of the newborn bathing practices. Evid Based Midwifery. 2009;7(4):112-21.

Lavender T, Furber C, Campbell M, Victor S, Roberts I, Bedwell C, et al. Effect on skin hydration of using baby wipes to clean the napkin area of newborn babies: assessor-blinded randomised controlled equivalence trial. BMC Pediatr. 2012;12(1):1.

Lodén M, Olsson H, Axéll T, Linde YW. Friction, capacitance and transepidermal water loss (TEWL) in dry atopic and normal skin. Br J Dermatol. 1992;126(2):137-41.

Löffler H, Happle R. Profile of irritant patch testing with detergents: Sodium lauryl sulfate, sodium laureth sulfate and alkyl polyglucoside. Contact Dermatitis. 2003;48(1):26-32.

Longo C, Casari A, Beretti F, Cesinaro AM, Pellacani G. Skin aging: In vivo microscopic assessment of epidermal and dermal changes by means of confocal microscopy. J Am Acad Dermatol. Elsevier Inc; 2013;68(3):e73-82.

Loring C, Gregory K, Gargan B, Leblanc V, Lundgren D, Reilly J, et al. Tub Bathing Improves Thermoregulation of the Late Preterm Infant. JOGNN. 2012;41:171-9.

Ludriksone L, Garcia Bartels N, Kanti V, Blume-Peytavi U, Kottner J. Skin barrier function in infancy: A systematic review. Arch Dermatol Res. 2014;306(7):591-9.

Lund C, Kuller J, Durand DJ. Baby's first bath: Changes in skin barrier function after bathing full-term newborns with water vs liquid baby cleanser. Pediatr Dermatol. 2020;37(1):115-9.

Lund $\mathrm{CH}$, Osborne JW. Validity and reliability of the Neonatal Skin Condition score. JOGNN - J Obstet Gynecol Neonatal Nurs. 2004;33(3):320-7.

Mehling A, Kleber M, Hensen H. Comparative studies on the ocular and dermal irritation potential of surfactants. Food Chem Toxicol. 2007;45(5):747-58.

Mendes B, Midori Shimabukuro D, Uber M, Taniguchi K. Avaliação crítica do pH dos sabonetes infantis. J Pediatr (Rio J). 2016;92(3):290-5.

Mertens S, Gilissen L, Goossens A. Allergic contact dermatitis caused by cocamide 
diethanolamine. Contact Dermatitis. 2016;75(1):20-4.

Nardelli A, Drieghe J, Claes L, Boey L, Goossens A. Fragrance allergens in "specific" cosmetic products. Contact Dermatitis. 2011;64(4):212-9.

Nikolovski J, Stamatas G, Kollias N, Wiegand B. Barrier Function and Water-Holding and transport Properties of Infant Stratum Corneum Are Different from Adult and Continue to Develop through the First year of life. J Investig dermatology. 2008;128:1728-36.

Niyonsaba F, Suzuki A, Ushio H, Nagaoka I, Ogawa H, Okumura K. The human antimicrobial peptide dermcidin activates normal human keratinocytes. Br J Dermatol . 2009;160(2):243-9.

Oliveira R. A pele nos diferentes ciclos da vida. In: Domansky R, Borges E, editors. Manual para prevenção lesões pele. Rio de Janeiro: Editora Rubio; 2012. p. 9-41.

Oranges T, Dini V, Romanelli M. Skin Physiology of the Neonate and Infant: Clinical Implications. Adv wound care. 2015;4(10):587-95.

Otterson R. Amphoteric Surfactants. In: Farn RJ, editor. Chem Technol Surfactants. Oxford: Blackwell Publishing Ltda; 2006. p. 170-85.

Polit, DF. Blinding during the analysis of research data. Int J Nurs Stud. 2011;48(5):636-641.

Rawlings AV. Ethnic skin types: Are there differences in skin structure and function? Int $\mathrm{J}$ Cosmet Sci. 2006;28(2):79-93.

Robinson VC, Bergfeld WF, Belsito D V., Hill RA, Klaassen CD, Marks JG, et al. Final report of the amended safety assessment of sodium laureth sulfate and related salts of sulfated ethoxylated alcohols. Int J Toxicol. 2010;29(Supplement 3):151S-161S.

Rogiers V. EEMCO guidance for the assessment of transepidermal water loss in cosmetic sciences. Skin Pharmacol Appl Skin Physiol. 2001;14:117-28.

Sociedade Brasileira de Cirurgia Plástica. Projeto diretrizes - Queimaduras: Diagnóstico e Tratamento Inicial. [texto da Internet]. São Paulo: Associação Médica Brasileira e Conselho Federal de Medicina; 2008. [citado em 2020 Out 20]. Disponível em: 
https://diretrizes.amb.org.br/_BibliotecaAntiga/queimaduras-diagnostico-e-tratamento-inicial.pdf

Schardosim J, Ruschel LM, Motta G de C, Cunha ML. Adaptação cultural e validação clínica da Neonatal Skin Condition Score para o português do Brasil. Rev Latino-Am Enferm. 2014;22(5):834-41.

Schoch JJ, Monir RL, Satcher KG, Harris J, Triplett E, Neu J. The infantile cutaneous microbiome: A review. Pediatr Dermatol. 2019;36(5):574-80.

Schulz KF, Altman DG, Moher D. CONSORT 2010 Statement: Updated guidelines for reporting parallel group randomised trials. BMJ. 2010;340(7748):698-702.

Shank C, Slaga TJ, Snyder PW, Andersen FA. Safety Assessment of Fatty Acids \& Fatty Acid Salts as Used in Cosmetics [texto da Internet]; 2013 [citado 2020 Jan 17]. Disponível em: https://online.personalcarecouncil.org/jsp/CIRList.jsp?id=609

Shaughnessy CN, Malajian D, Belsito D V. Cutaneous delayed-type hypersensitivity in patients with atopic dermatitis: Reactivity to surfactants. J Am Acad Dermatol . 2014;70(4):704-8.

Silverberg NB. A practical overview of pediatric atopic dermatitis, part 1: Epidemiology and pathogenesis. Cutis. 2016;97(4):267-71.

van Smeden J, Janssens M, Gooris GS, Bouwstra JA. The important role of stratum corneum lipids for the cutaneous barrier function. Biochim Biophys Acta Mol Cell Biol Lipids. 2014;1841(3):295-313.

Soares AVN, Gaidzinski RR, Cirico MOV. Identificação das intervenções de enfermagem no sistema de alojamento conjunto. Rev da Esc Enferm. 2010;44(2):308-17.

Solodkin G, Chaudhari U, Subramanyan K, Johnson AW, Yan X, Gottlieb A. Benefits of mild cleansing: Synthetic surfactant-based (syndet) bars for patients with atopic dermatitis. Cutis. 2006;77(5):317-24.

Stamatas G, Nikolovski J, Luedtke M, Kollias N, Wiegand B. Infant Skin Microstructure Assessed In Vivo Differs from Adult Skin in Organization and at the Cellular Level. Pediatr Dermatol. 2010;27(2):125-31. 
Stamatas G, Nikolovski M, Kollias N. Infant skin physiology and development during the first years of life: a review of recent findings based on in vivo studies. Int J Cosmet Sci. 2011;33:1724.

Taieb A. Skin barrier in the neonate. Pediatr Dermatol. 2018;35:s5-s9.

Tarun J, Susan J, Suria J, Susan VJ, Criton S. Evaluation of $\mathrm{pH}$ of bathing soaps and shampoos for skin and hair care. Indian J Dermatol. 2014;59(5):442-4.

Telofski L, Morello P, Correa MCM, Stamatas G. The Infant Skin Barrier: Can We Preserve, Protect, and Enhance the Barrier? Dermatol Res Pract. 2012;1-18.

UlProspector [Internet]. c2017 [citado em 2020 Feb 15]. Disponível em: https://www.ulprospector.com/pt/la/PersonalCare

United Kingdom. National Institute for Health and Care Excellence. Postnatal care up to 8 weeks after birth - Clinical Guideline 37 [texto da Internet]. London: NICE; 2015. [citado 2020 Oct 20]

Disponível em: https://www.nice.org.uk/guidance/cg37/chapter/1-

Recommendations\#maintaining-infant-health

Visscher M, Narendran V. Neonatal Infant Skin : Development, Structure and Function. Newborn Infant Nurs Rev. 2014a;14(4):135-41.

Visscher M, Narendran V. Reviews Vernix Caseosa: Formation and Functions. Newborn Infant Nurs Rev. 2014b;14(4):142-6.

Visscher MO, Adam R, Brink S, Odio M. Newborn infant skin: Physiology, development, and care. Clin Dermatol. 2015;33(3):271-80.

Visscher MO, Chatterjee R, Ebel JP, LaRuffa AA, Hoath SB. Biomedical assessment and instrumental evaluation of healthy infant skin. Pediatr Dermatol. 2002;19(6):473-81.

Visscher MO, Chatterjee R, Munson KA, Pickens WL, Hoath SB. Changes in diapered and nondiapered infant skin over the first month of life. Pediatr Dermatol. 2000;17(1):45-51.

Visscher MO, Narendran V, Pickens WL, LaRuffa AA, Meinzen-Derr J, Allen K, et al. Vernix 
caseosa in neonatal adaptation. J Perinatol. 2005;25(7):440-6.

Visscher MO, Narendran V, Pickens WL, LaRuffa AA, Meinzen-Derr J, Allen K, et al. Reviews Vernix Caseosa: Formation and Functions. Newborn Infant Nurs Rev. 2014;14(4):135-41.

Visscher MO, Taylor T, Narendran V. Neonatal intensive care practices and the influence on skin condition. J Eur Acad Dermatology Venereol. 2013;27(4):486-93.

Visscher MO, Utturkar R, Pickens WL, Laruffa AA, Robinson M, Wickett RR, et al. Neonatal skin maturation-vernix caseosa and free amino acids. Pediatr Dermatol. 2011;28(2):122-32.

Volochtchuk OM, Fujita EM, Fadel APC, Auada, Marian Patrícia Almeida, Tatiane de Marinoni LP. Variações do pH dos sabonetes e indicações para sua utilização na pele normal e na pele doente. An bras dermatol; 2000;75(6):697-703.

Walker L, Downe S, Hons BA, Gomez L, Hons BA. Skin Care in the Well Term Newborn : Two Systematic Reviews. Birth. 2005;(3):224-8.

World Health Organization. Newborn Care Until the First Week of Life: Clinical Practice Pocket Guide.[texto da Internet]. Suiça: World Health Organization; 2009. [citado em $2021 \mathrm{Fev}$ 15]. Disponível em: https://apps.who.int/iris/bitstream/handle/10665/207705/9789290614562_eng.pdf

Yamada B. Pele: o manto protetor, higiene \& hidratação. São Paulo: Andreoli; 2015a.

Yamada BFA. Legislação Nacional sobre produtos de higiene e hidratação. In: Yamada BFA, editor. Pele o manto protetor, Hig e hidratação. São Pualo: Andreoli; 2015b. p. 73-94.

Yosipovitch G, Maayan-Metzger A, Merlob P, Sirota L. Skin barrier properties in different body areas in neonates. Pediatrics. 2000;106:105-8.

Zemtsov A, Fett D. Occupational Allergic Contact Dermatitis From Sodium Lauroyl Sarcosinate in Liquid Soap. Dermatitis. 2005;16(2):97.

Zhang G, Xu B, Han F, Zhou Y, Liu H, Li Y, et al. Green Synthesis, Composition Analysis and Surface Active Properties of Sodium Cocoyl Glycinate. Am J Anal Chem. 2013;04(09):445-50.

Zimmerer RE, Lawson KD, Calvert CJ. The Effects of Wearing Diapers on Skin. Pediatr Dermatol.1986;3(2):95-101. 


\section{aPÂENDSES}




\section{APÊNDICES}

\section{APÊNDICE A \\ TERMO DE CONSENTIMENTO LIVRE E ESCLARECIDO (TCLE) \\ (Participante e/ou representante legal)}

Convido o(a) Senhor(a) para participar da pesquisa intitulada "Efeito do uso de sabonete com pH neutro a levemente acidificado em recém-nascidos a termo hospitalizados: ensaio clínico randomizado" desenvolvida pela senhora Mily Constanza Moreno Ramos, enfermeira e aluna de pós-graduação da Escola de Enfermagem da Universidade de São Paulo.

Nesta pesquisa, queremos saber se o uso de sabonete líquido é melhor para a limpeza e manutenção da pele do recém-nascido que o sabonete em barra. O motivo que nos leva a estudar o efeito dos sabonetes sobre a pele dos recém-nascidos são as alterações de pele que eles podem causar nos recém-nascidos.

Os sabonetes que vamos utilizar são sabonetes aprovados e utilizados normalmente para recém-nascidos. Caso o(a) senhor(a) aceite que o recém-nascido participe da pesquisa, será realizado um sorteio entre dois grupos: o grupo Experimental e o grupo Controle.

Caso o seu bebê seja sorteado para o grupo Experimental, o(a) senhor(a) deverá utilizar o sabonete líquido para dar banho no bebê durante os primeiros 28 dias de vida dele.

Caso o seu bebê seja sorteado para o grupo Controle, o(a) senhor(a) deverá utilizar o sabonete em barra para dar banho no bebê durante 28 dias de vida dele.

Também, será avaliada a pele do bebê em três momentos: antes da alta no hospital; entre o $7^{\circ}$ e $10^{\circ}$ dia de vida ( $1^{\circ}$ seguimento da pesquisa), no mesmo dia da consulta de enfermagem no ambulatório do hospital e; entre o $25^{\circ}$ e $28^{\circ}$ dia ( $2^{\circ}$ seguimento da pesquisa) na sala 512 do Alojamento Conjunto do hospital onde somente serão coletados os dados da pesquisa. Para essa avaliação, usaremos quatro aparelhos que medem a hidratação e a acidez da pele, mas não causam dor no recém-nascido. As medições serão realizadas em quatro regiões do corpo (braço, abdômen, costas e frente da coxa). Além disso, será realizado contato telefônico uma vez por semana.

Durante a internação no Alojamento Conjunto, a equipe de enfermagem ensinará todas as mães como fazer o banho e a aplicação do sabonete, que você deverá realizar posteriormente em casa diariamente no recém-nascido. Se você participar da pesquisa, no dia da alta hospitalar, lhe será entregue um panfleto com informações sobre o banho, e o sabonete em quantidade suficiente para uso durante o primeiro mês de vida do recém-nascido.

Além disso, vamos colher os dados do nascimento do recém-nascido e outras informações sobre a saúde dele do prontuário.

Ainda assim, é possível que o recém-nascido sinta algum desconforto em relação ao uso do sabonete como alergia, secura, coceira ou vermelhidão na pele. Isso pode acontecer por causa do uso de qualquer sabonete ou pelo contato da pele com outros materiais ou produtos.

Se você observar um problema na pele do recém-nascido, deverá levá-lo à Unidade Básica de Saúde da região, ou à consulta com o Pediatra que realiza o acompanhamento do seu recém-nascido.

Pesquisador

Participante da pesquisa 
O recém-nascido poderá se beneficiar do efeito do produto na higienização e manutenção da pele, além de contribuir para estabelecer orientações aos profissionais e pais sobre a escolha de produtos de higiene adequados para a pele de recém-nascidos.

As informações colhidas nesta pesquisa serão analisadas em conjunto com as informações dos outros participantes, sem identificação individual. Os resultados da pesquisa serão divulgados em eventos e publicações científicas mantendo o sigilo de seus dados de identificação assim como os dados do recémnascido.

A pesquisa não terá pagamento pela participação e não trará nenhum custo ao participante, pois será oferecido o dinheiro do transporte público utilizado (ida e volta: $\mathrm{R} \$ 8,00$ ) para os dois retornos ao ambulatório. Caso ocorra algum prejuízo relacionado à pesquisa, você terá direito a indenização.

Você tem o direito de querer continuar participando da pesquisa, desistir e retirar seu consentimento em qualquer etapa da pesquisa. Qualquer que seja sua decisão, será respeitada e não causará nenhum problema na continuidade de seu tratamento e do recém-nascido neste hospital.

Este documento foi elaborado em duas vias que serão rubricadas e assinadas a seu término pela participante e/o representante legal e a pesquisadora. Você receberá uma via e a outra ficará com a pesquisadora.

Durante todo o período da pesquisa, você tem o direito de tirar suas dúvidas e pedir qualquer esclarecimento, entrando em contato com as pesquisadoras responsáveis:

Mily Constanza Moreno Ramos - Aluna de Pós-Graduação da Escola de Enfermagem da USP. Telefone: (11)977815200. E-mail: milyconstanza@usp.br

Maria de La Ó Ramallo Veríssimo - Orientadora e Professora da Escola de Enfermagem da USP. Telefone: (11) 30617602. E-mail: mdlorver@usp.br

Endereço da Escola de Enfermagem da Universidade de São Paulo, Departamento de enfermagem materno-infantil e psiquiátrica. Av. Dr. Enéas de Carvalho Aguiar, 419. Cerqueira Cesar, São Paulo. CEP: 05403-000.

Para questões de ética, entrar em contato com:

Comitê de Ética em Pesquisa da Escola de Enfermagem da USP. Av. Dr. Enéas de Carvalho Aguiar 419 CEP: 05403-000 - São Paulo-SP. Telefone: (11) 30618858. E-mail: edipesq@usp.br

Comitê de Ética em Pesquisa do Hospital Universitário da USP. Av. Prof. Lineu Prestes 2565 - Cidade Universitária - CEP: 05508-000 - São Paulo-SP. Telefone: (11)30919457. E-mail: cep@ hu.usp.br

Esta pesquisa atende todas as especificações da Resolução 466, de 12 de dezembro de 2012 que aprova as diretrizes e normas regulamentadoras de pesquisas envolvendo seres humanos.

Assinatura da pesquisadora

Assinatura da mãe ou do representante legal 


\section{APÊNDICE B \\ TERMO DE ASSENTIMENTO LIVRE E ESCLARECIDO (TALE) (Participante com idade menor a 18 anos)}

Convido o(a) Senhor(a) para participar da pesquisa intitulada "Efeito do uso de sabonete com pH neutro a levemente acidificado em recém-nascidos a termo hospitalizados: ensaio clínico randomizado" desenvolvida pela senhora Mily Constanza Moreno Ramos, enfermeira e aluna de pós-graduação da Escola de Enfermagem da Universidade de São Paulo.

Nesta pesquisa, queremos saber se o uso de sabonete líquido é melhor para a limpeza e manutenção da pele do recém-nascido que o sabonete em barra. $\mathrm{O}$ motivo que nos leva a estudar o efeito dos sabonetes sobre a pele dos recém-nascidos são as alterações de pele que eles podem causar nos recém-nascidos.

Os sabonetes que vamos utilizar são sabonetes aprovados e utilizados normalmente para recém-nascidos. Caso o(a) senhor(a) aceite que o recém-nascido participe da pesquisa, será realizado um sorteio entre dois grupos: o grupo Experimental e o grupo Controle.

Caso o seu bebê seja sorteado para o grupo Experimental, o(a) senhor(a) deverá utilizar o sabonete líquido para dar banho no bebê durante os primeiros 28 dias de vida dele.

Caso o seu bebê seja sorteado para o grupo Controle, o(a) senhor(a) deverá utilizar o sabonete em barra para dar banho no bebê durante 28 dias de vida dele.

Também, será avaliada a pele do bebê em três momentos: antes da alta no hospital; entre o $7^{\circ}$ e $10^{\circ}$ dia de vida ( $1^{\circ}$ seguimento da pesquisa), no mesmo dia da consulta de enfermagem no ambulatório do hospital e; entre o $25^{\circ}$ e $28^{\circ}$ dia ( $2^{\circ}$ seguimento da pesquisa) na sala 512 do Alojamento Conjunto do hospital onde somente serão coletados os dados da pesquisa. Para essa avaliação, usaremos quatro aparelhos que medem a hidratação e a acidez da pele, mas não causam dor no recém-nascido. As medições serão realizadas em quatro regiões do corpo (braço, abdômen, costas e frente da coxa). Além disso, será realizado contato telefônico uma vez por semana.

Durante a internação no Alojamento Conjunto, a equipe de enfermagem ensinará todas as mães como fazer o banho e a aplicação do sabonete, que você deverá realizar posteriormente em casa diariamente no recém-nascido. Se você participar da pesquisa, no dia da alta hospitalar, lhe será entregue um panfleto com informações sobre o banho, e o sabonete em quantidade suficiente para uso durante o primeiro mês de vida do recém-nascido.

Além disso, vamos colher os dados do nascimento do recém-nascido e outras informações sobre a saúde dele do prontuário.

Ainda assim, é possível que o recém-nascido sinta algum desconforto em relação ao uso do sabonete como alergia, secura, coceira ou vermelhidão na pele. Isso pode acontecer por causa do uso de qualquer sabonete ou pelo contato da pele com outros materiais ou produtos.

Se você observar um problema na pele do recém-nascido, deverá levá-lo à Unidade Básica de Saúde da região, ou à consulta com o Pediatra que realiza o acompanhamento do seu recém-nascido.

Pesquisador

Participante da pesquisa 
O recém-nascido poderá se beneficiar do efeito do produto na higienização e manutenção da pele, além de contribuir para estabelecer orientações aos profissionais e pais sobre a escolha de produtos de higiene adequados para a pele de recém-nascidos.

As informações colhidas nesta pesquisa serão analisadas em conjunto com as informações dos outros participantes, sem identificação individual. Os resultados da pesquisa serão divulgados em eventos e publicações científicas mantendo o sigilo de seus dados de identificação assim como os dados do recémnascido.

A pesquisa não terá pagamento pela participação e não trará nenhum custo ao participante, pois será oferecido o dinheiro do transporte público utilizado (ida e volta: $\mathrm{R} \$ 8,00$ ) para os dois retornos ao ambulatório. Caso ocorra algum prejuízo relacionado à pesquisa, você terá direito a indenização.

Você tem o direito de querer continuar participando da pesquisa, desistir e retirar seu consentimento em qualquer etapa da pesquisa. Qualquer que seja sua decisão, será respeitada e não causará nenhum problema na continuidade de seu tratamento e do recém-nascido neste hospital.

Este documento foi elaborado em duas vias que serão rubricadas e assinadas a seu término pela participante e/o representante legal e a pesquisadora. Você receberá uma via e a outra ficará com a pesquisadora.

Durante todo o período da pesquisa, você tem o direito de tirar suas dúvidas e pedir qualquer esclarecimento, entrando em contato com as pesquisadoras responsáveis:

Mily Constanza Moreno Ramos - Aluna de Pós-Graduação da Escola de Enfermagem da USP. Telefone: (11) 977815200. E-mail: milyconstanza@usp.br

Maria de La Ó Ramallo Veríssimo - Orientadora e Professora da Escola de Enfermagem da USP. Telefone: (11) 30617602. E-mail: mdlorver@usp.br

Endereço da Escola de Enfermagem da Universidade de São Paulo, Departamento de enfermagem materno-infantil e psiquiátrica. Av. Dr. Enéas de Carvalho Aguiar, 419. Cerqueira Cesar, São Paulo. CEP: 05403-000.

Para questões de ética, entrar em contato com:

Comitê de Ética em Pesquisa da Escola de Enfermagem da USP. Av. Dr. Enéas de Carvalho Aguiar 419 CEP: 05403-000 - São Paulo-SP. Telefone: (11) 30618858. E-mail: edipesq@usp.br

Comitê de Ética em Pesquisa do Hospital Universitário da USP. Av. Prof. Lineu Prestes 2565 - Cidade Universitária - CEP: 05508-000 - São Paulo-SP. Telefone: (11)30919457. E-mail: cep@ hu.usp.br

Esta pesquisa atende todas as especificações da Resolução 466, de 12 de dezembro de 2012 que aprova as diretrizes e normas regulamentadoras de pesquisas envolvendo seres humanos.

Assinatura da pesquisadora

Assinatura da mãe 


\section{APÊNDICE C}

\section{Orientações para o cuidado da pele conforme tipo de sabonete}

\section{Orientações para o cuidado da pele do bebê em casa (Sabonete líquido)}

- Recomendamos que seja dado um banho diário no momento mais quente do dia com água morna e o sabonete líquido entregado pela pesquisadora.

- Aperte a válvula dosadora, receba o produto na palma da sua mão e logo aplique na pele do bebê delicadamente. Não precisa esfregar com esponja ou outro tecido.

- Para cada banho, utilize no máximo 3 pump ou aplicações do produto assim:

○ 1 pump: cabeça

- 1 pump (parte dianteira do corpo): braços, peito, abdômen e pernas

- 1 pump (parte traseira do corpo): costas, bumbum, e pernas

- É normal que a pele apresente um pouco de ressecamento nos primeiros dias de vida. Portanto, não é necessário aplicar cremes hidratantes ou perfumes na pele do bebê.

- Troque a fralda do bebê assim que sujar. Limpe o bumbum apenas com água e algodão.

- Três vezes ao dia abra a fralda no mínimo 5 minutos para permitir que a pele respire.

- Caso o bebê precise de hospitalização, se possível, continue usando o mesmo sabonete na hora do banho.

- Se você observar um problema na pele do bebê, deverá levá-lo à Unidade Básica de Saúde da região, ou à consulta com o Pediatra que realiza o acompanhamento dele.

\section{Orientações para o cuidado da pele do bebê em casa \\ (Sabonete em barra)}

- Recomendamos que seja dado um banho diário no momento mais quente do dia com água morna e o sabonete em barra entregado pela pesquisadora.

- No momento do banho ensaboe sua mão com o sabonete, e, logo a passe na pele do bebê delicadamente. Não precisa esfregar com esponja ou outro tecido.

- Não coloque diretamente o sabão em barra na pele do bebê.

- Não coloque o sabonete na água da banheira.

- Conserve o sabonete dentro da saboneteira após o uso.

- É normal que a pele apresente um pouco de ressecamento nos primeiros dias de vida. Portanto, não é necessário aplicar cremes hidratantes ou perfumes na pele do bebê.

- Troque a fralda do bebê assim que sujar. Limpe o bumbum apenas com água e algodão.

- Três vezes ao dia abra a fralda no mínimo 5 minutos para permitir que a pele respire.

- Caso o bebê precise de hospitalização, se possível, continue usando o mesmo sabonete na hora do banho.

- Se você observar um problema na pele do bebê, deverá levá-lo à Unidade Básica de Saúde da região, ou à consulta com o Pediatra que realiza o acompanhamento dele. 
APÊNDICE D

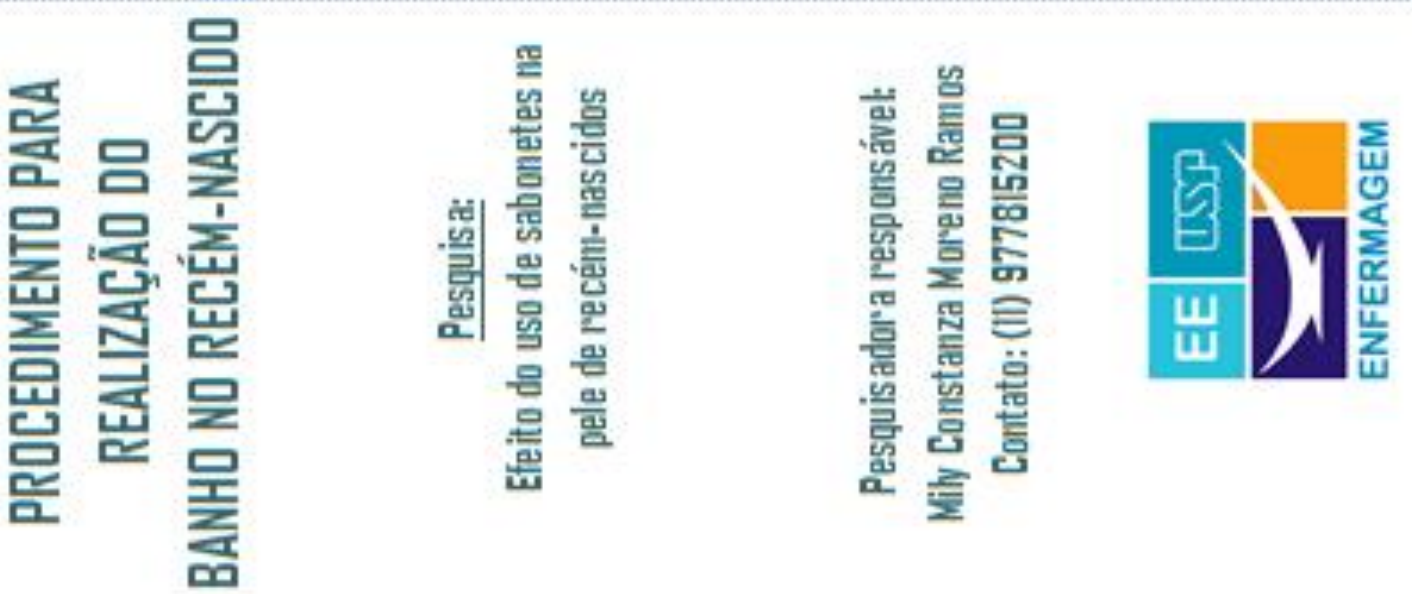

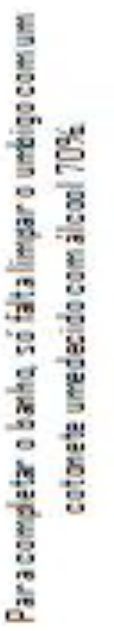

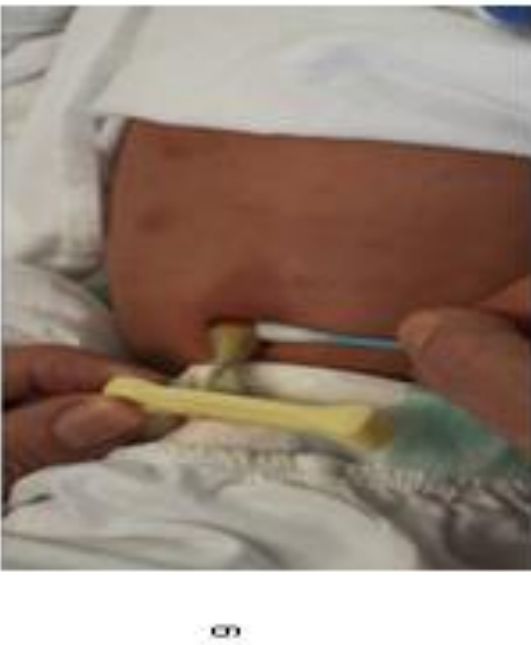

क
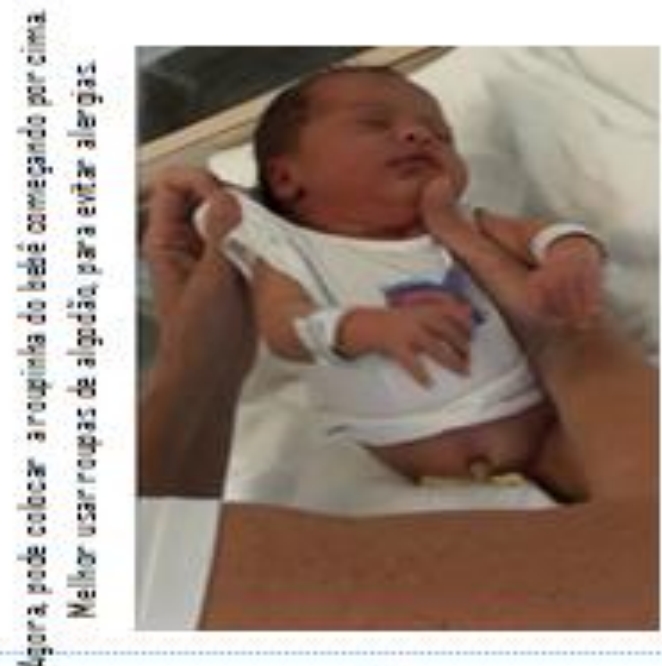

E.
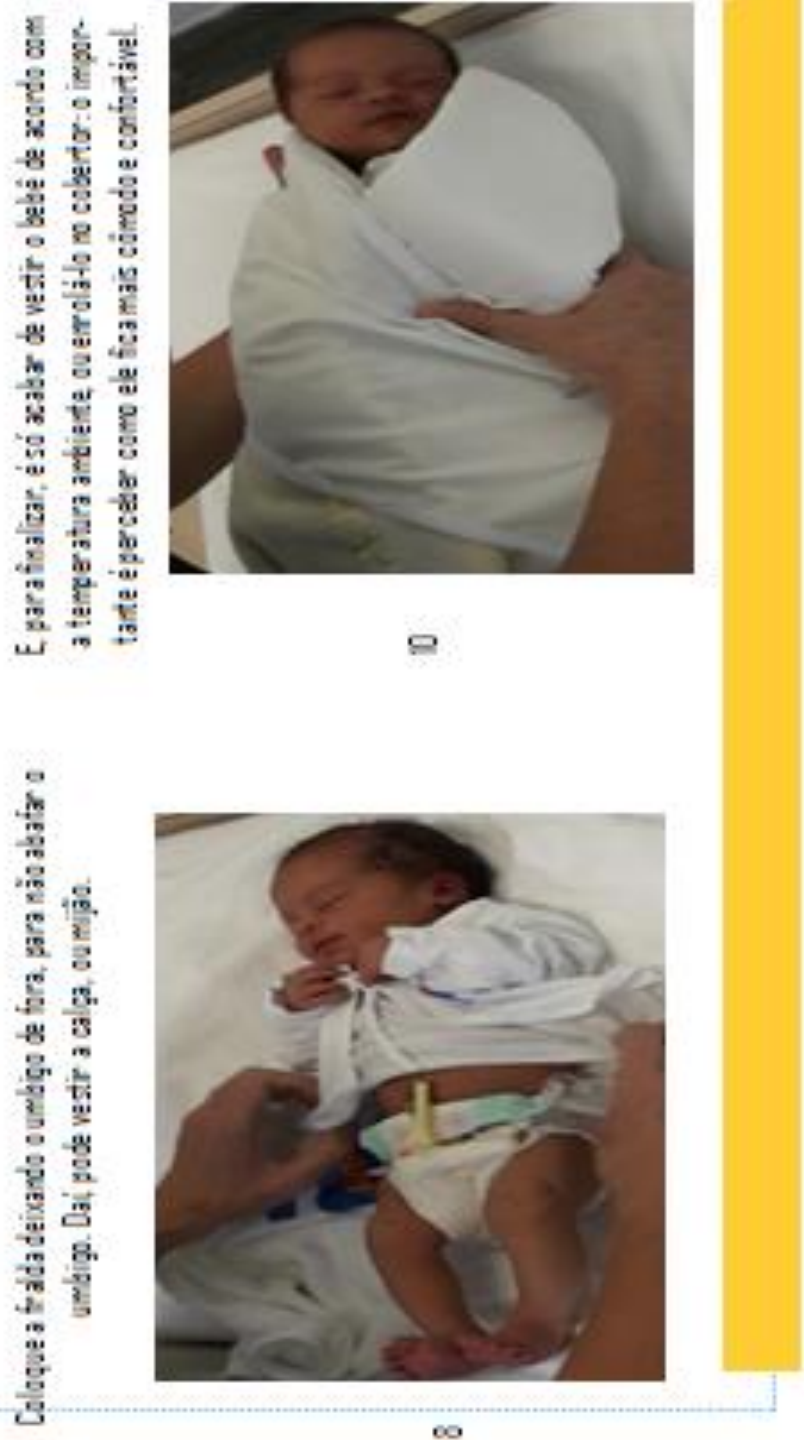

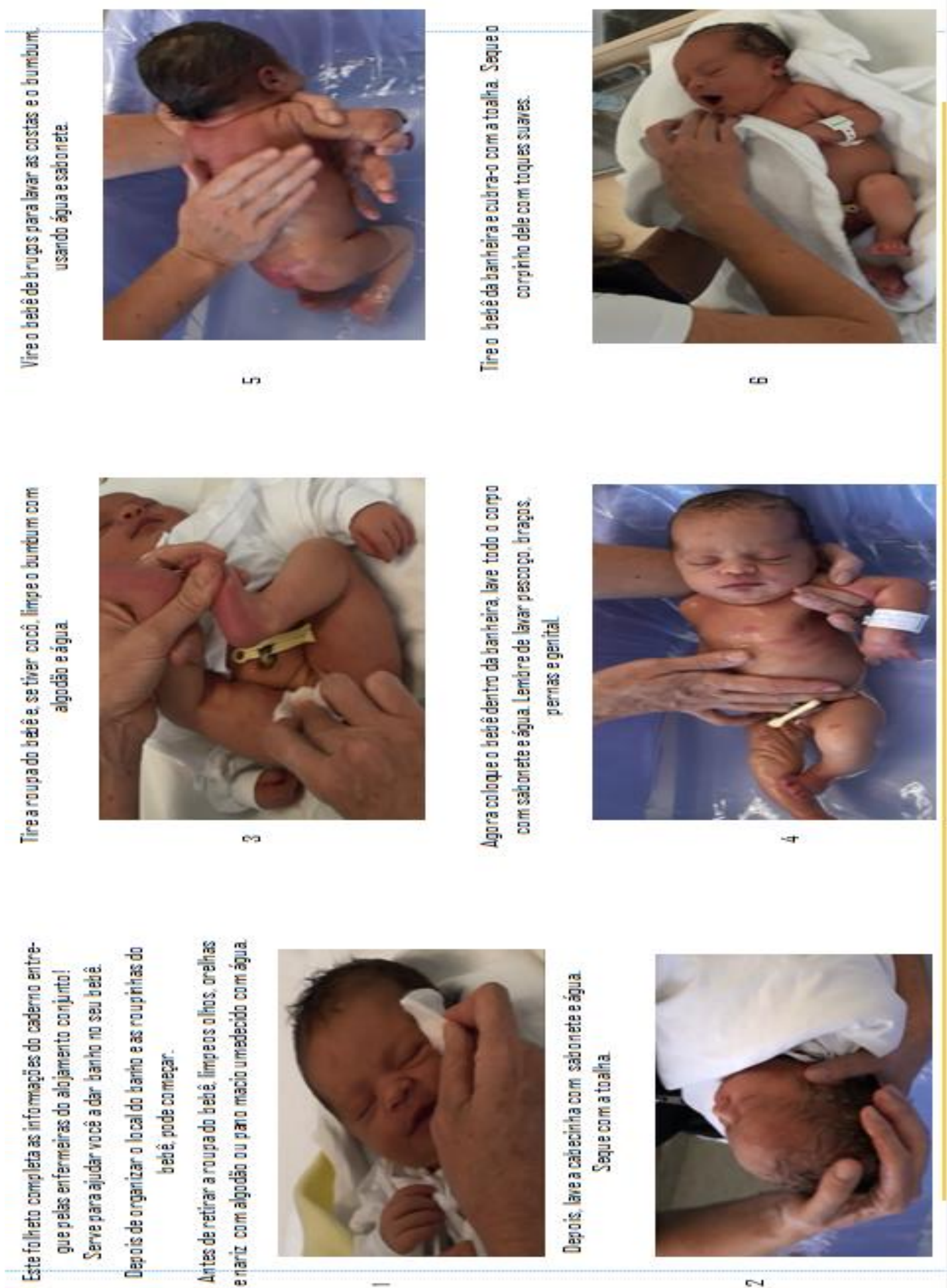


\section{APÊNDICE E}

\section{Critérios de elegibilidade}

Record ID

A idade gestacional ao nascimento do $\mathrm{RN}$ é entre 37 semanas e 42 semanas e seis dias?

Não

$\mathrm{Sim}$

O RN não é elegível para entrar no estudo

O RN tem menos de 48 horas de vida?

Não

Sim

O RN não é elegível para entrar no estudo

O RN é proveniente do Centro Obstétrico?

(Por favor, verifique a ficha obstétrica)

Não

Sim

O RN não é elegível para entrar no estudo

O RN tem respiração espontânea?

(Respiração espontânea: ausência de dispositivo externo para respirar)

Não

Sim

O RN não é elegível para entrar no estudo

O RN está sob tratamento com fototerapia?

Não

Sim

O RN não é elegível para entrar no estudo

O RN tem anomalias congênitas?

(anomalias congênitas como: anencefalia, mielomeningocele, gastroquise, espinha bífida, etc)

$\bigcirc$ Não

O RN não é elegível para entrar no estudo

O RN tem doenças dermatológicas?

(doenças como: epidermólise Bulhosa, impetigo neonatal, ictiose, onfalite neonatal, etc)

Não
Sim 
O RN não é elegível para entrar no estudo

O RN tem inflamação, irritação importante ou lesão na pele?

Não

○ Sim

O RN não é elegível para entrar no estudo

O RN tem alguma doença aguda ou crônica?

Não

O Sim

O RN não é elegível para entrar no estudo

O RN já teve o primeiro banho?

Não

O Sim

O RN não é elegível para entrar no estudo

A mãe ou responsável aceitou participar do estudo e assinou o TCLE?

(É obrigatório que a mãe ou responsável assine o TCLE antes de começar o estudo)

Não

O Sim

O RN não é elegível para entrar no estudo 


\section{APÊNDICE F \\ Dados sociodemográficos e clínicos}

Record ID

Data e hora do início do estudo

\section{Informações da mãe ou responsável}

Nome da mãe ou responsável

(Nome completo da mãe ou do responsável)

Idade da mãe ou responsável

(Informar somente números)

Quem é o cuidador principal?
$\square$ Mãe
$\square$ Pai
$\square$ Tio/a
$\square$ Avó/ô
$\square$ Irmão/ã
$\square$ Sobrinho/a
$\square$ Primo/a

\section{Escolaridade da mãe}

(Ensino fundamental: até 8a série ou 90 ano. Ensino médio até 30 ano.)
Analfabeta
Ensino fundamental completo
Ensino fundamental incompleto
Ensino médio completo
Ensino médio incompleto
$\bigcirc$ Ensino superior completo
Ensino superior incompleto
Ensino de pós-graduação completo
Ensino de pós-graduação incompleto
Informação não disponível

\section{Estado civil da mãe}
Solteira
Casada
Viúva
Divorciada
Separada
União estável
Informação não disponível 
Com quem você mora?

$\begin{aligned} & \square \text { Esposo/a } \\ & \square \text { Pai } \\ & \square \text { Mãe } \\ & \square \text { Tio/a } \\ & \square \text { Avó/ồ } \\ & \square \text { Irmão/ã } \\ & \square \text { Sobrinho/a } \\ & \square \text { Primo/a } \\ & \square \text { Outro }\end{aligned}$

Quem?

Quem vai ajudar a senhora (ou senhor) a cuidar do bebê?

$\square$ Esposo/a
$\square$ Pai
$\square$ Mãe
$\square$ Tio/a
$\square$ Avó/ô
$\square$ Irmão/ã
$\square$ Sobrinho/a
$\square$ Primo/a
$\square$ Outro

Quem?

História materna de dermatite atópica

Não

$\bigcirc \mathrm{Sim}$

Qual familiar?

$\square$ Ela mesma
$\square$ Pai
$\square$ Mãe
$\square$ Tio/a
$\square$ Avó/ô
$\square$ Irmão/ã
$\square$ Sobrinho/a
$\square$ Primo/a
$\square$ Outro

Quem? 
História paterna de dermatite atópica

Não

Sim

Qual familiar?

$\square$ Ele mesmo

$\square$ Pai

$\square$ Mãe

$\square$ Tio/a

$\square$ Avó/ô

$\square$ Irmão/ã

$\square$ Sobrinho/a

$\square$ Primo/a

$\square$ Outro

Quem?

Número de whatsapp ou celular 1

(Por favor, verifique o número)

Número de whatsapp ou celular 2

(Por favor, verifique o número)

Telefone residencial

E-mail ou correio eletrônico

Informações sociodemográficas e clínicas do RN

Nome do RN

(Caso não tiver nome o RN, colocar número 999) 


\section{Raça (Perguntar para a mãe)}
Branco
Preto
Pardo
Amarelo
Indígena
Desconhecido/não informado

Data e hora do nascimento

Tipo de parto

$\bigcirc$ Vaginal

Cesárea

Fórceps

Idade do RN

Idade gestacional do $\mathrm{RN}$

(idade em semanas. Coletar do prontuário. Exemplo: 37 )

Sexo do RN (coletar do prontuário)

feminino

masculino

Peso ao nascimento

(Peso em gramas. Coletar do prontuário)

Relação entre peso e idade gestacional do RN

$\bigcirc^{\text {AIG }}$ GIG

Altura ao nascimento

(Altura em centímetros. Coletar do prontuário)

Número de matrícula do RN

(coletar do prontuário)

Número de matrícula da mãe

(Coletar do prontuário) 


\section{APÊNDICE G}

\section{Randomização}

Record ID

A qual grupo o $\mathrm{RN}$ foi randomizado?

Experimental (sabonete líquido)

Controle (sabonete em barra) 


\section{APÊNDICE H \\ Desfechos biométricos da pele antes do primeiro banho}

\begin{tabular}{|c|c|}
\hline Record ID & \\
\hline O RN tem no mínimo 6 horas de nascido? & $\begin{array}{l}\text { Não } \bigcirc \text { Sim } \\
\text { (Se o RN tiver menos de } 6 \text { horas de vida, } \\
\text { por favor, espere a completar } 6 \text { horas } \\
\text { para dar o primeiro banho) }\end{array}$ \\
\hline $\begin{array}{l}\text { Temperatura corporal do RN } \\
\text { (inicial) }\end{array}$ & $\begin{array}{l}\text { (Informar somente números. Exemplo: } 36.7 . \\
\text { Se To } \\
<36.5 \text { ou To }>37.5 \text {, avalie a causa } \\
\text { (hipoglicemia, excesso ou deficiência de } \\
\text { roupas e cobertores, hipertermia maligna, } \\
\text { infecção), informe e reavalie em } 30 \\
\text { minutos. Caso a To se normalize prossiga } \\
\text { com as perguntas. ) }\end{array}$ \\
\hline
\end{tabular}

Temperatura corporal do RN (reavaliação)

(Informar somente números. Exemplo: 36.7. Preencha caso tenha realizado uma segunda medição de temperatura. Se To $<36.5$ ou To $>37.5$ o RN deverá sair do estudo. Informe à enfermeira do setor responsável)

Data e hora do primeiro banho

Horas de vida antes do primeiro banho

Temperatura ambiente

(Informar somente números. Exemplo: 24.6)

Umidade relativa do

ar

(Informar somente números. Exemplo:

63.4 Não colocar \%)

\section{Medidas biométricas da pele do RN (Aparelho MP9 e sondas)}

Perda de água transepidermal do antebraço direito 1

Perda de água transepidermal do antebraço direito 2

Perda de água transepidermal do abdômen 1

Perda de água transepidermal do abdômen 2 
Perda de água transepidermal do glúteo direito 1

Perda de água transepidermal do glúteo direito 2

Perda de água transepidermal da coxa direita 1

Perda de água transepidermal da coxa direita 2

Conteúdo de sebo da testa 1

Conteúdo de sebo da testa 2

Conteúdo de sebo do antebraço direito 1

Conteúdo de sebo do antebraço direito 2

Conteúdo de sebo do abdômen 1

Conteúdo de sebo do abdômen 2

Conteúdo de sebo do glúteo direito 1

Conteúdo de sebo do glúteo direito 2

Conteúdo de sebo da coxa direita 1

Conteúdo de sebo da coxa direita 2

Corneometría do antebraço direito 1

Corneometría do antebraço direito 2

Corneometria do adbômen 1

Corneometria do adbômen 2 
Corneometria do glúteo direito 1

Corneometria do glúteo direito 2

Corneometria da coxa direita 1

Corneometria da coxa direita 2

pH do antebraço direito 1

$\mathrm{pH}$ do antebraço direito 2

pH do abdômen 1

pH do abdômen 2

pH do glúteo direito 1

pH do glúteo direito 2

pH da coxa direita 1

pH da coxa direita 2

\section{Escala da Condição da Pele do Recém-nascido}

(Responda as perguntas a seguir avaliando o corpo inteiro, porém detalhando testa, antebraço direito, abdômen, glúteo direito, coxa direita)

Secura

(1) Pele normal nenhum sinal de pele seca

(2)Pele seca descamação visível

$\bigcirc$ (3)Pele muito seca, rachaduras/fissuras

Por favor, preencha o formulário complementar da escala (impresso) 
Eritema

Caso a pele do RN apresente eritema, por favor, calcule a porcentagem de superfície corporal afetada conforme a imagem e responda a pergunta na secuencia

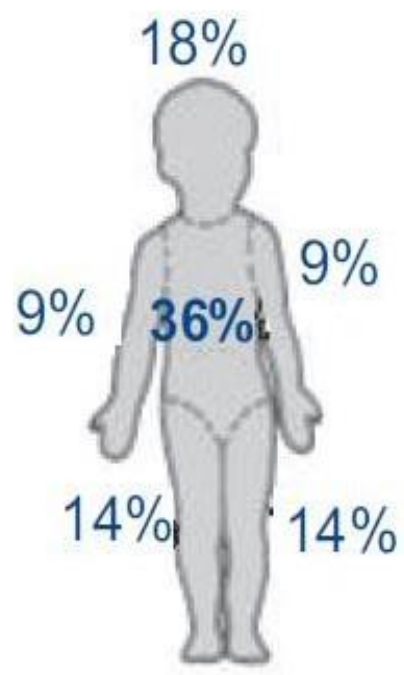

\begin{tabular}{ll}
\hline Eritema & (1) não há evidência de eritema \\
& (2) eritema visível, < $50 \%$ da superfície corporal \\
(3) eritema visível, $>$ ou $=50 \%$ da \\
superfície corporal
\end{tabular}

Por favor, preencha o formulário complementar da escala (impresso)

\begin{tabular}{ll}
\hline Ruptura/lesão & $\bigcirc(1)$ nenhuma lesão visível \\
& $\bigcirc(2)$ pequena, em áreas localizadas \\
& $\bigcirc(3)$ extensa
\end{tabular}

Por favor, preencha o formulário complementar da escala (impresso)

Tipo de ruptura/lesão

Lesão de espessura parcial (epiderme e derme)

Lesão de espessura total (derme e subcutâneo)

Dermatite atópica

OFissura

Dermatite associada à incontinência

Outra

Qual?

Descreva a(s) lesão(ões) observada(s)

(Informe a região anatômica, tipo de tecido presente, exsudato, sinais de infecção, bordas, e pele perilesional) 


\section{APÊNDICE I \\ Critérios de exclusão no hospital}

Record ID

O RN está sob tratamento de fototerapia?

Não

Sim

O RN não pode continuar no estudo

O RN foi transferido à unidade neonatal ou unidade de terapia intensiva após a inclusão?

Não

Sim

O RN não pode continuar no estudo

Qual a razão da transferência?

Ictericia neonatal

Desconforto

respiratório

Hipoglicemia Outra

Qual?

O RN não pode continuar no estudo

O RN foi diagnosticado com alguma anomalia congênita após a inclusão?

Não

Sim

Tipo de anomalia congênita

Cardiopatia

Neuropatia

Atresia

esofágica

Atresia

intestinal

Atresia anal

Outra

Qual?

Tipo de cardiopatia

Ductus arterial persistente

CIA

CIV

Tetralogia de fallot

Transposición de grandes

arterias Ventrículo único

hipoplásico Outra 
Se outra, escreva o nome da cardiopatia

Tipo de neuropatia

Neuropatia sensitivo-motora

hereditária Distrofia neuroaxonal

Neuropatia tomacular

Neuropatia a/hipomielinizante

congênita Outra

Se outra, escreva o nome da neuropatia

O RN não pode continuar no estudo 


\section{APÊNDICE J \\ Dados clinicos follow up}

Record ID

Você realizou o banho conforme a técnica e o sabonete entregado no Hospital Universitário?

Não

$\bigcirc$ Sim

Quais foram as mudanças?

Quais foram as razões da mudança?

Você utilizou algum produto tópico adicional?

Não

$\bigcirc$ Sim

Qual (ais) produto (s)?

Qual foi a razão da utilização?

Como observa a pele do Recém-nascido hoje?

Normal, sem alterações

Irritada, com alergia

Ressecada, com descamação

O recém-nascido ficou doente?

ก Não

O Sim 
Qual o nome da doença?

Doenças diarréicas

Infecções do trato

respiratório Asfixia

Anomalías congênitas

Septicemia e outras infecções neonatais

Desnutrição

Meningite

Causa externa (trauma, acidente)

Causa indeterminada/desconhecida

Informação não disponivel

Outra

Se outra, qual?

Você ofereceu medicações ao RN?

Não

Sim

Qual (ais) medicamento (s)?

Qual a razão?

Você ainda tem quantidade suficiente de sabonete? (Caso não, entregar mais uma unidade de sabonete)

Não

$\bigcirc \mathrm{Sim}$ 


\section{APÊNDICE K \\ Critérios de exclusão follow up}

Record ID

O RN foi diagnosticado com alguma anomalia congênita após a inclusão?

Não

$\bigcirc \mathrm{Sim}$

Tipo de anomalia congênita

Cardiopatia

Neuropatia

Atresia esofágica

Atresia intestinal

Atresia anal

Outra

Qual?

Tipo de cardiopatia

Ductus arterial

persistente CIA

CIV

Tetralogia de fallot

Transposición de grandes arterias

Ventrículo único hipoplásico

Outra

Se outra, escreva o nome da cardiopatia

Tipo de neuropatia

Neuropatia sensitivo-motora hereditária

Distrofia neuroaxonal

Neuropatia tomacular

Neuropatia a/hipomielinizante congênita

Outra

Se outra, escreva o nome da neuropatia

O RN não pode continuar no estudo 


\section{APÊNDICE L \\ Desfechos biometricos da pele follow up}

\author{
Record ID \\ Temperatura corporal do RN \\ (inicial)
}

(Informar somente números. Exemplo: 36.7. Se To

$<36.5$ ou To $>37.5$, avalie a causa

(hipoglicemia, excesso ou deficiência de roupas e cobertores, hipertermia maligna, infecção), informe e reavalie em 30 minutos. Caso a $\mathrm{T}^{\circ}$ se normalize prossiga com as perguntas. )
Temperatura corporal do RN (reavaliação)
(Informar somente números. Exemplo: 36.7. Preencha caso tenha realizado uma segunda medição de temperatura. Se To $<36.5$ ou To>37.5 o RN deverá sair do estudo. Informe à enfermeira do setor responsável)

Temperatura ambiente

(Informar somente números. Exemplo: 24.6)

Umidade relativa do ar

(Informar somente números. Exemplo:

63.4 Não colocar \%)

\section{Medidas biométricas da pele do RN (Aparelho MP9 e sondas)}

Perda de água transepidermal do antebraço direito 1

Perda de água transepidermal do antebraço direito 2

Perda de água transepidermal do abdômen 1

Perda de água transepidermal do abdômen 2

Perda de água transepidermal do glúteo direito 1

Perda de água transepidermal do glúteo direito 2

Perda de água transepidermal da coxa direita 1

Perda de água transepidermal da coxa direita 2 
Conteúdo de sebo da testa 1

\section{Conteúdo de sebo da testa 2}

Conteúdo de sebo do antebraço direito 1

Conteúdo de sebo do antebraço direito 2

Conteúdo de sebo do abdômen 1

Conteúdo de sebo do abdômen 2

Conteúdo de sebo do glúteo direito 1

Conteúdo de sebo do glúteo direito 2

Conteúdo de sebo da coxa direita 1

Conteúdo de sebo da coxa direita 2

Corneometría do antebraço direito 1

Corneometría do antebraço direito 2

Corneometria do adbômen 1

Corneometria do adbômen 2

Corneometria do glúteo direito 1

Corneometria do glúteo direito 2

Corneometria da coxa direita 1

Corneometria da coxa direita 2 
$\mathrm{pH}$ do antebraço direito 1

$\mathrm{pH}$ do antebraço direito 2

pH do abdômen 1

$\mathrm{pH}$ do abdômen 2

$\mathrm{pH}$ do glúteo direito 1

$\mathrm{pH}$ do glúteo direito 2

$\mathrm{pH}$ da coxa direita 1

$\mathrm{pH}$ da coxa direita 2

\section{Escala da Condição da Pele do Recém-nascido}

(Responda as perguntas a seguir avaliando o corpo inteiro, porém detalhando testa, antebraço direito, abdômen, glúteo direito, coxa direita)
Secura
(1) Pele normal nenhum sinal de pele seca
(2)Pele seca descamação visível
(3)Pele muito seca, rachaduras/fissuras

Por favor, preencha o formulário complementar da escala (impresso)

\section{Eritema}

Caso a pele do RN apresente eritema, por favor, calcule a porcentagem de superfície corporal afetada conforme a imagem e responda a pergunta na secuencia

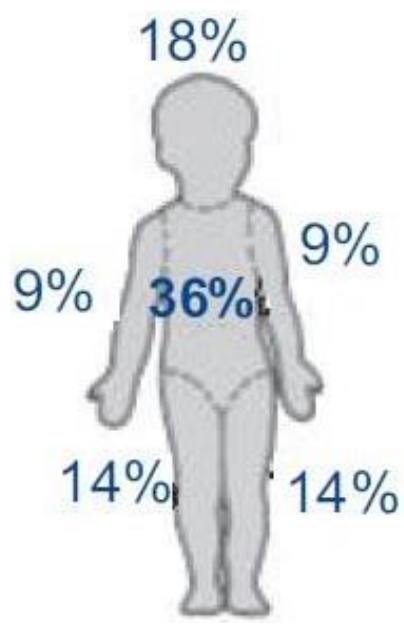




\begin{tabular}{|c|c|}
\hline Eritema & $\begin{array}{l}\bigcirc \text { (1) não há evidência de eritema } \\
\bigcirc \text { (2) eritema visível, < } 50 \% \text { da superfície corporal } \\
\text { (3) eritema visível, > ou }=50 \% \text { da superfície } \\
\text { corporal }\end{array}$ \\
\hline
\end{tabular}

Por favor, preencha o formulário complementar da escala (impresso)

Ruptura/lesão

(1) nenhuma lesão visível

(2)pequena, em áreas localizadas

(3)extensa

Por favor, preencha o formulário complementar da escala (impresso)

Tipo de ruptura/lesão

Lesão de espessura parcial (epiderme e derme)

Lesão de espessura total (derme e subcutâneo)

Dermatite atópica

Fissura

Dermatite associada à incontinência

Outra

Qual?

Descreva a(s) lesão(ões) observada(s)

(Informe a região anatômica, tipo de tecido presente, exsudato, sinais de infecção, bordas, e pele perilesional) 


\section{APÊNDICE M \\ Percepção da mãe, pai ou cuidador no uso de sabonete para o banho do recém-nascido}

Record ID

Como foi para você o uso sabonete?

Difícil

Indiferente (Nem díficil/nem fácil)

Fácil

Como foi para você o enxágue do sabonete?

Difícil

Indiferente (Nem difícil /nem fácil)

Fácil

O que você achou do cheiro do sabonete?

Desagradável

Indiferente (Nem desagradável /nem agradável)

Agradável

O que você achou da intensidade do cheiro do sabonete?

Forte

Indiferente (Nem forte /nem suave)

Suave

Foi possível sentir o cheiro do sabonete na pele do bebê depois do banho?

Não

$\bigcirc \operatorname{Sim}$

O que você achou do cheiro que ficou na pele do bebê?

Desagradável

Indiferente (Nem desagradável /nem agradável)

Agradável

Você achou que o sabonete limpou a pele do bebê?

Não

Sim

Como ficou a pele do bebê depois do banho?

Ressecada

Nem ressecada/nem hidratada

Hidratada e macia

Você gostaria de continuar usando o mesmo sabonete para o bebê?

Não

Sim 
Caso não deseje continuar usando o mesmo sabonete, responda qual o motivo

Você gostaria de fazer algúm comentário ou sugestão? 


\section{APÊNDICE N}

\section{Encerramento do estudo}

\section{Record ID}

Data da última visita

Tempo de seguimento total

O RN completou o tempo do estudo? (Sim, quando tempo de seguimento $=>25$ dias)

Não

Sim

Motivo do RN não ter completado o tempo do estudo

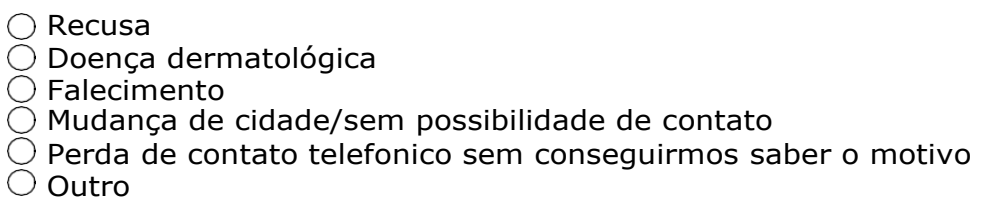

Se outro, qual?

O RN precisou de:

Internação

Consulta com o pediatra

Consulta com outro profissional

$\square$ Nenhuma das anteriores

Quantas internações ou consultas durante todo o seguimento?
1
$\bigcirc 2$
$3 \bigcirc 4$
$\bigcirc 5 \bigcirc 6$
7
$\bigcirc 8$ mais de 9

Causa da internação ou consulta

Doenças diarréicas

Infecções do trato respiratório

Asfixia

Anomalías congênitas

Septicemia e outras infecções neonatais

Desnutrição

Meningite

Causa externa (trauma, acidente)

Causa indeterminada/desconhecida

Informação não disponivel

Outra

Se outra, qual? 
Houve obito?

Não $\bigcirc \operatorname{Sim}$

Data de óbito

Causa do óbito

Doenças diarréicas

Infecções do trato respiratório

Asfixia

Anomalías congênitas

Septicemia e outras infecções neonatais

Desnutrição

Meningite

Causa externa (trauma, acidente)

$\bigcirc$ Causa indeterminada/desconhecida

Informação não disponivel

Outra

Tempo de sobrevida total

O RN foi perdido para o seguimento?

Não

Sim

Quantas vezes foi tentado seguimento

telefônico? $\bigcirc 1 \bigcirc 2 \bigcirc 3 \bigcirc 4 \bigcirc 5$

Data do último contato telefônico

Comentários 
aNEXOS 


\section{ANEXOS}

\section{ANEXO 1 \\ Descrição Geral do Multi Probe Adapter MPA-5 ${ }^{\circledR}$ \\ 2 - Descriçāo do Aparelho}

0 aparelho MPA 5 - Sebumeter 815 é apresentado numa caixa de dimensões reduzidas, de design compacto e leve, facilitando o transporte, além do Sebumeter 815 (para medir a oleosidade da pele) já incorporado no aparellho, un sistema plug-in pode reunir vários outros instrumentos de medida:

- Corneometer 825 para medir o teor de hidratação da pele

- Skin-pH-Meter 905 para medir o $\mathrm{pH}$ da pele

- Mexameter 18 para medir melanina e eritema

- Tewameter 300 para medir a perda transepidérmica de água

- Reviscometer 600 para medir a elasticidade e a direção das fibras de colágeno e elastina

OMPA 5 - Sebumeter 815 deve ser conectado a um PC compativel-IBM. Quatro sondas digitais (de tipos diferentes ou iguais) podem ser conectadas ao mesmo tempo. Um software especial permite a operação individual de cada sonda e armazena os resultados num banco de dados comum.

Adicionalmente há um sensor das condições ambientais (temperatura e umidade do ar) que quando conectado ao MPA 5 - Sebumeter 815 transmite os valores diretamente ao software que se juntam aos valores das mediç̧ões.

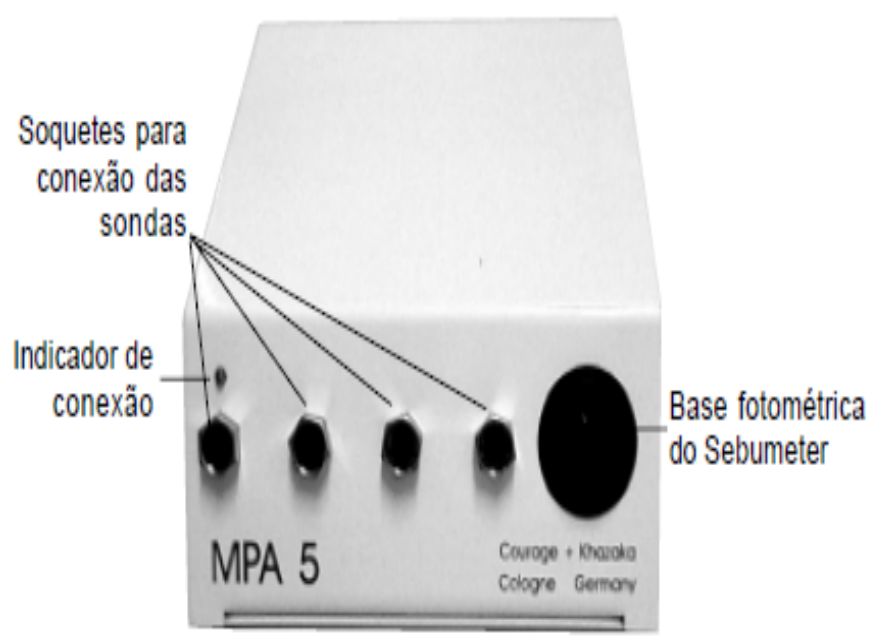

Painel frontal

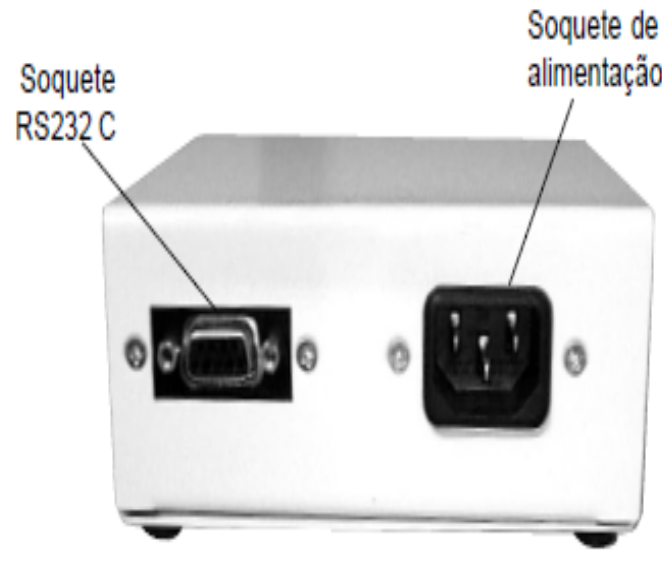

Painel posterior

Fonte: Manual de funcionamento Multi Probe Adapter - MPA5 e sondas. Distribuidor Tecnotests produtos e serviços ltda. São Paulo, 2018 


\section{ANEXO 2 \\ Descrição da sonda Skin-pH-Meter ${ }^{\circledR} 905$}

\section{1 - Princípio de Funcionamento}

A medição do pH avalia uma importante característica de qualquer solução aquosa: acidez ou alcalinidade. Esse valor é determinado pela concentração de ions hidrogênio ( $\mathrm{H}^{+}$, prótons) e de íons hidróxila $\left(\mathrm{OH}^{*}\right)$. Para água dissociada, segue o seguinte:

sendo:

$$
\mathrm{H}_{2} \mathrm{O} \leftrightarrow \mathrm{H}^{+}+\mathrm{OH}^{-}
$$

$$
\begin{aligned}
& \mathrm{H}^{*}=\text { ion hidrogênio positivamente carregado, ácido } \\
& \mathrm{OH}^{*}=\text { ion hidróxila negativamente carregado, alcalino }
\end{aligned}
$$

Segundo sua definição mais simples, apresentada por Soren Sorensen em 1909, opH é o logaritmo negativo da concentração molar de ions $\mathrm{H}^{+}$:

$$
\mathrm{pH}=-\log \left[\mathrm{H}^{*}\right]
$$

O valor de pH está compreendido num ponto da escala de 0 (fortemente ácido) a 14 (fortemente alcalino), com valor 7 representando neutralidade.

A medição do pH é preferencialmente feita por um eletrodo de vidro. É muito importante que um potencial reprodutivel seja desenvolvido e que o eletrodo não seja influenciado pela solução a ser avaliada. $O$ eletrodo de vidro é preenchido por uma solução tampão interna (mercíuio/calomelano: $\mathrm{Hg} / \mathrm{HG}_{2} \mathrm{Cl}_{2}$ ou prata/cloreto de prata: $\mathrm{Ag} / \mathrm{AgCl}$ ). Esta solução tampão intema é separada da solução de teste por uma membrana especial de vidroe trancmite o potencial intemamente à membrana (de um dos metais contidos na solução tampão interna). Um eletrodo chamado de referência transmite o potencial externamente a membrana de vidro, em contato com a solução de teste. O eletrodo de referência é preenchido com eletrólitos e equipado com um diafragma que garante o transporte de ions entre a solução de teste e a solução tampão interna, mas previne a mistura das duas substâncias.

Se as variações elétricas de ambos os eletrodos forem conectadas a um voltímetro (enquanto estiverem imersos na solução de teste), poderá ser lida uma diferença de potencial dependente somente do $\mathrm{pH}$ da solução.

Como a pele, com suas excreções, é quase uma solução aquosa, pode-se proceder à medida do pH diretamente sobre sua superficie.

Com a sonda Skin-pH-Meter PH 905 é possivel a medição de $\mathrm{pH}$ fácil, rápida e altamente precisa.

\section{2 - Medições com a Sonda Skin-pH-Meter 905}

No software selecione a função "Skin-pH-Meter". Em seguida selecione a escala de medição (baña, digital, curva ou tabela numérica).

A medição do $\mathrm{pH}$ da pele não é muito influenciada pelas condições ambientais (temperatura, umidade do ar), nem pelas condições fisicas do indivíduo de teste. Condições

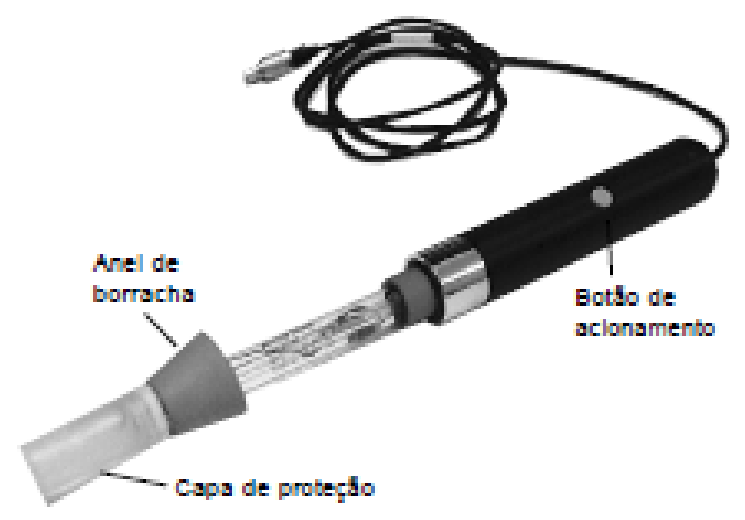

Fonte: Manual de funcionamento Multi Probe Adapter - MPA5 e sondas. Distribuidor Tecnotests produtos e serviços ltda. São Paulo, 2018 


\section{ANEXO 3 \\ Descrição da sonda Tewameter $^{\circledR}$ TM 300}

\section{1 - Principio de Funcionamento}

A sonda Tewameter 300 mede a taxa de evaporaçõo de água da superficie da pele, com base na Lei de Difusã descoberta por Adolf Fick, em 1885 :

$$
\frac{d m}{d t}=-D \cdot A \cdot \frac{d p}{d x}
$$

onde:

$$
\begin{aligned}
& A \text { = superficie em } \mathrm{m}^{2} \\
& \mathrm{~m}=\text { agua transportada }(g) \\
& \mathrm{t}=\text { tempo (h) } \\
& \text { D = constante de difusăo }(0,0877 \mathrm{~g} / \mathrm{m} . \mathrm{h} . \mathrm{mm} \mathrm{Hg}) \\
& \text { p = pressáo de vapor da atmosfera }(\mathrm{mm} \mathrm{Hg}) \\
& x=\text { distăncia entre a superficie da pele e o ponto de medição (m) }
\end{aligned}
$$

O tuwo de difisaso "dm/dt" indica a massa por $\mathrm{cm}^{2}$ que ettá sendo tranportada durante certo periodo de tempo. Este é proporcional à área "A" e à variação da concentraçẩo em funçẫo da distânia " $\mathrm{dp}$ / $\mathrm{dx}$ ". "D" é o coeficiente de difisăo do vapor de água no ar. Esta lei é unicamente válida dentro de uma zona de difusăo homogênea, semelhantemente aquela formada por um cilindro oco. 0 gradiente de densidade resultante é medido indiretamente por dois pares de sensores (temperatura e umidade relativa) e são analisados por um microprocessador.

Os sensores de temperatura e de umidade relativa estäo instalados no interior da sonda Tewameter 300.0 cabeçote de medição da sonda tem a forma de um cilindro 0 co (10 mm de diâmetro $20 \mathrm{~mm}$ de altura) com objetivo de minimizar influências da tubulência de ar no interior da sonda.

Devido ao uso de um microprocessador e dois pares de sensores, a sonda Tewameter 300 pode receber : informação dos valores de temperatura e unidade de cada valor de TEWL (perda transepidémica de água durante um ciclo completo de medição. Os sensores de temperatura podem ser pré-aquecidos para estabilizar mai rapidamente a mediçâo. Este recurso é de grande importância para avaliar a precisăo e a reprodutibilidade d sonda.

Ambas a cuvvas de mediçäo (umidade e temperatura) podem ser mosthadas no monitor.

Fonte: Manual de funcionamento Multi Probe Adapter - MPA5 e sondas. Distribuidor Tecnotests produtos e serviços ltda. São Paulo, 2018 


\section{ANEXO 4 \\ Descrição da sonda Corneometer ${ }^{\circledR} 825$}

\section{1 - Princípio de Funcionamento}

O contenido de umidade do estrato cómeo pode variar muito, dependendo de sua capacidade de anmazenagem. Trata-se de um parâmetro crítico para a película hidrolipidica da pele.

Esse fator desempenha importante papel na vida diánia, pois a pele pode se ressecar devido aos efeitos deleténios do sol, ao ar condicionado dos ambientes, à poluç̧ão, etc. A pele seca tende a se enrugar.

A medida da hidratação da pele utilizando a sonda Comeometer 825 é baseada no efeito capacitivo. Oestrato cóneo seco é um meio dielétrico. Suas propriedades dieléticas se alteram com a mudança no conteúdo de umidade. O princípio de medida baseia-se na extrema diferença entre a constante dielétrica da água (81) e a de outras substâncias (a maioria delas $<7$ ). 0 capacitor formado entre a base da sonda Comeometer 825 e a pele, apresenta alterações no valor da capacitância conforme o conteúdo de água da pele. Na base da sonda, uma lâmina de vidro separa da pele as tiras metálicas (banhadas a ouro) instaladas na base da sonda. Um campo elétrico difuso penetra a pele e mede a diferença dielétrica. Uma tira acumula uma quantidade de elétrons (carga negativa) e a outra tira acumula a falta de elétrons (carga positiva). A altemância de atração entre as tiras desenvolve então um campo elétrico.

Oresultado é mostrado no monitor do PC.

\section{2 - Medições com a sonda Corneometer 825}
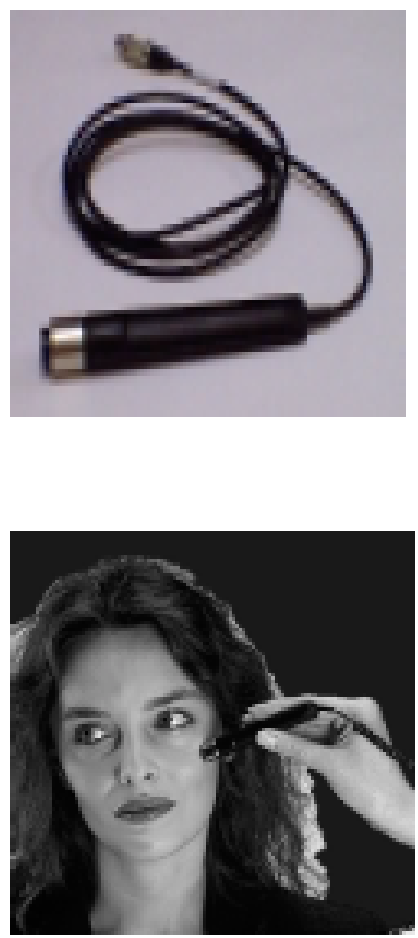

No software selecione a função "Comeometer". Em seguida selecione a escala de medição (baña, digital, curva ou tabela numérica).

Posicionar a sonda do Comeometer 825 perpendiculanmente sobre a pele da área que está sendo medida, exercendo ligeira pressão para acionar a mola .

Após a sonda tocar a pele ouve-se um "bip" e o valor do resultado da medida surge no monitor.

Para a próxima medição, deslocar a sonda para outra região e seguir o mesmo procedimento. Medidas seguidas no mesmo ponto, num intervalo curto, poderão ocasionar distorções nos valores medidos, devido ao efeito de oclusão.

Outros fatores que poderão influenciar nos resultados das mediçōes:

- Contato desigual da superfície da sonda (muita pressão, sonda não perpendicular, apoio não uniforme, pêlos do corpo).

-Medições realizadas imediatamente após ou durante uma situação de estresse físico ou emocional (por exemplo: após uma caminhada)

- Mediçôes demoradas (efeito de oclusão) devido à sujeira e umidade sobre a camada vítrea que recobre a base da sonda.

- Recomenda-se enxugar o suor antes de

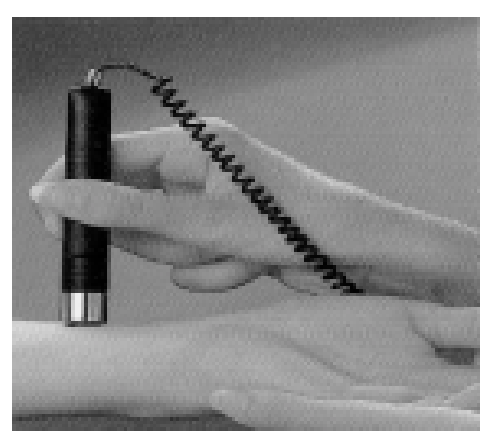

Fonte: Manual de funcionamento Multi Probe Adapter - MPA5 e sondas. Distribuidor Tecnotests produtos e serviços ltda. São Paulo, 2018 


\section{ANEXO 5 \\ Descrição da sonda Sebumeter ${ }^{\circledR}$ SM81O}

\section{4 - Princípio de Funcionamento do MPA 5 - Sebumeter 815}

A medida da oleosidade da pele, dos cabelos e do couro cabeludo com o uso do MPA 5 - Sebumeter 815 é baseada num método de medida direta da secreção sebácea, um método de fotometria da mancha de gordura, que não é influenciado pelaumidade.

A gordura é coletada sobre a fita de plástico translúcido do cassette Sebumeter SM 810 que se toma transparente, e o resultado é obtido pela medida da diferença do valor da transmitância da luz através da fita, antes e após a impregnação pela gorcura.

A fita de plástico translúcido tem espessura de $0,1 \mathrm{~mm}$. 0 cabeçote de medida do cassette corresponde à área de $64 \mathrm{~mm}^{2}$. A cada medida deve se utilizar um segmento de fita não utilizado, que é obticka acionando-se 0 gatilho do cassette. Abaixo da fita, no cabeçote, há uma superficie espelhada com dimensões que ultrapassam em cerca de $1 \mathrm{~mm}$ nas laterais da fita. Quando das medições, uma mola pressiona com força de $0,3 \mathrm{~N}$ a superficie refletora sobre a fita e esta sobre a pele, de modo a garantir pressão constante durante a operação. 0 tempo de contato da fita sobre a pele deve ser de 30 segundo, controlado pelo timer instalado no software de operação.

\section{5 - Cassette Sebumeter SM 810}

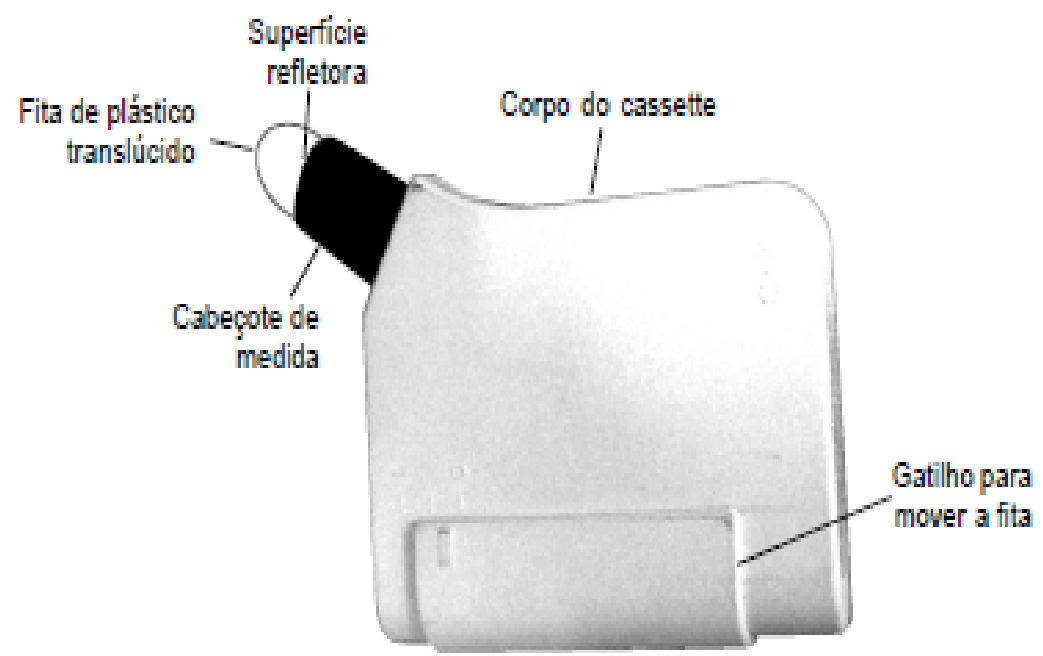

Cassete SM810
Recomenda-se limpar periodicamente a superficie refletora do cassette do Sebumeter SM 810 com um pano macio, umedecido com álcool etilico $70^{\circ} \mathrm{GL}$ para retirar $0 \mathrm{~s}$ resíduos de gordura.

Fonte: Manual de funcionamento Multi Probe Adapter - MPA5 e sondas. Distribuidor Tecnotests produtos e serviços ltda. São Paulo, 2018 


\section{ANEXO 6 \\ Escala da Condição da Pele do Recém-nascido (ECPRN)}

\begin{tabular}{l} 
Secura \\
$1=$ pele normal, nenhum sinal de pele seca \\
$2=$ pele seca, descamação visível \\
$3=$ pele muito seca, rachaduras/fissuras \\
Eritema \\
$1=$ não há evidência de eritema \\
$2=$ eritema visível, $<50 \%$ da superfície corporal \\
$3=$ eritema visível, $>$ ou $=50 \%$ da superfície corporal \\
Ruptura/lesão \\
$1=$ nenhuma visível \\
$2=$ pequena, em áreas localizadas \\
$3=$ extensa \\
\hline Observação \\
Resultado ideal $=3$ \\
Pior resultado $=9$
\end{tabular}

Fonte: SCHARDOSIM. 2012. 


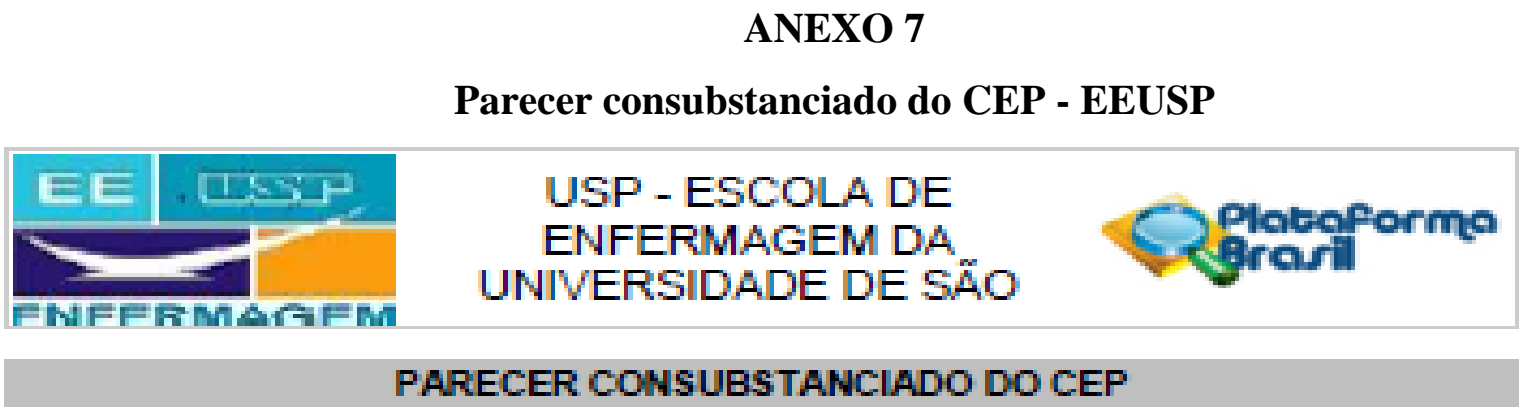

DADOS DO PROUETO DE PESQUISA

THUlb da Pagqulga: EFEITO DO USO DE QABONETE OOM PH NEUTRO A LEMEMENTE ACIDIFICADO EM RECEM-NABCIDOB A TERIMO HOBPITALIZADOB: ENBAIO CLINICO

PGGqulcador: MILT CONGTANEA MORENO RMMOB:

Aroa Tomatloa:

Yertas: 2

CAAE: B2219118. DODU.5392

Inctitulpso Proponente:Eecols de Enfermapem da UPP

Patroolnador Frinolpal: Finamalamento Proprio

DADOS DO PARECER

Mümero do Parbobr: 2.542.995

Apresenta,so do Projito:

Trata-se de um projeb de pesqua de doutorado da aluna Mly Conatanza Moreno Famos orientada pela Prota Dra Marla de La or Ramalho Verlaglmo que tem como foco fomecer evldenclas abre a eficacla de abonebes comercla|mente dlsponiwela quando comparados a um sabonete com caracterlaticas lesla em

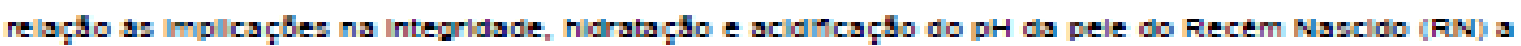

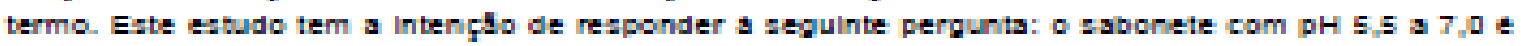

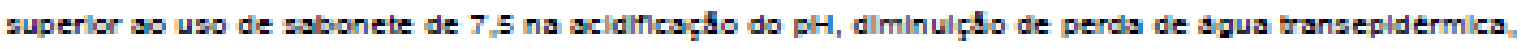
hldratacto = Integrldade da pele do RN a temo? Fara tanto, aera deaenolvido um ensalo clinibo randomliado com R.Na a termo, Internados no Aojamento Conjunto do Hospltal Unlveraltarlo da

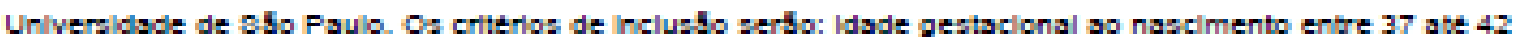

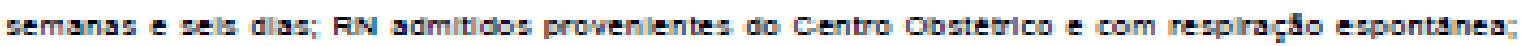
ausencla de anomallas conptnltas fex anence'alla, mielomeningocele, pastroqulse, esplnha bifldaj e doengas dermatologleas (ex: epldenolles bolhosa, limpetgo neonats, letiose, onfallte neonstain: e temperstura axllar minlma pre-banho de $36.5 \cdot 0$. Berso excluldos da casuletica fiN portadorea de

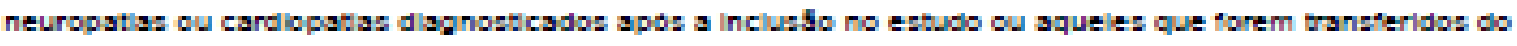
alojsmento con|unto para unidsde neonstal ou unldside de terapla litenziva. OE FN (n-Ed) seriso alocsdos

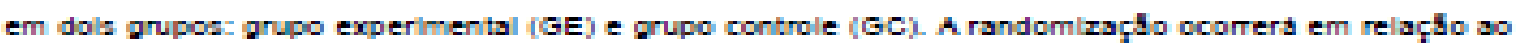
tpo de sabonete para hlglenizagho que serd utilzado, pelo

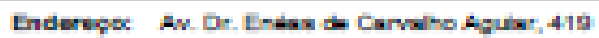

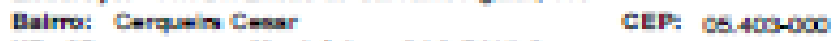

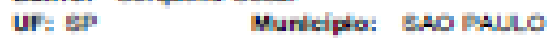

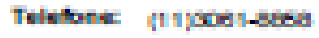

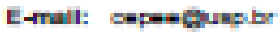




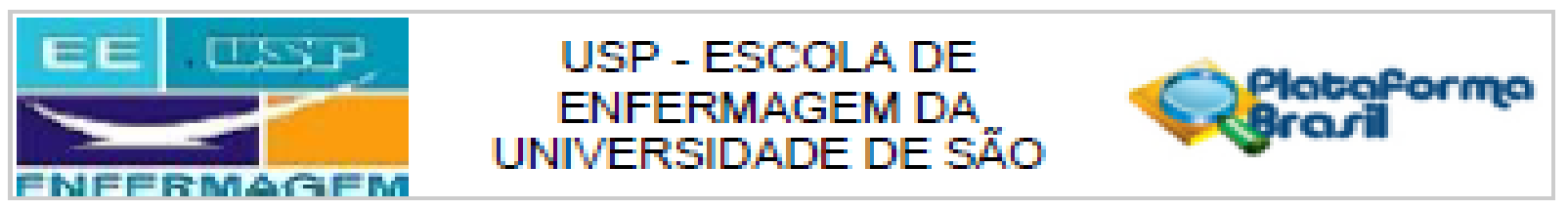

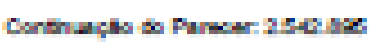

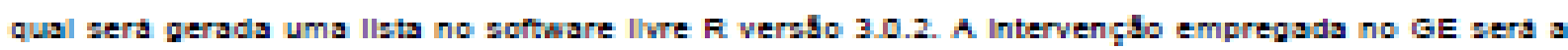

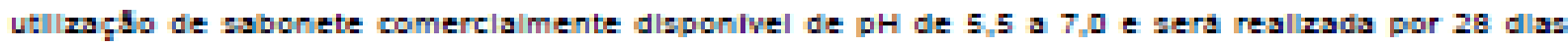
consecuthos a parti do primelro banho no hospial apds sels horas do nasclmento, uma ver por dla. os

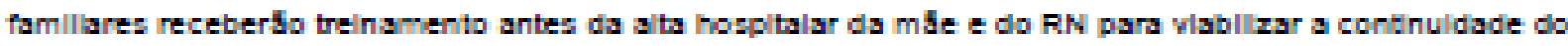

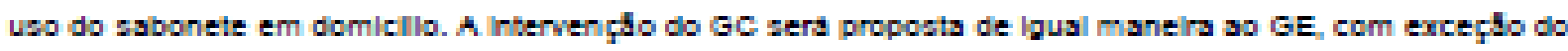

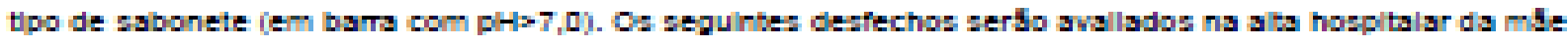
e do FN, no retomo ao ambulsterlo aos 14 dlsa e aos 28 dlas: valor do pH da pele, perda de apus transepldemlca e mensurapgo de comeometria ónivel da hidratacto da pelej e Intepridade da pele.

\section{Objativo da Fesqular:}

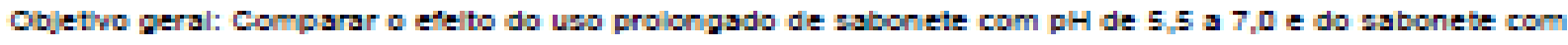
pH malor de 7,5 nas condples da pele do RiN a termo. Oblethos eepecificos: comparar o efelto do uso probngado de sabonete com pH de 5,5 a 7,0 e do sabonete com pH malor de 7,5 no pH da pele do Fry a termo; Comparar óteto do uso prolongado de sabonete com pH de 5,5 a 7,0 e do sabonete com pH malor de 7,5 na perda de agus transepldermics do FW a temo; Compararo efelto do uso prolongado de sabonete

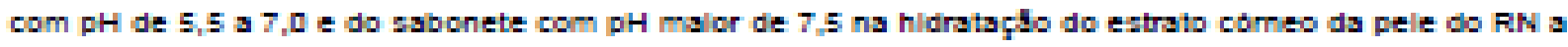
termo; Comparar o efelto do uso prolongado de sabonete com plH de 5,5 a 7, $\mathrm{D}$ e do sabonete com pH malor de 7,5 ng Integridade da pele do RiN a termo.

\section{Aralla,so doc Rlgooc Boneflolos:}

E posshel que o recem-nascido sinta alpum dezconforto do tpo flalco em relapto ao uso do sabonete dentre eles: alerpla ou problemas dermatologlcos como ressecamento, prurldo ou dermatte de contato decomente do uso dos abonetes. Caso las acontefa, o rectm-hascldo serd acompanhado pelo pesqubador e encaminhado para conaulta com o dermabloplsta, onde recebera o tratamento e zepulmento

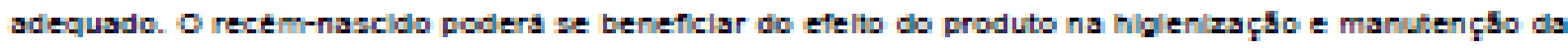
pele, altm de contribulr para estabelecer orientagdes acs profisanale e pals sobre a tesolha de produtos de Mlglene adequados para a pele de recem-nascidos.

\section{Comantarios e concldarapose cobro a Pacqulea:}

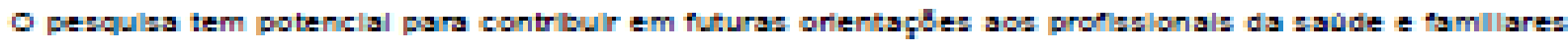
quanto ao melhor culdado a pele do RH. O cronograma e exequheL

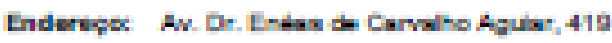

Buira: Lerquen tesar

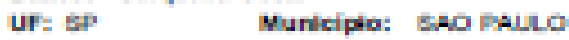

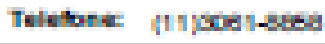

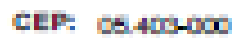

Entil: cepesthest 


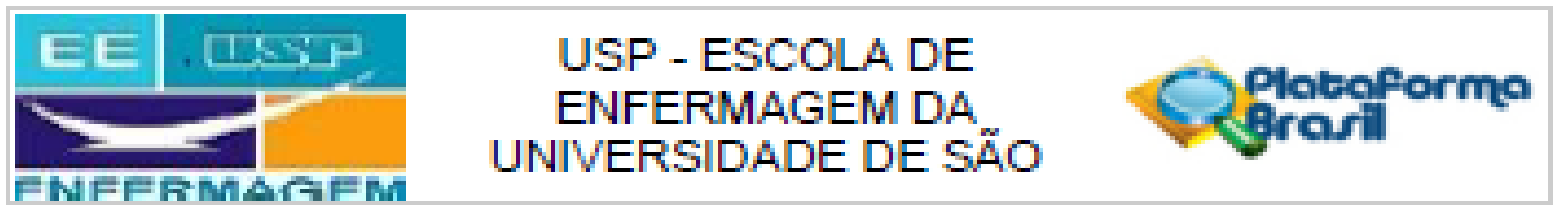

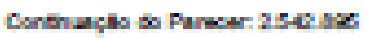

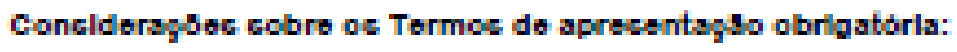

Os pesqulesdores apresentaram os sepulntes documentos: proleto detalhado, TCLE E temo de

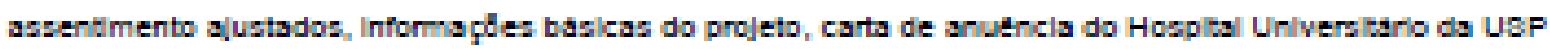
e a folhs de rosto datuda e assinsda.

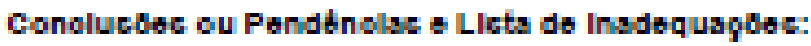

Os peaquadores realizaram todos os alutes solldtados. Bem bblces ticos.

Concldarapog Finsic a ortterlo do CEP:

- Este CEP Infoma a necesaldade de reglatro dos resultados parclale e fnals na Fiataforma Enasil;

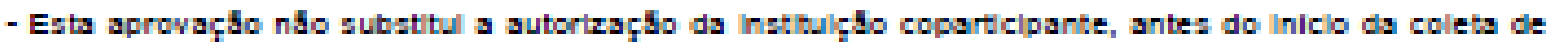
dador.

Ecte parbosr fol elaborado backado noc doummentoc abalio relaolonado:

\begin{tabular}{|c|c|c|c|c|}
\hline Thpo Documento & Arquho & Foatagem & Autar & Bhturps \\
\hline $\begin{array}{l}\text { Informages Edsicas } \\
\text { do Proleto }\end{array}$ & $\begin{array}{l}\text { PE_IFFOFHAQDES_EABICAB_DO_F } \\
\text { ROJETO_ADES733.pdf }\end{array}$ & $\begin{array}{c}270220118 \\
15: 10: 15\end{array}$ & & Are $\mathrm{D}$ \\
\hline $\begin{array}{l}\text { TCLE / Tenmos de } \\
\text { Acsentimento if } \\
\text { Justiflatha de } \\
\text { Burencis. }\end{array}$ & $\begin{array}{l}\text { TERHO_DE_AREENTHENTO_Gomlgld } \\
\text { oudocx }\end{array}$ & $\begin{array}{c}271222019 \\
15: 09: 28\end{array}$ & $\begin{array}{l}\text { MILY CONETAHZA } \\
\text { MOFENO RAMOS }\end{array}$ & AvE 70 \\
\hline $\begin{array}{l}\text { TCLE / Tenos de } \\
\text { Acsentimento if } \\
\text { Justifuatha da } \\
\text { Ausencla }\end{array}$ & TCLE_compldbudecx & $\begin{array}{l}271022019 \\
15: 09: 17\end{array}$ & $\begin{array}{l}\text { MILY CONETAHZA } \\
\text { MOAENO RAMOS }\end{array}$ & ArE 70 \\
\hline $\begin{array}{l}\text { Frajeto Deta hado I } \\
\text { Brochura } \\
\text { Inusptipador }\end{array}$ & Pro|eto_de_pesqula_eorigldo.docr & $\begin{array}{l}\text { 27r202019 } \\
15: 09: 56\end{array}$ & $\begin{array}{l}\text { MILY CONETAHZA } \\
\text { MOAENO RAMOS }\end{array}$ & Areto \\
\hline Folha de Rosta & folhs_de_rosto.pdf & $\begin{array}{c}\text { 19010019 } \\
21: 05: 09\end{array}$ & $\begin{array}{l}\text { MILY CONETAHZA } \\
\text { MOAENO RAMOS }\end{array}$ & ArE $=8$ \\
\hline $\begin{array}{l}\text { TCLE / Termos de } \\
\text { Acsentimento if } \\
\text { Justiflatha de } \\
\text { Bupends. }\end{array}$ & TIEFUD_DE_ABEENTIUENTO.dDCX & $\begin{array}{l}\text { 181012018 } \\
15: 25: 40\end{array}$ & $\begin{array}{l}\text { MLY CONETAHZA } \\
\text { MOAENO RAMOS }\end{array}$ & Ace 70 \\
\hline $\begin{array}{l}\text { TCLE / Tenos de } \\
\text { Acsentimento if } \\
\text { dustilicatha de } \\
\text { Ausencls }\end{array}$ & TCLEdoCX & $\begin{array}{c}180112019 \\
16: 25: 24\end{array}$ & $\begin{array}{l}\text { MILY CONETANZA } \\
\text { MOFENO RAMOS }\end{array}$ & Ace 70 \\
\hline
\end{tabular}

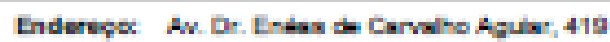

Dalma: Cerqu-n tesar

다: Bs+ritho

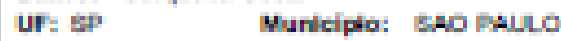

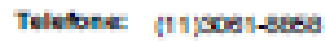

Entl: sepelausb 


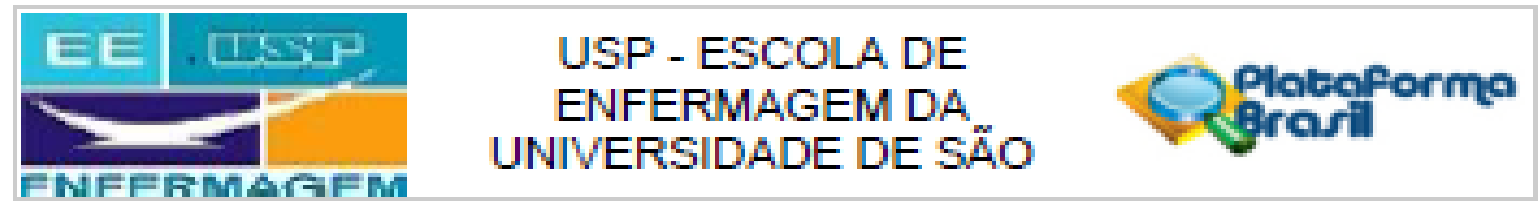

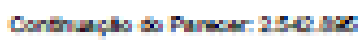

\begin{tabular}{|c|c|c|c|c|}
\hline Dutros: & Carts_de_anuenclapd' & $\begin{array}{c}\text { 16012019 } \\
\text { व1:14:56 }\end{array}$ & $\begin{array}{l}\text { MILY CONBTAHZA } \\
\text { MOAENO RAMOS }\end{array}$ & Ace 70 \\
\hline $\begin{array}{l}\text { Projeto Deta hado If } \\
\text { Brochura } \\
\text { Invettpador }\end{array}$ & Proleto_de_pesquba.decx & $\begin{array}{c}\text { 1601/20-19 } \\
\text { 01:12:19 }\end{array}$ & $\begin{array}{l}\text { MIL'T CONBTAHZA } \\
\text { MOFENO RAMOS }\end{array}$ & Ace 7 \\
\hline
\end{tabular}

situagso do Fareos:

Aproviodo

Neobccita Apreolagso da CoNEP:

NSo

BAO FAULO, t4 de Margo de 2015

Accinado por:

Maroslo Joct doc santos

Goordenador)

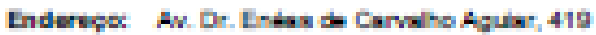

Dairo: terquen tesar

다: BS4THBD

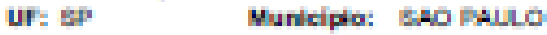

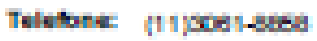

E-mull: ceperaust

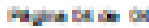




\title{
ANEXO 8 \\ Parecer consubstanciado do CEP - HUUSP
}

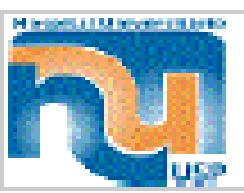

\author{
USP - HOSPITAL \\ UNIVERSITARIO DA \\ UNIVERSIDADE DE SAO
}

Plobeforma

\section{PARECER CONSUBSTANCIADO DO CEP}

Elaborado pola Inottulgso copartlolpants

\section{DADOS DO PROJETO DE PESGUISA}

Trtulo da Pagqulea: EFEITO DQ UQQ DE DABONETE COM PH NEUTRO A LEVEMENTE ACIDIFICADO EM RECEM-NABCIDOB A TEFMO HOEFITALIZADOB: ENBAIO CLIFICO Pocqulcador: MILT CONGTANRA MORENO RAMOQ

Area Tematloa:

Vercso: 3

CAAE: B2219118B 3001.0075

Inctitulpso Propononts: Hoaplal Uhivera zarb ds Unherzldade de eso Paulo

Patroolnador Frinolpal: Financlamento Froprio

DADOS DO PARECER

Hümero do Paroove: 2.714 .919

Apresenta,jo do Projeto:

O sutor reapresenta o projeto, com a sergço na metodologla proposta, onde serto wermcados os desfechos apenas apos o banho do recem-nascldo com os dols diferentes toos de eabonetea lorupos experimentail e

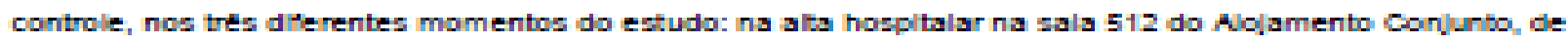

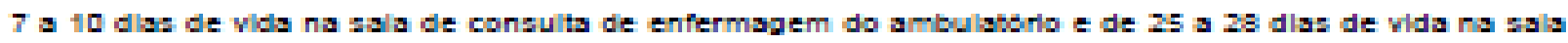
St2 do AJolamento Conjunto. Fara as duas ütimas avalsptes as mbes serbo orientadas a darem banho nos

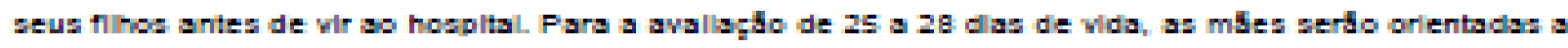
trazerem os seus mihos ao hospltal somente para a avallaglo da pesqulasdora, estando previsto o

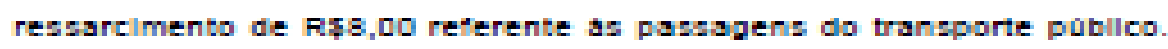

Objotivo da Fecaules:

Eem alteraptes

Arallago dog Fleoge Bonefolos:

eem alteraptez

Comantarloc e cancldaragdec cobre a Pacqulas:

Mesodologla fol reformulada e o TCLE e Termo de Aasentimento foram alterados, eaclarecendo que a avalapto de 25 a 23 das de vida na sala 512 do AJojamento Con/unto eerd somente para fins da pesqules.

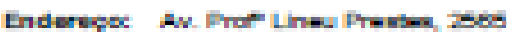

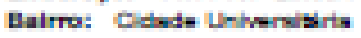

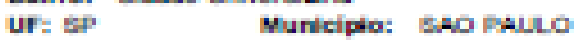

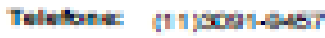

다: Bescon

EAmil: septitumbr 


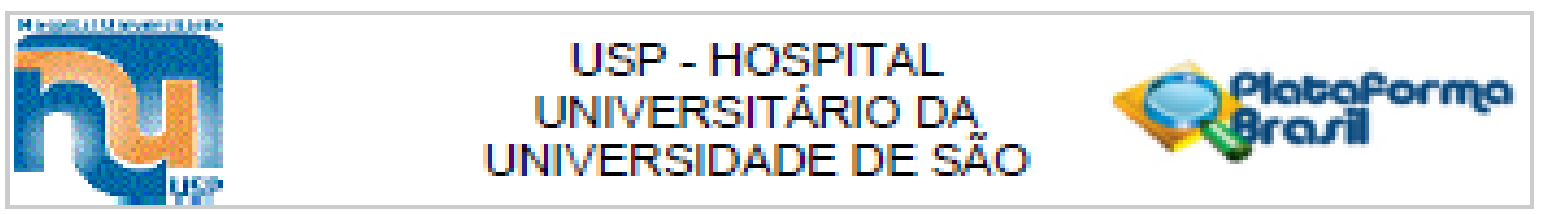

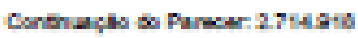

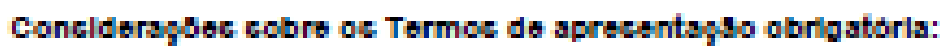

O autor aterou o TCLE e o Temo de Aszertimento, conforme allelado.

Conolucbec ou Pandenolac : Licta de Inadequapose:

Nis in.

Concldora; oug Finalg a ortterlo do CEF:

Ecte parbosr fol elaborado baceado nos documentoc abalieo relaolonados:

\begin{tabular}{|c|c|c|c|c|}
\hline Thpo Documento & Arquhe & Fostapem & Autor & Ehtuspas \\
\hline $\begin{array}{l}\text { Informagdes Eds/cas } \\
\text { do Proleto }\end{array}$ & 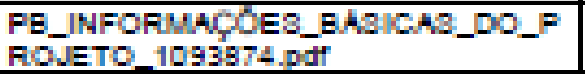 & $\begin{array}{c}05052019 \\
12.02: 41\end{array}$ & & $A c=70$ \\
\hline Dutros: & Cata_HUSpd & $\begin{array}{c}\text { 05052019 } \\
12: 12:-19\end{array}$ & $\begin{array}{l}\text { MILY CONBTAHZA } \\
\text { MORENO RAUOS }\end{array}$ & Areto \\
\hline $\begin{array}{l}\text { Frojeto Deta hado of } \\
\text { Erochura } \\
\text { Invettpador }\end{array}$ & $\begin{array}{l}\text { Fro|eto_de_pesqula_aomigldo_HU3.do } \\
\mathrm{cr}\end{array}$ & $\begin{array}{l}\text { 05ा0520-19 } \\
11: 59: 20\end{array}$ & $\begin{array}{l}\text { MILY CONBTAHZA } \\
\text { MOAENO RAMOS }\end{array}$ & Ace 5 \\
\hline $\begin{array}{l}\text { TCLE / Termos de } \\
\text { Acsentimento I } \\
\text { Justricatha de } \\
\text { Ausencls }\end{array}$ & $\begin{array}{l}\text { Termo_de_Asestimento_combldo_HUY } \\
\text { docx }\end{array}$ & $\begin{array}{l}\text { 05/562019 } \\
11: 57: 57\end{array}$ & $\begin{array}{l}\text { MILY CONETANZA } \\
\text { MORENO RAMOS }\end{array}$ & Ace 70 \\
\hline 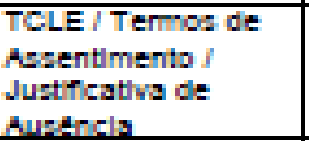 & TCLE_compldo_HU3_docr & $\begin{array}{l}\text { 05052018 } \\
11: 57: 41\end{array}$ & $\begin{array}{l}\text { MILY CONBTANZA } \\
\text { MOAENO RAMOS }\end{array}$ & Axe \\
\hline Outros & Gata_pesqulasdora_HU.pdf & $\begin{array}{c}\text { 07/0520119 } \\
11: 45: 43\end{array}$ & $\begin{array}{l}\text { MILY CONBTANZA } \\
\text { MOAENO RAMOS }\end{array}$ & Ace 70 \\
\hline $\begin{array}{l}\text { Declarapdo de } \\
\text { Instipulpho e } \\
\text { Infrestrutura }\end{array}$ & Anuenclahopattdpante_Fesq_Mly.pdt & $\begin{array}{l}101042018 \\
15: 11: 24\end{array}$ & $\begin{array}{l}\text { Wims Montelro } \\
\text { Frescs }\end{array}$ & AuE \\
\hline Dutros & 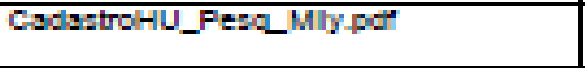 & 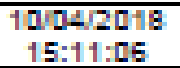 & $\begin{array}{l}\text { Wima Mantelno } \\
\text { Frescs }\end{array}$ & Axt70 \\
\hline Dutras & Anuencls_CFesq_Mlly.pdf & $\begin{array}{c}057012019 \\
07: 52: 52\end{array}$ & $\begin{array}{l}\text { MILY CONBTANZA } \\
\text { MORENO RAHOS }\end{array}$ & $\operatorname{AcE}=7$ \\
\hline 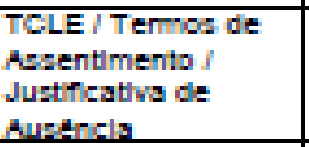 & $\begin{array}{l}\text { TEFUO_DE_ABEENTUENTO_Comlald } \\
\text { o.docr }\end{array}$ & $\begin{array}{l}\text { 27102019 } \\
15: 09: 29\end{array}$ & $\begin{array}{l}\text { MILT CONBTANZA } \\
\text { MORENO RAHOS }\end{array}$ & Act 70 \\
\hline $\begin{array}{l}\text { TCLE / Termos de } \\
\text { Acsentimento if } \\
\text { Justricatha de } \\
\text { Ausencls }\end{array}$ & TCLE_comlaldodocx & $\begin{array}{l}27022019 \\
15: 09: 17\end{array}$ & $\begin{array}{l}\text { MILY CONETANZA } \\
\text { MOAENO RAMOS }\end{array}$ & $A c E 7$ \\
\hline $\begin{array}{l}\text { Frojeto Deta hado f } \\
\text { Pmahura }\end{array}$ & Fro|eto_de_pesqula_corridododocr & $\begin{array}{c}\text { 271020019 } \\
15.18: 55 \\
\end{array}$ & $\begin{array}{l}\text { MILY CONETAHZA } \\
\text { MOEENO RAMOS }\end{array}$ & Ace 50 \\
\hline
\end{tabular}

Enderess An Prut Line- Prember

Balmo: Cinde Lrhersisita

UI: $\mathbf{E}$

Toluber

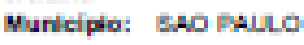

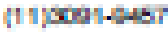

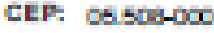

Ertall: certitumptr 


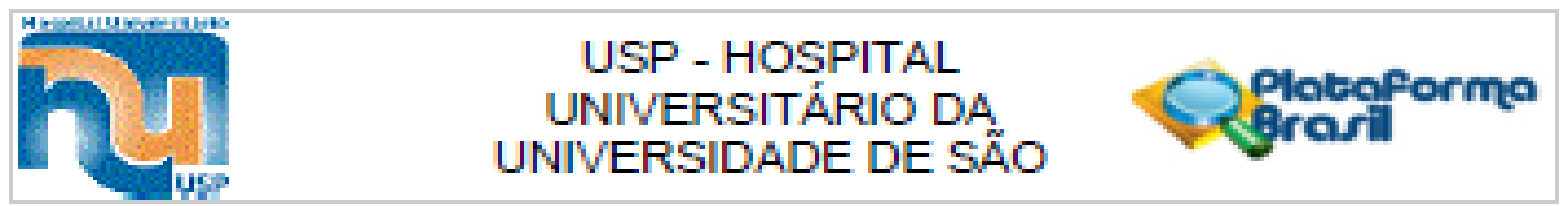

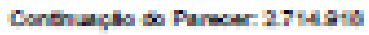

\begin{tabular}{|c|c|c|c|c|}
\hline Inveztpador & Proleto_de_pesqulsa_compldo.docr & $\begin{array}{c}27.022019 \\
15: 08: 56\end{array}$ & $\begin{array}{l}\text { MILY OONGTANZA } \\
\text { MORENO RAMOS }\end{array}$ & Ace 50 \\
\hline 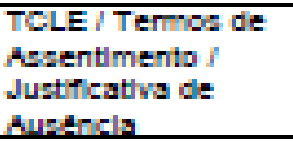 & TERUO_DE_ABEENTMENTO.dOCX & $\begin{array}{c}\text { 18I10019 } \\
16: 25: 40\end{array}$ & $\begin{array}{l}\text { MILY CONSTANZA } \\
\text { MORENO RAMOS }\end{array}$ & Ace 50 \\
\hline $\begin{array}{l}\text { TCLE / Termos de } \\
\text { Aesentimenis If } \\
\text { Justiflathya de } \\
\text { Ausencls }\end{array}$ & TCLE.doTr & $\begin{array}{c}\text { 18:112019 } \\
16: 25: 24\end{array}$ & $\begin{array}{l}\text { MILY CONETAHZA } \\
\text { MOFENO RAMOS }\end{array}$ & Ace 70 \\
\hline Dutras & Carts_de_anuenclapd' & 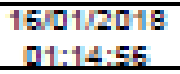 & $\begin{array}{l}\text { MILY CONETAHZA } \\
\text { MOEFNO RAMOS }\end{array}$ & Ace 70 \\
\hline $\begin{array}{l}\text { Projeto Deta hado if } \\
\text { Brochura } \\
\text { Inuatipador }\end{array}$ & Proleto_de_pezquladedacx & $\begin{array}{c}\text { 15012019 } \\
\text { 01:12:19 }\end{array}$ & $\begin{array}{l}\text { MILY CONBTAHZA } \\
\text { MORENO RAMOS }\end{array}$ & Ace 70 \\
\hline
\end{tabular}

situagso do Pareos:

Aprovedo

Neocccita Apreolaqso da coneP:

N5o

BAO FAULO, 15 dE Junho de 2018

Accinado por:

Mauriolo saokiler

ceoordenadort

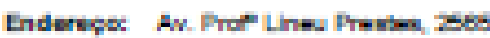

Dairu: Cidede L-heralsh

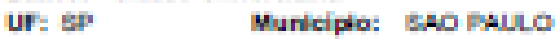

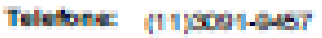

LEF: Dtsthen

Entl: sepshumptr 